Projeto de uma VPN (Rede Privada Virtual) baseada em computação reconfigurável e aplicada a robôs móveis

\author{
Marcelo Honorato Marleta
}


SERVIÇO DE PÓS-GRADUAÇÃO DO ICMC-USP

Data de Depósito: 15 de fevereiro de 2007

Assinatura:

\title{
Projeto de uma VPN (Rede Privada Virtual) baseada em computação reconfigurável e aplicada a robôs móveis
}

\author{
Marcelo Honorato Marleta
}

Orientador: Prof. Dr. Eduardo Marques

Dissertação apresentada ao Instituto de Ciências Matemáticas e de Computação - ICMC/USP, para obtenção do título de Mestre em Ciências de Computação e Matemática Computacional. 


\section{Dedicatória}

Dedico este trabalho a meus pais, Edson Honorato Marleta e Sônia Maria Tomé Marleta, pelo grande amor, incentivo, apoio e zêlo que tiveram para comigo por toda a minha existência e que me proporcianaram a realização deste sonho. Dedico também as minhas irmãs, Fernanda Tomé Marleta e Paula Cristina Tomé Marleta, pelo amor e incentivo demonstrados mesmo nos momentos mais difíceis. 
"O futuro tem muitos nomes: para os fracos, ele é inatingível; para os temerosos, ele é o desconhecido; para os corajosos, ele é a chance, a oportunidade."

(Victor Hugo) 


\section{Agradecimentos}

A Deus pela saúde, energia e pela família maravilhosa que me proporcionou.

Agradeço muito aos meus pais, Edson Honorato Marleta e Sônia Maria Tomé Marleta, pelo incansável apoio, amor, carinho, incentivo e respeito que me dispensaram ao longo da minha jornada. São exemplos de honestidade, determinação, perseverança e coragem que eu tento me espelhar.

As minhas irmãs, Fernanda Tomé Marleta e Paula Cristina Tomé Marleta, por estarem sempre me incentivando e me apoiando, formando junto com meus pais uma base familiar sólida que fez com que eu não perecesse.

A meus verdadeiros familiares que oram por mim, me incentivam e que sempre prezam pelo meu bem-estar.

Ao Prof. Dr. Eduardo Marques que é mais do que um orientador, um amigo que tive a oportunidade de trabalhar. Suas diretrizes seguras, sua paciência e seu apoio foram de fundamental importância para a conclusão deste trabalho.

A Neimar Marques Duarte por me ceder gentilmente o coprocessador AES desenvolvido em sua dissertação de mestrado além de me dar suporte durante todo o período deste trabalho.

Ao Prof. Dr. Denis Fernando Wolf pela ajuda e paciência na revisão do texto em inglês.

Aos meus amigos do LCR pela amizade, compreensão e pela ajuda mútua ao longo do período de mestrado.

A todos meus amigos que me ajudaram, direta ou indiretamente, que me emanaram fluídos positivos e que me proporcionaram diversos momentos de felicidade.

A Capes pelo apoio financeiro durante o mestrado. 
Este trabalho apresenta uma implementação de $V P N$ utilizando-se dos circuitos reprogramáveis do tipo FPGA (Field Programmable Gate Array) que são a base da computação reconfigurável. VPNs utilizam criptografia para permitir que a comunicação seja privada entre as partes. Assim, todo o custo computacional decorrente desta prática é executado em nível de hardware, procurando-se atingir um alto desempenho e voltado para as aplicações de sistemas embutidos.

O uso desta solução, VPN por hardware, será na interligação de um robô (em desenvolvimento no Laboratório de Computação Reconfigurável - LCR do Instituto de Ciências Matemáticas e de Computação da Universidade de São Paulo) ao seu servidor de configuração e tarefas, através de linhas privadas. O emprego de uma $V P N$ em robótica permitirá a utilização de um sistema de comunicação, com ou sem fio, e toda a infra-estrutura da Internet para a comunicação com o robô (e no futuro entre os robôs) a qualquer distância de forma segura e confiável.

O hardware reconfigurável utilizado para a VPN deste trabalho proporciona flexibilidade no modo de implementação, possibilitando que o sistema seja adequado para satisfazer situações que exijam alto desempenho. Além disso, a arquitetura proposta possibilita que parte das operações sejam executadas em software (no caso, foi utilizado o sistema operacional $\mu$ Clinux e ferramentas para se estabelecer a VPN) e parte das operações executadas em hardware (um coprocessador criptográfico AES). As principais ferramentas de software são o conjunto ipsec-tools que foram desenvolvidas para serem executadas com o IPSec nativo do Kernel e devidamente portadas para o $\mu$ Clinux. 
This work designs a system that implements a VPN using FPGA (Field Programmable Gate Array) reprogrammable circuits, which are the basis of reconfigurable computing. VPNs use cryptography to allow private communication between parts. In this manner, the computational cost of the cryptography is handled by the hardware, achieving great performance and allowing its usage on embedded systems applications.

The system proposed in this thesis has been used to establish secure communication between a PC and a mobile robot (that is in development at Reconfigurable Computing Laboratory - LCR of Institute of Mathematics and Computer Science of Univesity of São Paulo). The use of VPN in robotics will allow a communication, either wired or wireless, using Internet's infrastructure with the robot (and in the future among robots), in a secure and trustable manner.

The reconfigurable hardware used in this work allows flexibility in the implementation, making possible its usage in situations that requires high performance. Furthermore, the proposed architecture allows part of applications executing in software (using $\mu$ Clinux operating system and tools to establish the VPN) and other parts in hardware (a cryptographic coprocessor AES). The main software tools are the ipsec-tools that were developed to execute with native Kernel IPSec's implementation and were properly ported to $\mu$ Clinux. 
Resumo iv

$\begin{array}{lll}\text { Abstract } & \mathbf{v}\end{array}$

1 Introdução e Objetivos $\quad 1$

1.1 Considerações Iniciais $\ldots \ldots \ldots \ldots \ldots \ldots \ldots$

2 Computação Reconfigurável 3

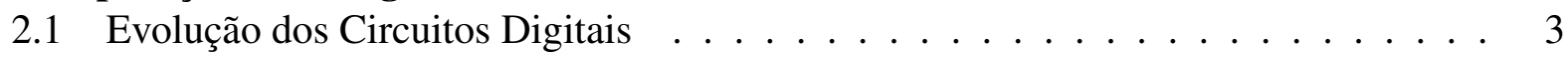

2.2 Circuitos FPGAs . . . . . . . . . . . . . . . . . . 4

2.3 Sistemas Reconfiguráveis . . . . . . . . . . . . . . . . . . . . 6

2.4 Classificação . . . . . . . . . . . . . . . . . . . . . 8

2.5 A Família de FPGA Stratix da Altera . . . . . . . . . . . . . . . . . . 10

2.6 Linguagens de Descrição de Hardware . . . . . . . . . . . . . . . . . . . . . . . . . . . . . . . . . . . . . . . . . . .

2.7 System-on-a-Programmable-Chip (SOPC) . . . . . . . . . . . . . . . 12

2.8 Ferramentas de Desenvolvimento de Hardware . . . . . . . . . . . . . . . 13

2.8 .1 Quartus II . . . . . . . . . . . . . . . . . . . . . . 14

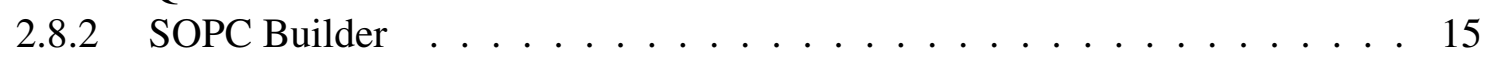

2.9 Considerações Finais . . . . . . . . . . . . . . . . . . 17

3 VPN (Virtual Private Network) 18

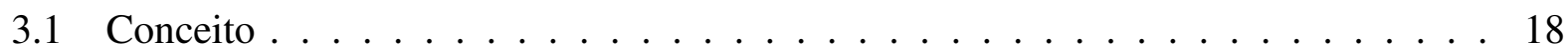

3.2 Segurança da informação . . . . . . . . . . . . . . . . . . 18

3.2.1 Conceitos básicos de segurança . . . . . . . . . . . . . . 19

3.3 Conceitos de Criptografia . . . . . . . . . . . . . . . . . . 20

3.3 .1 Modos de Operação . . . . . . . . . . . . . . . . . . . . . . . . . . . . . . . . 23

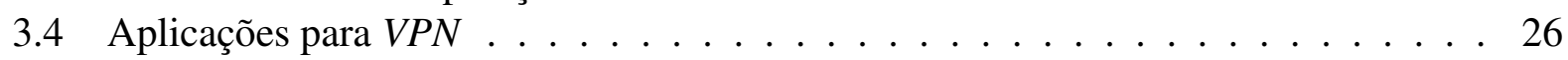

3.5 Encapsulamento e Criptografia . . . . . . . . . . . . . . . . . 30

3.6 Protocolos de Encapsulamento . . . . . . . . . . . . . . . . . . 31

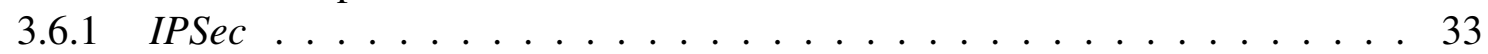

3.6 .2 Uma outra solução de VPN . . . . . . . . . . . . . . . . . . . . . . . . . . . . 37

3.7 Considerações Finais . . . . . . . . . . . . . . . . . . 37 
4 Material e Metodologia $\quad 38$

4.1 Definição Geral . . . . . . . . . . . . . . . . . . . . . . . . 38

4.2 O processador NIOS II . . . . . . . . . . . . . . . . . . . . . . . 39

4.3 O Barramento Avalon . . . . . . . . . . . . . . . . . . . . . . 40

$4.4 \mathrm{O}$ sistema operacional $\mu$ Clinux . . . . . . . . . . . . . . . . . 42

4.4 .1 Ferramenta NIOS II IDE . . . . . . . . . . . . . . . . . . . . 43

4.5 Ferramentas de Software . . . . . . . . . . . . . . . . . . . . 47

4.6 Algoritmos Criptográficos . . . . . . . . . . . . . . . . . . . . . . . . . . . . . . . . . . 48

4.7 Considerações Finais . . . . . . . . . . . . . . . . . . . . . . 49

5 Implementação e Resultados $\quad 50$

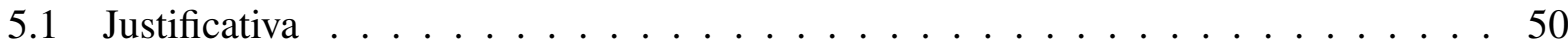

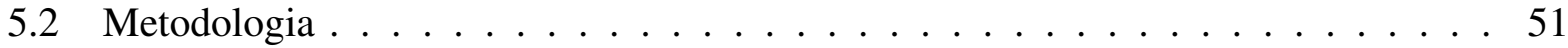

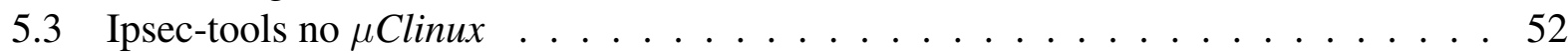

5.4 Implementação do Hardware . . . . . . . . . . . . . . . . . . . . . . . . . . . . . . . . 56

5.5 Construção da solução final . . . . . . . . . . . . . . . . . . . . . . . 59

5.6 Resultados Obtidos . . . . . . . . . . . . . . . . . . . 63

5.7 Considerações Finais . . . . . . . . . . . . . . . . . . 66

6 Conclusão e Trabalhos Futuros $\quad 68$

6.1 Trabalhos Futuros . . . . . . . . . . . . . . . . . . . . . . . 69

$\begin{array}{lll}\text { A Apêndice A } & 71\end{array}$

$\begin{array}{lll}\text { B } & \text { Apendice B } & 77\end{array}$ 


\section{Lista de Figuras}

2.1 Principais tipos de circuitos digitais $\ldots \ldots \ldots \ldots$

2.2 Um Elemento Lógico de uma FPGA Stratix . . . . . . . . . . . . . . . . . . . 7

2.3 Formas de Reconfiguração (COMPTON e HAUCK, 1999) . . . . . . . . . . . . . 8

2.4 Formas de Acoplamento (COMPTON e HAUCK, 1999) . . . . . . . . . . . . . . 9

2.5 Foto da placa que será utilizada para desenvolvimento do projeto . . . . . . . . . . 10

2.6 Tela principal do Quartus II . . . . . . . . . . . . . . . . . . . . . . . . . . . 14

2.7 Diagrama de Blocos com as tarefas realizadas pelo SOPC Builder . . . . . . . . 16

2.8 Exemplo de um sistema criado com o SOPC Builder . . . . . . . . . . . . . . . 17

3.1 Criptografia Simétrica . . . . . . . . . . . . . . . . . . . . 21

3.2 Criptografia Assimétrica . . . . . . . . . . . . . . . . . 22

3.3 Diagrama de funcionamento do modo ECB . . . . . . . . . . . . . . 24

3.4 Diagrama de funcionamento do modo CBC . . . . . . . . . . . . . . . 25

3.5 Diagrama de funcionamento do modo CFB . . . . . . . . . . . . . . 26

3.6 Diagrama de funcionamento do modo OFB . . . . . . . . . . . . . . . 27

3.7 Diagrama de funcionamento do modo CTR . . . . . . . . . . . . . . 28

3.8 VPN de Cliente/Servidor a Cliente/Servidor . . . . . . . . . . . . . . . . . 28

3.9 VPN entre um Usuário Remoto e uma Rede . . . . . . . . . . . . . . . . . . . . 29

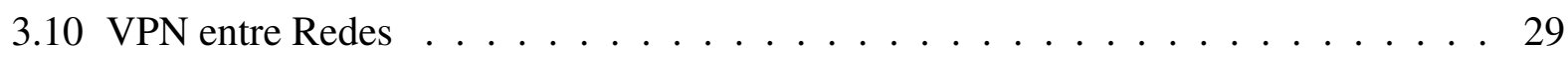

3.11 VPN com situações mistas . . . . . . . . . . . . . . . . . . . 30

3.12 Túnel criado pela Internet $(\mathrm{CHIN}, 1998) \ldots \ldots \ldots \ldots \ldots$

3.13 VPN entre o robô e um Notebook . . . . . . . . . . . . . . . . . 32

3.14 Uma VPN com o robô em modo transporte . . . . . . . . . . . . . . . 35

3.15 Uma VPN com o robô em modo túnel . . . . . . . . . . . . . . . . . . . . . . . . . . . . . . . . . . .

3.16 Disposição dos dados em um pacote AH . . . . . . . . . . . . . . . . . . . . . . . . . . . . . . .

3.17 Disposição dos dados em um pacote ESP . . . . . . . . . . . . . . . 37

4.1 Diagrama de blocos de um sistema com o processador NIOS II . . . . . . . . . . . 39

4.2 Sistema destacando o barramento AVALON . . . . . . . . . . . . . . . . 41

4.3 Criação de um novo projeto utilizando o NIOS II $\mu$ Clinux . . . . . . . . . . . . . . 44

4.4 Opções para configurar Hardware e Software . . . . . . . . . . . . . . . . . . . . . . . . . . . . . . . . . . . .

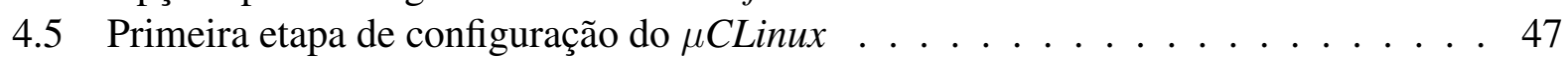

4.6 Segunda etapa de configuração do $\mu$ CLinux . . . . . . . . . . . . . . . . . . . . . 47

4.7 Terceira etapa de configuração do $\mu$ CLinux . . . . . . . . . . . . . . . . . . . 48

5.1 Ambiente de desenvolvimento do robô do LCR . . . . . . . . . . . . . . . 51 
5.2 Visão geral do sistema . . . . . . . . . . . . . . . . . . 53

5.3 SOPC Builder com todo o sistema implementado . . . . . . . . . . . . . . 59

5.4 Diagrama do sistema completo visto pelo RTL Viewer . . . . . . . . . . . . . 60

5.5 Resumo das características utilizadas na FPGA após a compilação . . . . . . . . . 61

5.6 Menu para selecionar o coprocessador AES na configuração do Kernel . . . . . . . 63

5.7 Análise dos pacotes ICMP com TCPDump . . . . . . . . . . . . . . . . . . 64

5.8 Análise dos pacotes ESP com TCPDump . . . . . . . . . . . . . . . 65

5.9 Análise de Pacotes ICMP com o Ethereal . . . . . . . . . . . . . . . . 66

5.10 Análise dos Pacotes ESP com o IPSec . . . . . . . . . . . . . . . . . 67

B.1 Descarregando a imagem do Kernel na placa . . . . . . . . . . . . . . . 79 


\section{Lista de Tabelas}

2.1 Características da $F P G A$ utilizada. . . . . . . . . . . . . . . . . . . 11

4.1 Características das diferentes versões do NIOS II _ . . . . . . . . . . . . . . 40

5.1 Tabela comparativa de desempenho entre diferentes tipos de conexão . . . . . . . . 65 


\section{Lista de Abreviaturas}

\begin{tabular}{|c|c|}
\hline ASIC & Application Specific Integrated Circuit \\
\hline AES & Advanced Encryption Standard \\
\hline $\mathrm{AH}$ & Authentication Header \\
\hline CPLD & Complex Programmable Logic Device \\
\hline CPU & Central Processing Unit \\
\hline CRL & Certificate Revocation Lists \\
\hline DAC & Data Authentication Code \\
\hline DES & Data Encryption Standard \\
\hline DDR & Double Data Rate \\
\hline DMIPS & Drystone Million Instructions Per Second \\
\hline DSP & Digital Signal Processing \\
\hline $\mathrm{E} / \mathrm{S}$ & Entrada e Saída \\
\hline $\mathrm{eCos}$ & embedded Configurable operating system \\
\hline EDIF & Eletronic Interchange Format \\
\hline EEPROM & Electrical Erasable PROM \\
\hline EPROM & Erasable PROM \\
\hline ESP & Encapsulating Security Payload \\
\hline FSF & Free Software Foundation \\
\hline FPGA & Field Programmable Gate Array \\
\hline GNU & GNU is Not Unix \\
\hline GPL & General Public License \\
\hline HAL & Hardware Abstraction Layer \\
\hline IDE & Integrated Development Environment \\
\hline IP & Intellectual Property ou (Internet Protocol) \\
\hline IV & Initialization Vector \\
\hline $\mathrm{L} 2 \mathrm{~F}$ & Layer-to-Forwarding \\
\hline L2TP & Layer-to-Tunelling-Protocol \\
\hline LCR & Laboratório de Computação Reconfigurável \\
\hline LE & Logic Elements \\
\hline LUTs & Look-up Tables \\
\hline MAC & Message Authentication Code \\
\hline $\mathrm{MDC}$ & Manipulation Detection Code \\
\hline MIC & Message Integrity Check \\
\hline MMU & Memory Management Unit \\
\hline MUX & Multiplexador \\
\hline
\end{tabular}




$\begin{array}{ll}\text { PLD } & \text { Programmable Logic Device } \\ \text { PPTP } & \text { Point-to-Point Tunneling Protocol } \\ \text { PROM } & \text { Programable Read Only Memory } \\ \text { OCF } & \text { OpenBSD Criptography Framework } \\ \text { OCSP } & \text { Online Certificate Status Protocol } \\ \text { QDRII } & \text { Quad Data Rate 2 } \\ \text { RAM } & \text { Random Access Memory } \\ \text { RCU } & \text { Reconfigurable Unit } \\ \text { RISC } & \text { Reduced Instruction Set Computer } \\ \text { RSA } & \text { Rivest-Shamir-Adleman } \\ \text { RTOS } & \text { Real-Time Operating System } \\ \text { SADB } & \text { Security Association Database } \\ \text { SDRAM } & \text { Synchronous Dynamic Random Access Memory } \\ \text { SIC } & \text { Segmented Integer Counter } \\ \text { SMP } & \text { Symmetric Multiprocessor } \\ \text { SO } & \text { Sistemas Operacional } \\ \text { SoC } & \text { System-on-a-Chip } \\ \text { SoPC } & \text { System-on-a-Programmable-Chip } \\ \text { SRAM } & \text { Static RAM } \\ \text { UART } & \text { Universal Asynchronous Receiver/Transmitter } \\ \text { ULA } & \text { Unidade Lógica Aritmética } \\ \text { VPN } & \text { Virtual Private Network } \\ \text { VHDL } & \text { Very High Speed Integrated Circuit Hardware Description Language } \\ \text { VHSIC } & \text { very-high-speed integrated circuits }\end{array}$




\subsection{Considerações Iniciais}

Atualmente, é consenso que segurança de dados digitais é condição sine qua non para qualquer organização. O que falar então de empresas de grande porte? Uma empresa que não possui segurança digital perde, dentre outros aspectos importantes, grande parte da sua credibilidade. A Internet, por ser de domínio público, é por sua própria natureza uma rede insegura. Por outro lado, a Internet possui uma ampla infra-estrutura que interliga praticamente todos os pontos do globo terrestre. É neste ponto que surgem as redes privadas virtuais ou, de forma simplificada, VPNs. Graças as VPNs, é possível se utilizar a Internet para que as empresas possam se comunicar de forma segura usando a sua estrutura ao invés de ter que comprar uma linha privada e dedicada. Desta forma, há uma redução significativa nos custos.

Aproveitando-se desta tecnologia muitas empresas têm utilizado ou migrado para esta solução. Mas não é apenas nesse plano que entram as VPNs. Em Intranets podemos utilizar uma VPN para proteger os dados de serem capturados e/ou modificados por entidades não autorizadas, principalmente se pensarmos em uma rede sem fio como uma MAN ou uma WAN. Outra solução interessante seria na robótica. Podemos utilizar a Internet para comunicar com um robô conectado em qualquer lugar do mundo. Como é desejado que apenas as pessoas autorizadas possam controlar o robô e que as mensagens passadas para o mesmo não sejam interceptadas e modificadas, podemos utilizar uma VPN para atingir essas metas.

Pensando nestas conveniências trazidas em decorrência do uso das VPNs é que partiu a motivação deste trabalho. Visto que deseja-se controlar um robô móvel de qualquer lugar do globo 
terrestre que tenha um ponto de Internet e que as VPNs necessitam de bastante poder computacional para uma solução efetiva de segurança (como uma criptografia de 128 bits por exemplo), elas tornam o sistema um pouco lento. Neste trabalho foi desenvolvida uma solução através da computação reconfigurável para ser utilizada em um sistema embarcado de forma a tirar o máximo proveito do hardware proposto, conseguindo-se assim um desempenho melhor.

Os principais objetivos deste trabalho envolvem:

- Desenvolver um módulo de VPN sobre o conceito de computação reconfigurável, mais especificamente utilizando-se de FPGA (PERKOWSKI, 2004) (GLESNER, 2004) (BROWN, 1992) (CHAN e MOURAD, 1994)

- Obter um desempenho de criptografia - que é a base da VPN - superior ao de um algoritmo executado em um processador de uso geral.

- Contribuir com a evolução do ambiente para projeto e implementação de controle evolucionário embarcado de robôs móveis reconfiguráveis dinamicamente, que vem sendo desenvolvido pelo Laboratório de Computação Reconfigurável - LCR do Instituto de Ciências Matemáticas e de Computação da Universidade de São Paulo;

O capítulo 2 será relativo a conceitos de hardware onde será discutido a evolução da tecnologia e será apresentada a computação reconfigurável bem como a plataforma que será utilizada, as ferramentas de desenvolvimento e linguagens de descrição de hardware. No capítulo 3 será apresentado o conceito de VPN demonstrando suas características e os protocolos existentes; será ainda apresentado alguns conceitos sobre segurança e criptografia. O capítulo 4 discorre sobre o material e a metodologia que serão utilizados no decorrer do trabalho, apresentando também o sistema operacional que será utilizado. No capítulo 5 são apresentadas justificativas para a realização do trabalho e como foi realizada toda a implementação do mesmo; também serão descritos resultados obtidos e testes de desempenho realizados. O capítulo 6 apresenta as conclusões obtidas e os trabalhos futuros. 


\section{Computação Reconfigurável}

\subsection{Evolução dos Circuitos Digitais}

Conforme é de conhecimento geral, a tecnologia tem evoluído a passos largos nos últimos tempos. Dispositivos eletrônicos são grandes propulsores de tecnologia e estão em contínua modificação / evolução. Neste contexto, têm-se os sistemas digitais que sofreram profundas transformações ao longo do século passado e a tendência é que surjam cada vez mais dispositivos diferentes. De forma a introduzir o conceito de computação reconfigurável, será apresentado aqui uma breve descrição da evolução dos componentes eletrônicos.

No final do século XIX surgiu o relê um dispositivo eletromecânico, formado por um magneto móvel, que se deslocava unindo dois contatos metálicos. O relê foi muito utilizado no sistema telefônico, aliás algumas centrais analógicas ainda utilizam estes dispositivos até hoje. Os relês podem ser considerados uma espécie de antepassados dos transistores. Suas limitações eram o fato de serem relativamente caros, grandes demais e ao mesmo tempo muito lentos: um relê demora mais de um milésimo de segundo para fechar um circuito.

Ainda no final do século XIX, após alguns experimentos de Thomas Edson, surgiram as primeiras válvulas. As válvulas foram usadas para criar os primeiros computadores eletrônicos na década de 40. Estes dispositivos têm seu funcionamento baseado no fluxo de elétrons no vácuo, através de um conceito físico conhecido como efeito termoiônico. As válvulas já eram bem mais rápidas que os relês, atingiam frequências de alguns Megahertz, porém esquentavam demais, consumiam muita eletricidade e se queimavam com certa facilidade.

No final da década de 40 foram descobertos certos materiais que eram capazes de funcionar tanto como isolantes como condutores. Estes materiais foram denominados semicondutores. Estas 
pesquisas foram a base para o surgimento dos transistores os quais foram evoluindo, diminuindo de tamanho, aumentando de freqüência (alguns transistores podiam operar até $100 \mathrm{MHz}$ ) e gradualmente dominando a indústria na década de 50. Este cenário permaneceu até a década de 60 em que os sistemas digitais eram construídos a partir de componentes discretos, tais como diodos, transistores e resistores. A partir de então, surgiram os circuitos integrados (CIs) que tornaram possíveis a integração de vários transistores em uma única pastilha (waffer) de silício. Atualmente, é possível integrar cerca de 14 milhões de transistores por $\mathrm{cm}^{2}$, podendo esta densidade atingir 100 (cem) milhões até o ano de 2012 (BROWN e VRANESIC, 2000). Com isto foi possível a implementação de uma grande variedade de circuitos digitais e analógicos em pastilhas de silício. A maior densidade em transistores $/ \mathrm{mm}^{2}$ é encontrada em circuitos digitais, onde a tecnologia atual permite implementar comercialmente circuitos com geometria de 90 (noventa) nm e com interconexão entre os transistores sendo feita utilizando cobre para se obter o maior desempenho possível. (NEXSYS, 2000)

\subsection{Circuitos FPGAs}

Até pouco tempo atrás existiam duas formas de se executar um algoritmo computacional (COMPTON, 1999): através de ASICs (Application Specific Integrated Circuit) ou de microprocessadores. Os ASICs (também chamados de hardware totalmente customizados) são projetados para executar uma operação com alto grau de especificidade, sendo portanto para executar somente aquela operação. Conseqüentemente, são extremamente rápidos e eficientes para a operação para a qual foram implementados. Entretanto, uma vez terminado, o ASIC não pode ser modificado. Caso ocorra uma mudança na operação para a qual foi projetado, é necessário desenvolver outro ASIC, o que se constitui num alto custo financeiro, além do tempo demandado. De toda forma, quando produzidos em larga escala, os ASICs constituem-se na alternativa mais eficiente e, portanto, são bastante utilizados pela indústria.

Em contrapartida, temos os microprocessadores, os quais são dispositivos que podem executar qualquer tipo de operação digital. Todavia, a vantagem obtida com esta abordagem é exatamente oposta ao ASIC, pois por sua característica principal ser a flexibilidade, o tempo demandado em instruções de decodificação e busca é muito maior, resultando, obviamente, em um desempenho consideravelmente menor. Portanto este era o cenário encontrado até pouco tempo atrás: dois tipos de processadores completamente distintos sendo que a grande vantagem de um é a grande desvantagem do outro e vice-versa. De forma a suprir essa lacuna, uma nova forma de computação vem surgindo nos últimos anos e ganhando bastante destaque: trata-se da computação reconfigurável. (COMPTON e HAUCK, 2000) (DEHON, 1996) (DEHON e WAWRZYNEK, 1997) (VILLASENOR e MANGIONE-SMITH, 1997) (BROWN e ROSE, 1997) (HAUCK, 1998) (BECKET, 2000) 
De uma maneira simplificada, pode-se definir a computação reconfigurável como sendo a capacidade que um hardware possui de ser programado e reprogramado após sua fabricação. Cabe ressaltar que essa programação ou reprogramação pode ser feita de maneira dinâmica (em tempo de execução) ou de maneira estática (com o sistema desligado).

A computação reconfigurável apresenta um novo conceito: o de hardware virtual. Isto significa que só é necessário ter ativo no sistema o hardware dedicado para executar as tarefas que estão sendo executadas naquele instante. Deste modo, toda vez que uma parte do hardware virtual não é necessário, ele é desativado do circuito ocorrendo o contrário quando se necessita de uma nova funcionalidade. Desta forma o hardware se adapta as reais necessidades do software de maneira bastante eficiente. Assim, obtem-se a flexibilidade do software com o desempenho do hardware. Com isso, preenche-se a lacuna que existia anteriormente entre o software (flexível e lento) e o hardware (inflexível e rápido) (COMPTON e HAUCK, 2000).

A figura 2.1 é apresentada para elucidar os principais tipos de circuitos digitais existentes atualmente, divididos em categorias de acordo com a tecnologia utilizada, o grau de integração e a possibilidade ou não de se alterar a funcionalidade do dispositivo.

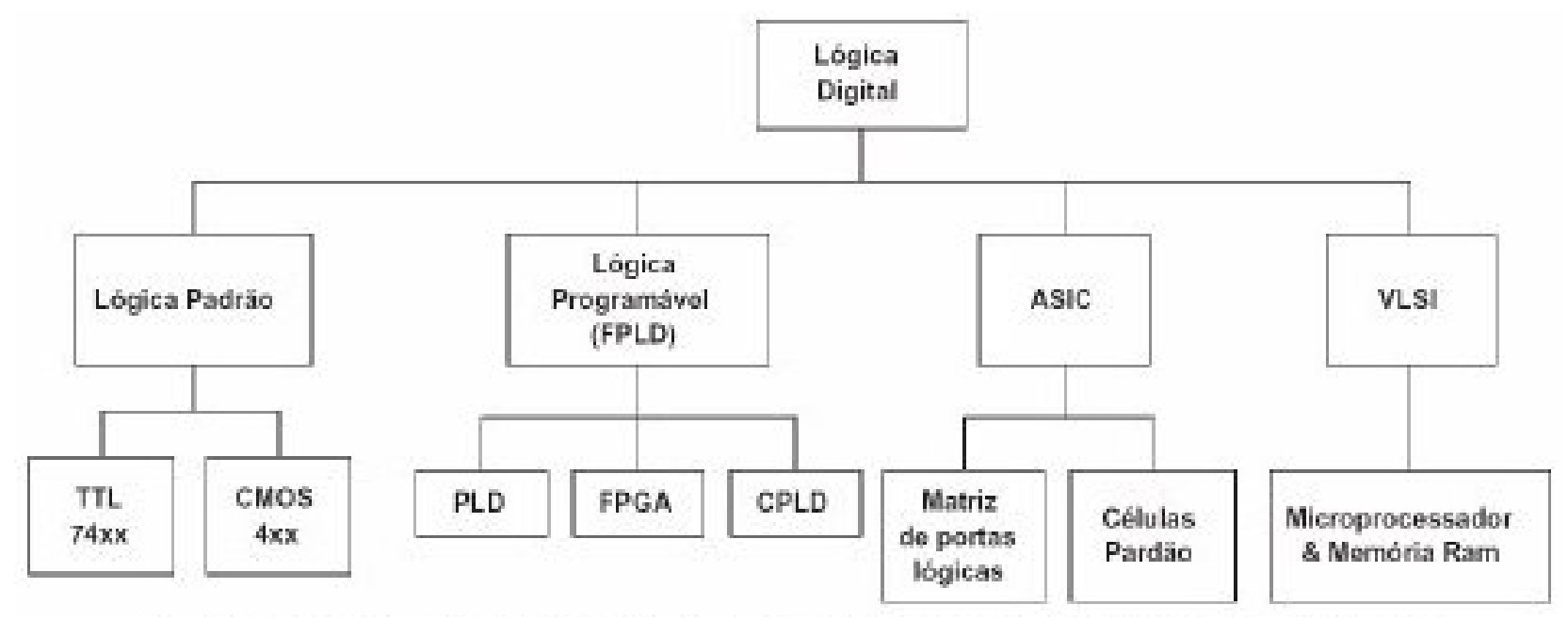

Figura 2.1: Principais tipos de circuitos digitais

Os dispositivos descritos na figura 2.1 incluem os dispositivos lógicos padrões (também chamados de dispositivos lógicos de baixa integração), os dispositivos lógicos programáveis, com densidades que podem variar bastante de um dispositivo para outro, os ASICs e os dispositivos VLSI (Very Large Scale Integration), completamente customizados e de alta densidade, usados para implementar processadores, memórias e outros dispositivos modernos tais como SRAM e DRAM (SDRAM, QDR, DDR, RAMBUS, etc). 


\subsection{Sistemas Reconfiguráveis}

Antigamente, quando se pensava em computação reconfigurável se pensava em problemas intrinsecamente paralelos onde a habilidade do hardware reconfigurável em explorar o paralelismo espacial (DEHON, 2000) garantia um desempenho muito maior que os dispositivos de propósito geral. Em alguns casos, o desempenho era maior até do que os de supercomputadores. Entretanto, essas tarefas eram bastante específicas e em grande parte dos casos poderiam ser melhor solucionadas através do uso de ASICs.

A tendência atual é a de se utilizar computação reconfigurável para acelerar aplicações de propósito geral ou de uma área específica (VEMURI e HARR, 2000). Desta forma, se faz necessário o desenvolvimento de novas ferramentas que apóiem o desenvolvimento das aplicações para esses sistemas como novos compiladores capazes de tirar o máximo proveito do hardware reconfigurável. O desenvolvimento dessas ferramentas ainda está numa fase inicial, mas os resultados obtidos em simulações são bastante promissores.

Dentre os dispositivos programáveis temos os seguintes tipos (BIRKNER, 2000) (PERKOWSKI, 2004) (GLESNER, 2004) (BROWN, 1992) (CHAN e MOURAD, 1994):

- Programmable Logic Devices (PLD): surgiram na década de 70 constituindo-se nos primeiros dispositivos lógicos programáveis disponíveis comercialmente. São dispositivos de baixa densidade e que podem ser encontrados até nos dias atuais. Nesta família de dispositivos encontram-se as Programmable Logic Array (PLAs), Programmable Array Logic (PALs) e as Field Programmable Logic Array (FPLAs).

- Complex Programmable Logic Device (CPLD): são a evolução das PLDs, com maior densidade contudo, se comparada com outras opções de dispositivos lógicos programáveis, possuem uma densidade ainda baixa. Estes dispositivos ao serem ligados passam a funcionar instantaneamente, e são na sua grande maioria baseados em tecnologia FLASH ou EEPROM.

- Field Programmable Gate Array (FPGAs): são os dispositivos que possuem maior densidade dentre os dispositivos de lógica programável. A tecnologia de configuração destes dispositivos utiliza memória SRAM como unidade de armazenamento e os dispositivos precisam ser configurados após serem ligados para iniciar o seu funcionamento com a configuração definida pelo usuário. Para armazenar esta configuração são utilizados dispositivos externos de armazenamento não-voláteis tais como memórias FLASH, ROM ou EPROM. Dependendo do fabricante elas podem ter uma série de funções extras, além de lógica, tais como blocos de memória RAM, RAM Dual-Port, CAM, blocos de DSP, processadores (Powerpc e ARM), $P L L s, D L L s$, interfaces seriais rápidas, dentre outros.

Um Field Programmable Gate Array (FPGA) consiste de um grande arranjo de célular configuráveis (ou blocos lógicos) contidos em um único chip. Cada uma dessas células contém uma 
capacidade computacional para implementar funções lógicas e/ou realizar roteamento para permitir a comunicação entre as células. Todas essas operações podem acontecer simultaneamente no arranjo de células inteiro. (ROSE, 1993) (BROWN e ROSE, 1997) (DONACHY, 1996)

Para este trabalho será utilizado um chip com a tecnologia FPGA o qual será apresentado em mais detalhes abaixo bem como o dispositivo utilizado na seção 2.5.

Como explanado anteriormente, FPGAs são dispositivos lógicos programáveis baseados em tecnologia $S R A M$ sendo os elementos lógicos que constituem estes dispositivos, blocos lógicos menores que as PLAs, PALs e CPLDs, permitindo assim sua maior densidade.

Cada bloco lógico em uma FPGA é composto por um registrador e uma tabela do tipo Look-Up Table ( $L U T$ ), que na maioria dos dispositivos FPGAs é implementada como um bloco de memória de 16 bits internos, 4 bits de entrada (endereço) e um bit de saída. Toda a implementação da lógica combinatória (exceto a implementação do $M U X$ ) é feita utilizando-se um cascateamento de LUTs podendo-se implementar qualquer lógica combinatória com qualquer complexidade (limitada logicamente ao número de elementos lógicos disponíveis no chip). A configuração inicial das LUTs é feita pelo software de desenvolvimento o qual é responsável por criar a tabela de configuração das LUTs capazes de definirem as operações lógicas, bem como a interligação das LUTs para implementar esta lógica. Na figura 2.2 é apresentado o diagrama de um elemento lógico de um dispositivo FPGA da família Stratix(ALTERA, 2002), da Altera:

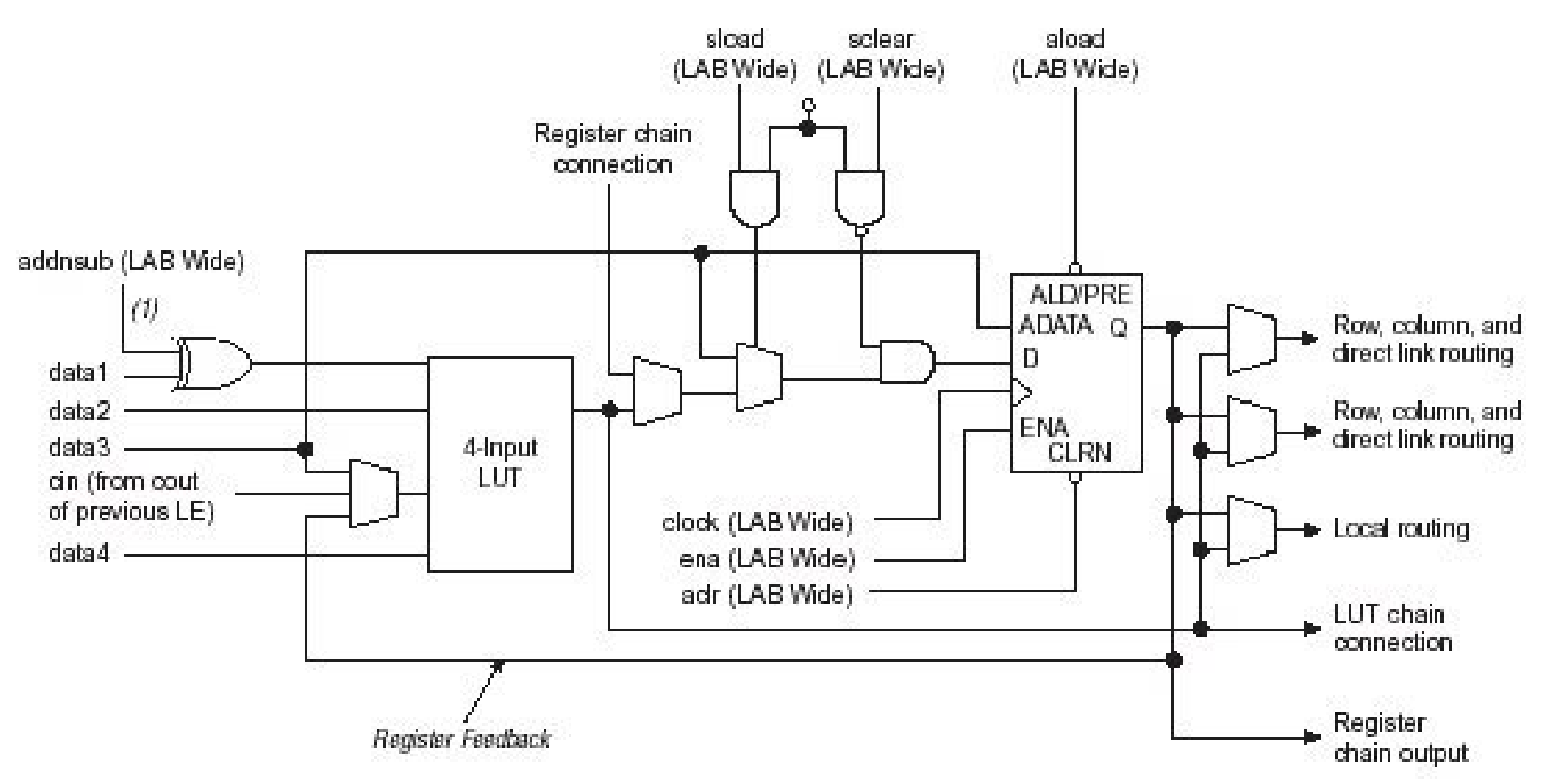

Figura 2.2: Um Elemento Lógico de uma FPGA Stratix

Outras características das FPGAs são que, em geral, além dos dispositivos lógicos estes dispositivos incluem outros blocos funcionais dependendo do fabricante e da família de dispositivos FPGA de quem os fabrica. Pode-se citar alguns exemplos de blocos disponíveis como 
os PLLs, conversores analógico-digital e digital-analógico, blocos de memória, DLLs, multiplicadores, MACs completos, sistemas Clock Data Recovery (CDR), interfaces de variados tipos e processadores implementados em hardware, dentre outros.

A interconexão e a arquitetura dos elementos lógicos também variam entre as diversas opções disponíveis no mercado, porém uma característica comum a todas as FPGAs é que os pinos de E/S são independentes dos elementos lógicos, sendo os sinais roteados da lógica interna para os pinos de E/S usando o sistema de roteamento do próprio dispositivo.

\subsection{Classificação}

O hardware reconfigurável pode ser classificado segundo dois critérios (COMPTON, 1999): reconfigurabilidade e acoplamento. Com relação a reconfigurabilidade, temos 2.3:

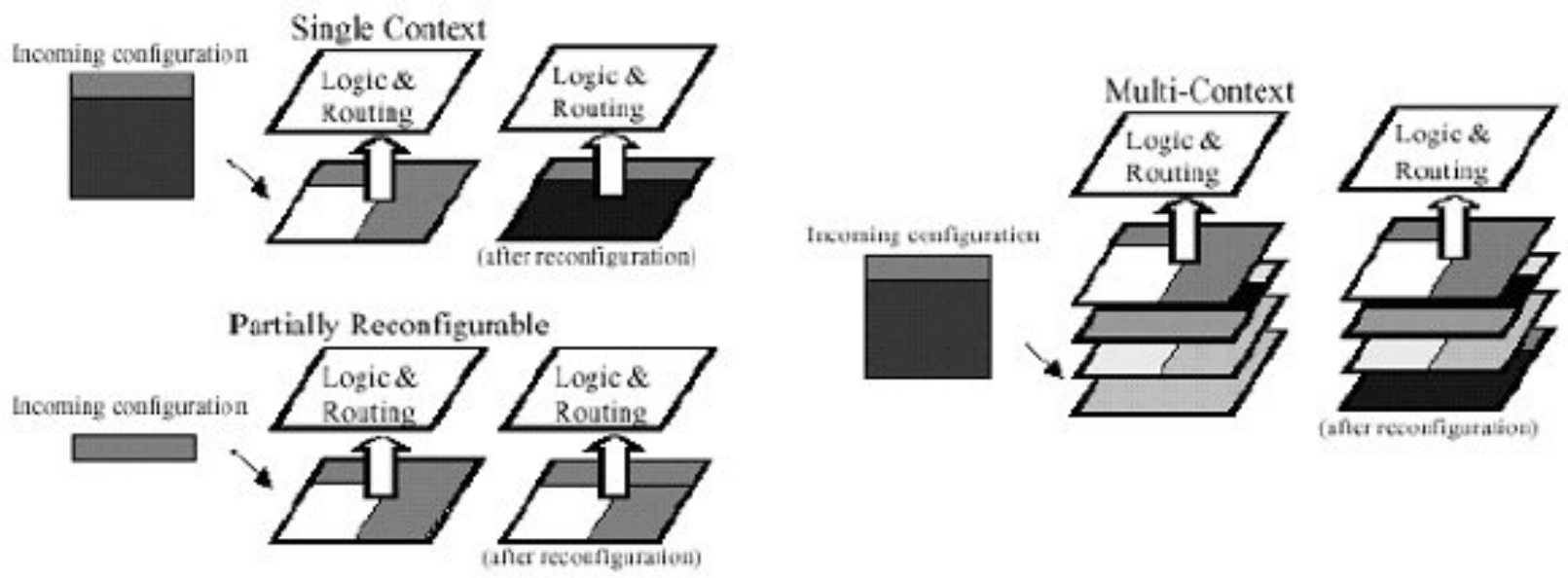

Figura 2.3: Formas de Reconfiguração (COMPTON e HAUCK, 1999)

- Parcial: permite que se reconfigure apenas algumas partes do hardware;

- Total: o hardware inteiro deve ser reconfigurado de uma só vez;

- Estática: deve-se desligar o dispositivo para reconfigurá-lo;

- Dinâmica: a reconfiguração pode ser feita em tempo de execução. No mercado, atualmente, apenas a Xilinx possui alguns dispositivos capazes de se reconfigurar dinamicamente;

- De contexto único: apenas uma configuração pode ser carregada por vez;

- De múltiplos contextos: múltiplas configurações podem ser carregadas em um determinado momento. De qualquer forma, apenas uma configuração pode estar sendo executada por vez.

Com relação ao acoplamento, como pode ser visto na figura 2.4 , temos: 


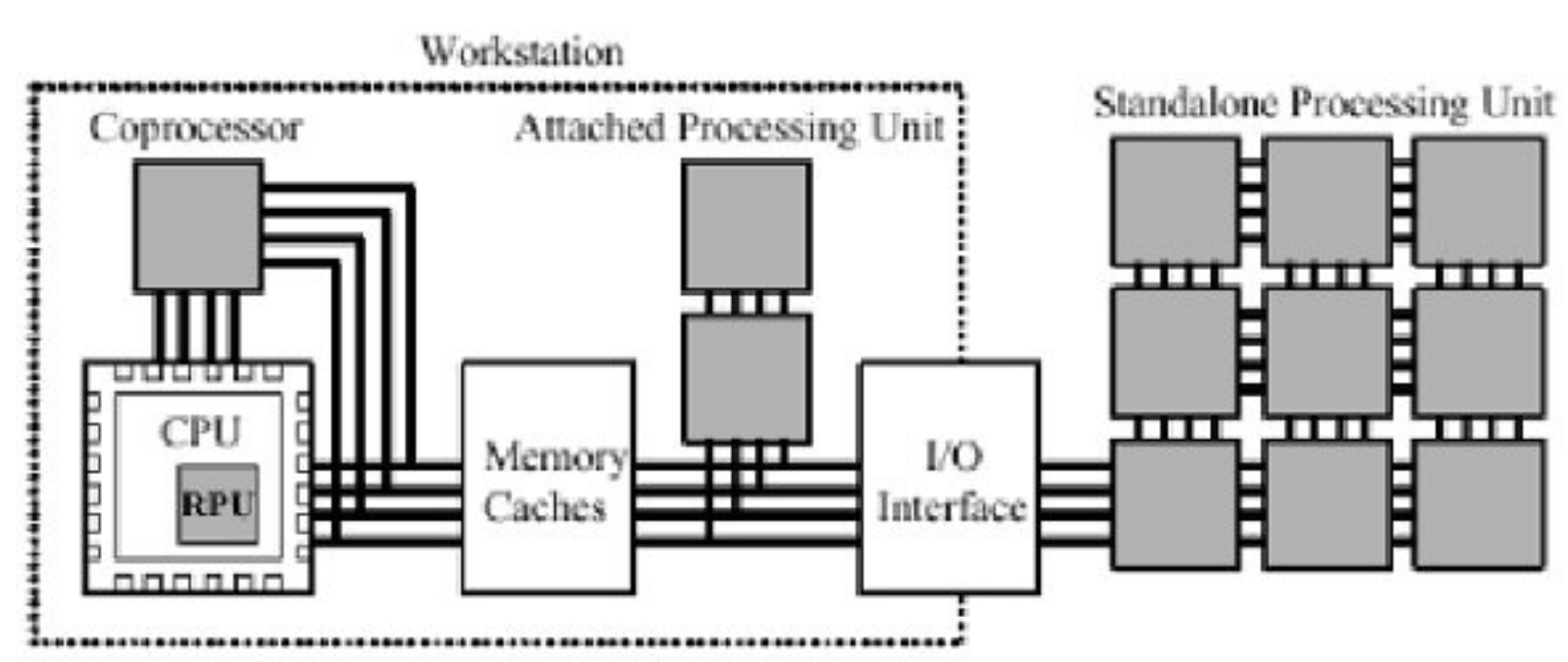

Figura 2.4: Formas de Acoplamento (COMPTON e HAUCK, 1999)

- Unidades Funcionais Reconfiguráveis (RPUs): o hardware reconfigurável é utilizado como se fosse uma unidade funcional do processador principal, acessando os registradores do próprio processador para armazenar seus dados de entrada e saída. Desta forma, podemos ter uma ambiente de programação tradicional com adição de instruções especiais que podem ser alteradas com o tempo.

- Coprocessadores reconfiguáveis: neste modelo, o processador principal inicializa o coprocessador dizendo ao coprocessador onde estão ou quais são as informações que ele necessita. O coprocessador efetua as operações necessárias independente do processador principal e retorna o resultado após o término da sua execução. Esse modo implica numa maior sobrecarga de comunicação entre o processador e o hardware reconfigurável, porém pode aumentar o grau de paralelismo do sistema já que o coprocessador opera de forma independente ao processador principal. Geralmente, os coprocessadores reconfiguráveis são maiores do que as RPUs.

- Processador: neste modo o hardware reconfigurável opera como um processador adicional em um ambiente multiprocessado. A sobrecarga de comunicação é ainda maior do que no modelo coprocessador. Contudo, o hardware reconfigurável ganha mais independência do processador, o que possibilita que ainda mais partes do processamento sejam passadas para o hardware reconfigurável.

- Standalone: neste modo o hardware reconfigurável atua sozinho sem a interferência de um processador. É recomendado para casos nos quais necessita de um processamento de hardware de alta capacidade. 


\subsection{A Família de FPGA Stratix da Altera}

Para o projeto desta dissertação foi utilizado para implementação um dispositivo FPGA modelo EP2S60F672C3, parte integrante da família Stratix da Altera. Mais especificamente este componente encontra-se no kit de desenvolvimento denominado Nios II Development Kit - Stratix II Edition. A família Stratix foi introduzida em 2002 no mercado sendo que a característica principal desta linha de produtos é que seus dispositivos são de alta densidade, oferecendo os melhores desempenhos e possuindo uma grande quantidade de elementos lógicos para implantação do sistema ${ }^{1}$. Na figura 2.5 é apresentada uma foto da placa que acompanha o kit.

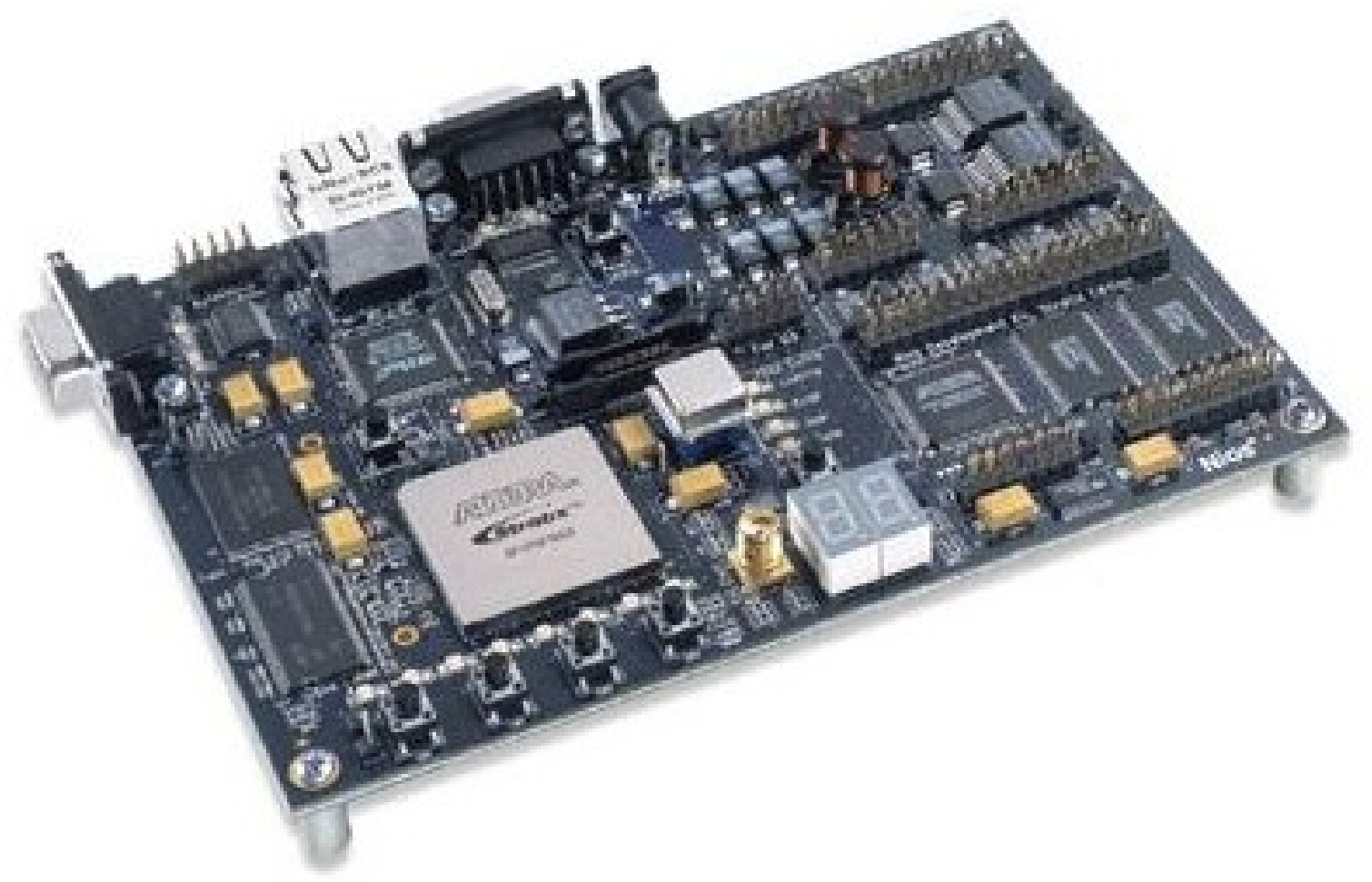

Figura 2.5: Foto da placa que será utilizada para desenvolvimento do projeto

Os principais recursos da placa que acompanha o kit de desenvolvimento são:

- Dispositivo FPGA Stratix II EP2S60F672C3

- 16 MBytes de memória SDRAM

- 8 MBytes de memória FLASH

- 1 MBytes de memória SRAM

- Dois portos $R S-232$

- Conector para depuração de hardware e software padrão Mictor

\footnotetext{
${ }^{1}$ A FPGA usada neste trabalho possui o equivalte a 24.176 elementos lógicos
} 
- Um Dispositivo de interface ethernet $10 / 100 \mathrm{Mbits} / \mathrm{s}$

- Um conector para CompactFlash

As principais características do dispositivo FPGA Stratix da Altera que é parte integrante da placa serão apresentadas na tabela 2.1:

\begin{tabular}{|c|c|}
\hline Característica & EP1S10 \\
\hline $\mathrm{ALMs}^{2}$ & 60.440 \\
\hline Elementos Lógicos Equivalentes & 24.176 \\
\hline $\begin{array}{c}\text { Blocos de } R A M M 512 \\
\text { (512 bits + paridade })\end{array}$ & 329 \\
\hline $\begin{array}{c}\text { Blocos de RAM M4K } \\
\text { (4 Kbits + paridade) }\end{array}$ & 255 \\
\hline $\begin{array}{c}\text { Blocos } M-R A M \\
\text { (512 Kbits + paridade })\end{array}$ & 2 \\
\hline Total de bits de $R A M$ & 2.544 .192 \\
\hline Blocos DSP & 36 \\
\hline Multiplicados Embutidos ${ }^{3}$ & 144 \\
\hline PLLs & 6 \\
\hline Quantidade Máxima de Pinos de E/S & 718 \\
\hline
\end{tabular}

Tabela 2.1: Características da FPGA utilizada.

\subsection{Linguagens de Descrição de Hardware}

Parafraseando a escritura sagrada, no princípio da eletrônica só existiam os esquemas elétricos. Eles eram responsáveis por representar os circuitos digitais através de primitivas gráficas que representavam as diversas funções digitais. As funções lógicas básicas como E, OU, NEGAÇÃO, OU-EXCLUSIVO, FLIP-FLOP, MUX, eram, e ainda são, representados por símbolos gráficos sendo o meio mais eficiente de se descrever circuitos eletrônicos.

À medida que foram evoluindo os circuitos eletrônicos, foram tornando-se cada vez mais complexos fazendo com que esta forma de representação gráfica se tornasse inadequada. Assim, novas formas de representação dos circuitos foram surgindo, como por exemplo as linguagens de descrição de hardware (HDLs) que estão se consolidando como forma padrão de descrição de projetos. Essas linguagens permitem construir um hardware com função equivalente e são capazes de facilitar a simulação do circuito implementado com ou sem a utilização dos tempos de propagação do circuito. Outra vantagem trazida em decorrente das HDLs é que o ciclo de vida dos produtos modernos está se tornando mais curto que os tradicionais ciclos de projeto, exigindo uma rápida prototipação.

As principais linguagens de descrição de hardware em uso atualmente são (BTF, 2004) (STEVEN, 2004) (SYSTEMC, 2004) (VHDL, 2003) (PERRY, 1999) (MAZOR e LANGSTRAAT, 1993) (IEEE, 1998): 
- Verilog Hardware Description Language (Verilog) - IEEE 1364: trata-se de uma linguagem desenvolvida em 1983 pela Gateway Design Automation Co., sendo a primeira linguagem padrão para desenvolvimento de sistemas complexos. Tornou-se padrão IEEE em 1995 sofrendo uma revisão do padrão definido em 2001. Possui recursos similares ao do VHDL porém com sintaxe mais simples.

- Altera Hardware Description Language (AHDL) - como o próprio nome induz, é uma linguagem de descrição de hardware proprietária da Altera desenvolvida no final da década de 80 com a finalidade de ser uma alternativa de baixo custo ao VHDL e ao Verilog. Trata-se de uma linguagem mais simples com poucos recursos para descrição do funcionamento do circuito baseada no ABEL (SPIEGEL, 1999), que permite instanciar primitivas e módulos prontos.

- SystemC: esta é uma linguagem de descrição de hardware baseada na amplamente conhecida linguagem $\mathrm{C}$. Faz uso de bibliotecas em $\mathrm{C}$ que podem ser compiladas utilizando-se de compiladores $\mathrm{C} / \mathrm{C}++$ padrões como o $G C C$ da $G N U$. É uma linguagem relativamente nova definida por um consórcio de fabricantes de ferramentas de desenvolvimento cujo mentor principal é a Synopsis e que ainda não possui um desempenho adequado se comparado com VHDL ou Verilog.

- Very High Speed Integrated Circuit (VHDL) - IEEE 1076: trata-se de uma linguagem de descrição de hardware com recursos para descrição funcional e estrutural dos circuitos além de simulação. Há ainda recursos para especificar tempos de propagação, leitura e escrita de dados em arquivos. Surgiu como um ramo do programa VHSIC que foi fundado pelo Departamento de Defesa dos Estados Unidos (DOD), no final dos anos 70 e começo dos anos 80. O objetivo do programa VHSIC era produzir a próxima geração de circuitos integrados. Os participantes do programa foram desafiados a expandir os limites da tecnologia em cada fase do projeto e fabricação de circuitos integrados (PERRY, 1991). Foi proposta em 1981 e chamada de VHSIC Hardware Decription Language, ou como é conhecida atualmente, VHDL. Posteriormente em 1987 tornou-se padrão IEEE, designada como IEEE-1076-1987. Em 1993 sofreu uma revisão onde foi ampliada e publicada como IEEE-1076-1993. Em 2002 foi liberada a terceira revisão da linguagem, como padrão IEEE 1076-2002. Por ser a mais completa e amplamente utilizada por projetistas de hardware, essa foi a linguagem escolhida para este trabalho. Assim, o coprocessador criptográfico AES possui todo o código em VHDL.

\subsection{System-on-a-Programmable-Chip (SOPC)}

Com a evolução dos sistemas computacionais tem-se notado cada vez mais a tendência de colocar a maior quantidade de funcionalidades possíveis em um único chip. Esta abordagem é conhe- 
cida como System-on-a-chip (SOC) (KAMATH e KAUDIN, 2004) (NEKOOGAR, 2003). No contexto de sistemas reconfiguráveis essa abordagem recebe o nome de System-on-a-ProgrammableChip (SOPC).

Atualmente há disponível no mercado algumas soluções SOPC tais como os processadores da Altera NIOS (NIOS, 2004) e NIOS II (NIOSII, 2004), os processadores Microblaze (MICROBLAZE, 2004) e Picoblaze (PICOBLAZE, 2004) da Xilinx. Estes processadores são construídos com códigos proprietários e fechados conhecidos como IP (Intelectual Property) e devem ser comprados dos respectivos fabricantes para poderem ser implementados. Todavia há algumas soluções independentes de fabricantes com código aberto e livre como é o caso do Gnome (GNOME, 2002), o Leon (LEON, 2004) e o OpenRISC (OPENRISC, 2004).

\subsection{Ferramentas de Desenvolvimento de Hardware}

Após ser devidamente implementado em uma linguagem de descrição de hardware, um projeto deve ser convertido para um formato de gravação que permita configurar uma FPGA de forma a se implementar o circuito na tecnologia desejada. Para tanto são necessárias as ferramentas de desenvolvimento. Estas ferramentas além de compilar o projeto para a plataforma desejada, permitem depuração (tanto em software quanto em hardware), simulação, dentre outras funcionalidades para auxiliar ao máximo o desenvolvimento.

Existem ferramentas de desenvolvimento de lógica programável genéricas que podem gerar arquivos de configuração ou arquivos intermediários para mais de um fabricante e ferramentas de desenvolvimento específicas para dispositivos de um único fabricante.

Há dois tipos de ferramentas de desenvolvimento de lógica programável:

- genéricas: servem para uma gama de dispositivos de diferentes fabricantes podendo gerar arquivos de configuração ou arquivos intermediários. Neste caso, temos os compiladores Verilog $H D L$ e $V H D L$ desenvolvido por empresas que fornecem ferramentas de desenvolvimento e simulação para o mercado de lógica programável, como a Synopsis - a qual é lider mundial do mercado de ferramentas de desenvolvimento, a Mentor Graphics, a Cadence, a Synplicity, dentre outras.

- específicas: são projetadas para o desenvolvimento de dispositivos de um único fabricante. Neste caso temos ferramentas como ISE, Embedded Development Kit da Xilinx (XILINX, 2004) e Quartus II, SOPC Builder (ALTERA, 2004c) ambas da Altera.

Neste trabalho serão usadas as ferramentas de desenvolvimento da Altera para a família Stratix, os quais estão disponíveis, tanto software quanto hardware no laboratório de computação reconfigurável da Usp. 


\subsubsection{Quartus II}

Atualmente na versão 6.1, o Quartus II é a ferramenta de desenvolvimento principal da Altera estando disponível tanto para Windows quanto para Linux. Esta ferramenta permite ao projetista desenvolver na forma de esquemático, $A H D L$, Verilog $H D L, V H D L$, ou ainda usar um arquivo do tipo Eletronic Interchange Format (EDIF) gerado por um compilador de linguagens de descrição de hardware genérico. Uma vez confeccionada a descrição do projeto, o sofware se encarrega de gerar o arquivo no formato adequado para o dispositivo desejado e o arquivo de descrição de tempos de propagação internos usados para gerar os arquivos de simulação. A figura 2.6 apresenta a tela de desenvolvimento principal do Quartus II com um processador NIOS II implementado em esquemático.

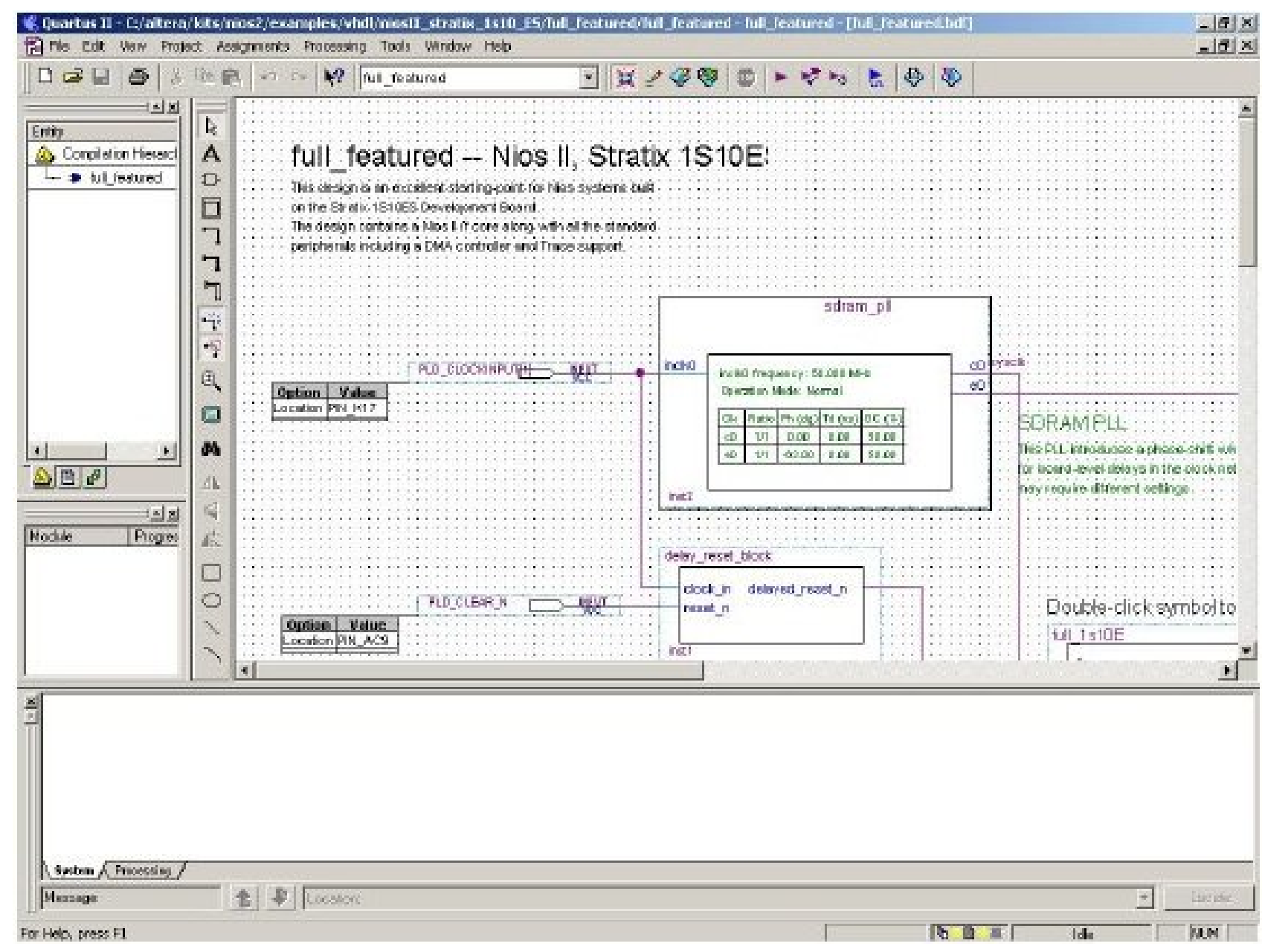

Figura 2.6: Tela principal do Quartus II

O Quartus II possui suporte completo a ferramentas de controle de versão permitindo, desta forma, que mais de um projetista possa trabalhar ao mesmo tempo sobre o mesmo projeto. Além disso, permite que se acesse um determinado projeto pela Internet podendo acessá-lo, alterá-lo e compilá-lo de qualquer lugar do globo terrestre. O software oferece também como recursos a possibilidade de recompilação parcial do projeto, avaliação de funções $I P$, configuração de com- 
ponentes, geração de arquivos para máquina de teste automático, programação de componentes de configuração e integração com a ferramenta de desenvolvimento SOPC Builder.

Outros recursos disponíveis no software são:

- SignalTap II (SIGNALTAPII, 2004): é um recurso que permite a implementação de analisadores lógicos no próprio circuito, bem como a amostragem de sinais baseados em condições de disparo definidas pelo projetista e ainda a taxa de amostragem destes sinais;

- LogicLock (LOGICLOCK, 2004): trata-se de um recurso que permite a implementação de projetos em módulos, de forma hierárquica, onde cada módulo é compilado e otimizado individualmente;

- RTL Viewer(ALTERA, 2004a) e Technology Viewer (ALTERA, 2004b): recursos estes que permitem, respectivamente, a visualização gráfica do resultado da compilação de um projeto na forma de primitivas digitais e da tecnologia que o projeto está sendo desenvolvido

\subsubsection{SOPC Builder}

Para se configurar um sistema $S O P C$ devem ser definidas dentre um conjunto de opções as características que permitam descrever de forma correta o sistema. Estas características envolvem a configuração do endereço de cada periférico, o número de interrupção usado pelos periféricos que geram sinais de interrupção, as conexões aos mestres do barramento, etc. Para se fazer isso a Altera disponibiliza, junto com o conjunto de ferramentas que acompanham a placa de desenvolvimento Stratix, o SOPC Builder, um programa desenvolvido em Java, integrado com o Quartus II, que possui uma interface gráfica amigável de forma a facilitar a especificação do sistema como um todo.

Na figura 2.7 é apresentado um diagrama de blocos destacando as atividades realizadas pelo SOPC Builder que serão descritas em mais detalhe no decorrer desta seção.

A sequiência de operações que devem ser efetuadas é a seguinte:

- Configuração do processador: especifica-se o processador, no caso o NIOS II com suas características, opções de otimização e depuração do sistema. Pode-se especificar também instruções proprietárias e/ou customizadas que devem estar definidas em um bloco de hardware (pode estar em esquemático ou em alguma linguagem de descrição de hardware).

- Seleção e configuração dos periféricos que comporão o sistema: aqui se adiciona e se configura os periféricos desejados pelo projetista para compor o sistema. Estes periféricos podem ser desenvolvidos pelo usuário, podem fazer parte do pacote que acompanha o software ou ainda adquiridos na forma de $I P$ gratuitos ou de empresas especializadas no assunto. Nesta etapa, configura-se o endereço de cada periférico e o número de interrupção do mesmo (no caso do periférico utilizar sinais de interrupção). 


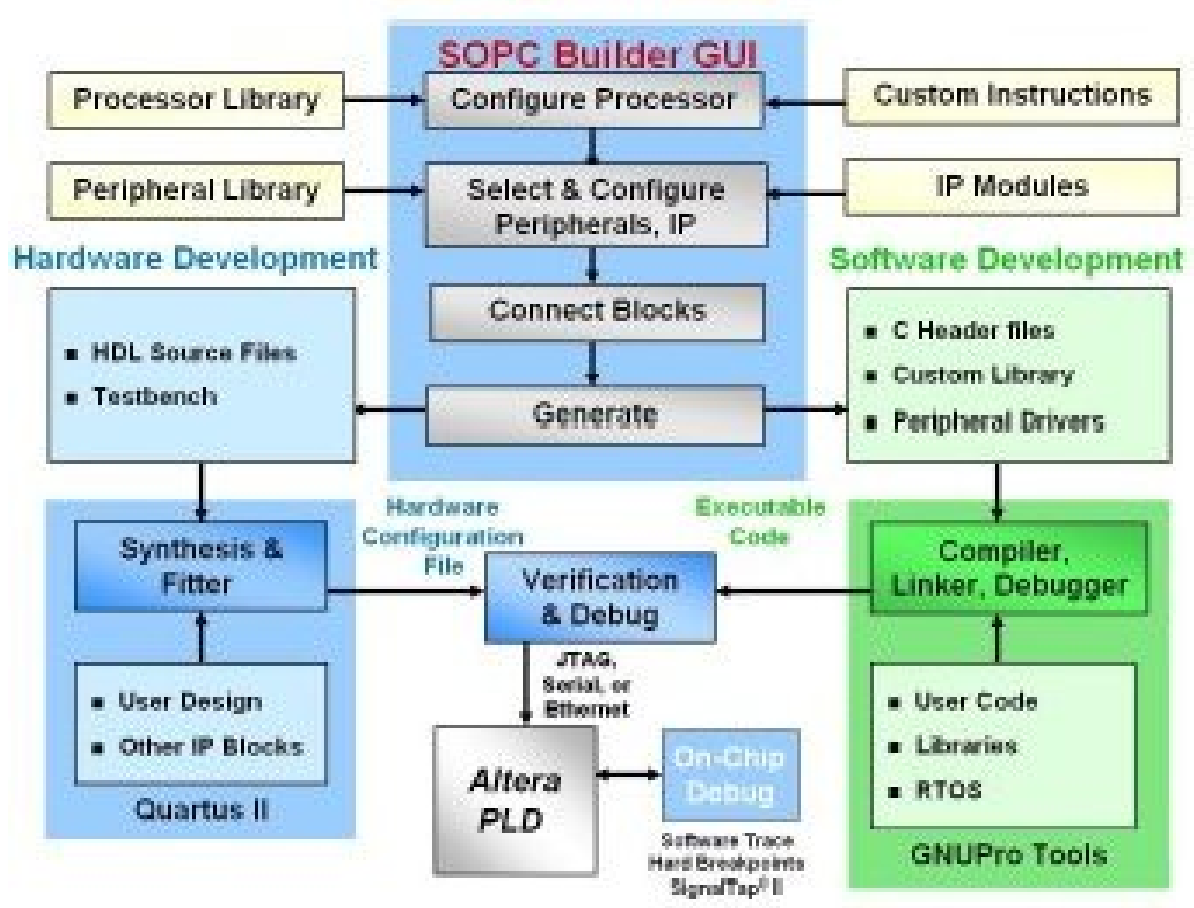

Figura 2.7: Diagrama de Blocos com as tarefas realizadas pelo SOPC Builder

- Interconexão dos módulos: nesta etapa se conecta todos os módulos que farão parte do sistema configurando as característica do barramento AVALON (barramento padrão do sistema que será descrito mais adiante) tais como as possíveis interrupções e conexões de $D M A$ a serem criadas e os recursos necessários. O coprocessador utilizado neste trabalho deve ser instanciado e devidamente configurado, por exemplo a atribuição do endereço de memória, para se realizar a conexão com o Nios II.

- Configurações gerais: em uma outra etapa do SOPC Builder devem ser realizadas algumas configurações que serão usadas na geração do sistema. Essas configurações envolvem a determinação dos endereços de ínicio de execução após se reinicializar o sistema, a interface que será utilizada na troca de mensagens entre o sistema e um computador externo, uma interface para depuração que manterá a tabela de vetores de interrupções, dentre outras.

- Geração do sistema: a última etapa do desenvolvimento envolve a compilação de todo o sistema sendo que o SOPC Builder se encarrega de gerar o código do sistema de conexão em alguma linguagem de descrição de hardware como VHDL ou Verilog.

Finalmente, após o sistema ter sido desenvolvido utilizando-se do SOPC Builder e gerado todos os arquivos necessários para configuração deve-se retornar ao Quartus II para determinar a configuração do FPGA, compilar o projeto total e descarregar no dispositivo de hardware desejado. 


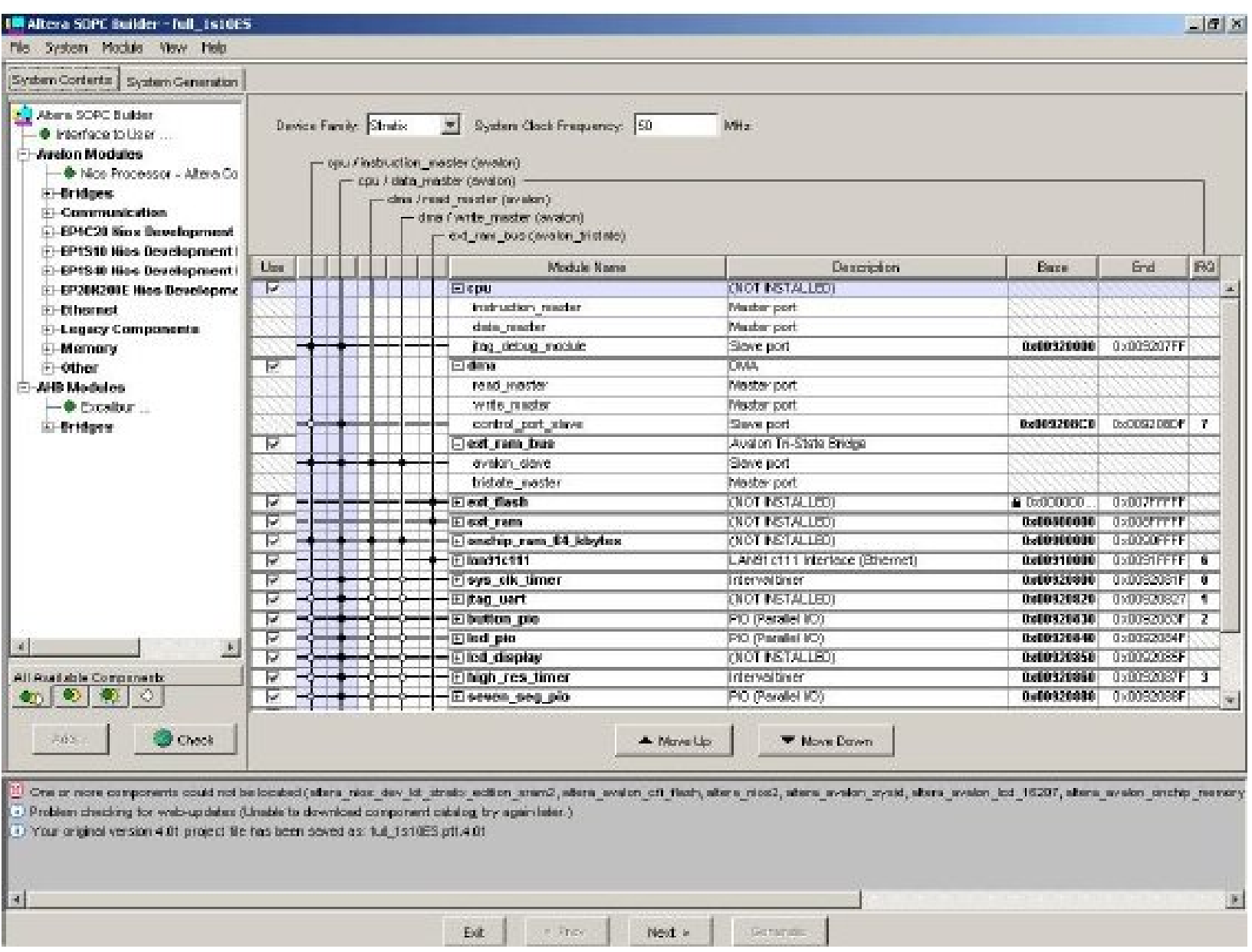

Figura 2.8: Exemplo de um sistema criado com o SOPC Builder

\subsection{Considerações Finais}

Este capítulo apresentou conceitos de hardware desde uma sucinta descrição da evolução da eletrônica até a computação reconfigurável tema principal desta dissertação. Foram apresentados os dispositivos de lógica programável com destaque para a tecnologia FPGA e os dispositivos Stratix, os melhores dispositivos da Altera. Também foi discorrido sobre as linguagens de descrição de hardware, principalmente $V H D L$ por ser de suma importância para o desenvolvimento deste projeto. Por fim, destaque para as ferramentas de desenvolvimento de hardware que estão sendo e continuarão a serem utilizadas. 


\section{VPN (Virtual Private Network)}

\subsection{Conceito}

Rede Privada Virtual $(V P N)$ é uma rede privada de dados que faz uso da infra-estrutura de telecomunicação pública, mantendo privacidade através do uso de um protocolo de tunelamento e procedimentos de segurança (VPNC, 2002). O termo virtual é utilizado pois depende de uma conexão virtual, temporária e sem presença física no meio. Esta conexão virtual consiste de troca de pacotes, sendo roteados entre vários equipamentos.

Antigamente, as instituições que quisessem utilizar uma rede de computadores para troca de informações entre filiais e matriz, distantes entre si, deveriam montar sua própria infra-estrutura particular demandando uma grande quantidade de recursos tanto financeiros quanto humanos para a implantação e manutenção desta rede. A Internet era inviável de ser utilizada por ser de domínio público e portanto podendo ser monitorada por entidades não desejáveis. Neste contexto surge a proposta das VPNs, visando reduzir sensivelmente os custos por utilizar toda a infra-estrutura da Internet, uma rede de alcance global, eliminando a necessidade de linhas dedicadas de longa distância e mantendo a segurança necessária para a instituição. Esta segurança é basicamente garantida através de encapsulamento e criptografia como será descrito mais adiante.

\subsection{Segurança da informação}

Segurança da informação é uma das questões mais relevantes quando pretende-se construir uma rede entre quaisquer dispositivos. Apesar da relevância, é um dos aspectos mais difíceis de se 
garantir devido as inúmeras funcionalidades que uma rede pode ter. Segurança é algo que sempre se deve perseguir, ou seja, sempre será necessário novas modificações no sistema, como por exemplo atualizações de programas, a fim de se proteger efetivamente uma rede de vulnerabilidades.

\subsubsection{Conceitos básicos de segurança}

Quando se trata de segurança de informação três conceitos são considerados primordiais:

- Confidencialidade: visa garantir que a informação não será lida nem copiada por qualquer pessoa que não esteja autorizada. Essa informação pode estar em transitando em uma rede ou mesmo em um host específico. Para vários tipos de informações (por exemplo, segredos industriais de fabricação de um determinado produto, segredos militares, e-mais confidenciais, número de cartão de crédito, etc) confidencialidade é considerada fundamental.

- Integridade: visa garantir a informação incólume, ou seja, garantir que a informação não seja apagada nem modificada tanto em curso quanto em um host.

- Disponibilidade: visa manter a informação sempre disponível para pessoas autorizadas. Ataques que indisponibilizam serviços (por exemplo, Denial of Service ou Distributed Denial of Service) causam milhões em prejuízos todos os anos a sites que comercializam produtos na Internet.

Outros conceitos importantes, que estão diretamente relacionados com os conceitos acima e, são de igual importância para se obter segurança são:

- Autenticação: significa provar que um usuário é quem ele realmente diz que é. Para que se realize autenticação, o usuário deve fornecer uma informação como uma senha, um objeto exclusivo de sua propriedade (um smartcard) ou uma característica pessoal que prove sua identidade (impressão digital ou reconhecimento pela íris). Há também sistemas de autenticação mais poderosos conhecidos como autenticação forte, que utilizam mais de um método dos descritos acima para autenticar o usuário. Um exemplo comum são os caixas eletrônicos que utilizam tanto uma senha como um cartão magnético para identificar que o usuário realmente é o dono de determinada conta. Há também a autenticação mútua na qual ambos os lados da comunicação devem ser devidamente autenticados antes de se estabelecer a comunicação. Um exemplo interessante de autenticação mútua é quando um usuário deseja entrar em um site de banco. Assim, tanto o usuário quanto o site devem provar a sua identidade.

- Autorização: consiste determinar quais informações um usuário, ou um sistema de computador autenticado, tem direito a acessar e/ou manipular.

- Não repudiação: consiste em garantir que determinado usuário que se autenticou é realmente o usuário proprietário daquela conta. Assim, o usuário não poderá negar posteriormente que ele realizou determinada atividade. 


\subsection{Conceitos de Criptografia}

Criptografia é uma ciência, praticada por criptógrafos, que estuda formas de se transformar um texto em algo ininteligível. Este texto pode então ser recuperado (como por exemplo, com a finalidade de se realizar uma comunicação) ou pode ser impossível (ou pelo menos deveria ser) a reconstrução do texto original. A criptografia é a base fundamental para a VPN.

O processo de tornar uma mensagem incompreensível é chamado de encriptar. O processo reverso, que consiste em pegar um texto cifrado (ou encriptado), recebe o nome de decriptar. Um algoritmo criptográfico é uma função usada para encriptação e decriptação. No geral, existem duas funções relacionadas, uma para se encriptar e outra para se decriptar.

Algoritmos cuja segurança está baseada no segredo de como o algoritmo funciona são conhecidos como algoritmos restritos. Se for denotada a função de encriptação por E e a de decriptação por $\mathrm{D}$, pode-se descrever o processo criptográfico da seguinte forma:

$$
\begin{gathered}
E(T)=C \\
D(C)=T \\
D(E(T))=T
\end{gathered}
$$

onde,

Té o texto original e

Cé o texto cifrado.

Esta classe de algoritmos não é mais adequada atualmente. Por exemplo, um grupo de pessoas que utiliza um algoritmo restrito precisa trocá-lo toda vez que alguém sair deste grupo. Mais ainda, se alguém revelar mesmo que de forma acidental o algoritmo todos devem trocá-lo. Além disso, estes tipos de algoritmos não permitem controle de qualidade ou de padronização. Cada grupo de usuários deve ter seu próprio algoritmo sendo que não podem utilizar hardware ou software pronto, pois alguém pode comprar o mesmo produto e aprender o algoritmo. Assim, as pessoas envolvidas devem criar seus próprios algoritmos e implementações. Todavia, ainda são utilizados alguns algoritmos restritos em aplicações que necessitam de baixa segurança.

A criptografia moderna resolve o problema por meio da utilização de uma chave, que será denotada por K. Podem haver inúmeras chaves para um mesmo algoritmo criptográfico, sendo que os possíveis valores são denotados por espaço de chaves. Dentro deste conceito, o algoritmo se torna de domínio público pois não é nele que se encontra a segurança e sim na chave. Desta forma, um grupo que desejar utilizar um algoritmo criptográfico basta criar uma ou mais chaves secretas, pertencentes exclusivamente ao grupo, que a segurança será garantida. Assim surgem três novas abordagens para os algoritmos: simétricos, assimétricos e híbridos.

- Algoritmos Criptográficos Simétricos: são aqueles que se utilizam apenas de uma chave tanto para encriptar o texto quanto para decriptar. Desta forma: 


$$
\begin{gathered}
\mathrm{E}_{k}(\mathrm{~T})=\mathrm{C} \\
\mathrm{D}_{k}(\mathrm{C})=\mathrm{T} \\
\mathrm{D}_{k}\left(\mathrm{E}_{k}(\mathrm{~T})=\mathrm{T}\right.
\end{gathered}
$$

A figura 3.1 apresenta estas expressões matemáticas de uma maneira mais clara possível.

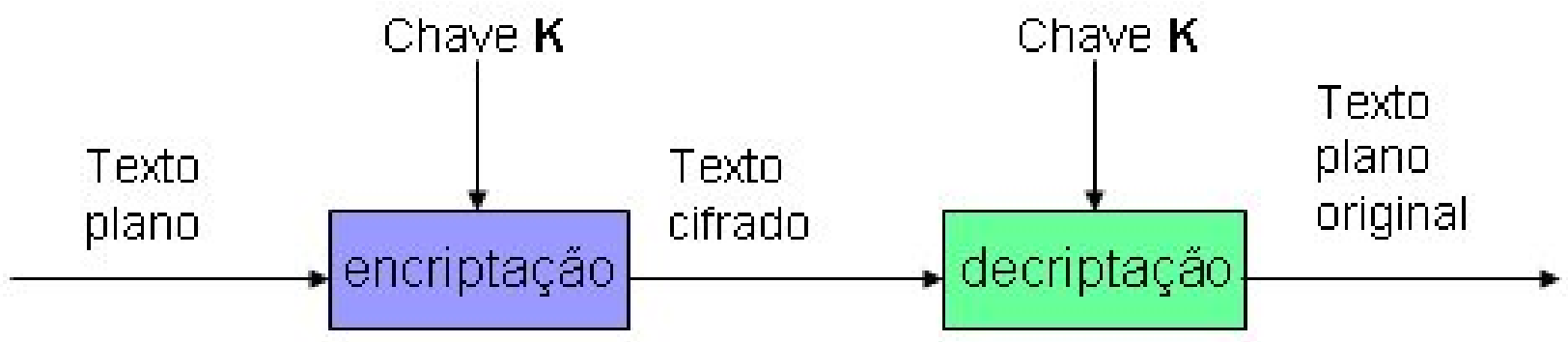

Figura 3.1: Criptografia Simétrica

Estes algoritmos possuem uma grande desvantagem pois há uma dificuldade em se trocar a chave para o início do processo criptográfico. A chave que é o recurso mais importante deve ser conhecida por todos os membros do grupo e exclusivamente por eles.

- Algoritmos Criptográficos Assimétricos: são algoritmos no qual existem chaves diferentes para encriptar e decriptar. Cada participante do processo criptográfico possui uma chave pública, de conhecimento geral, e uma chave privada, de conhecimento apenas de uma pessoa. As chaves são exclusivas e possuem uma relação matemática entre si, mas é (ou pelo menos deveria ser) impossível derivar a chave privada através da pública. O processo criptográfico ocorre então da seguinte forma:

$$
\begin{gathered}
\mathrm{E}_{k 1}(\mathrm{~T})=\mathrm{C} \\
\mathrm{D}_{k 2}(\mathrm{C})=\mathrm{T} \\
\mathrm{D}_{k 2}\left(E_{k 1}(\mathrm{~T})=\mathrm{T}\right.
\end{gathered}
$$

Isto também pode ser visto na figura 3.2

Apesar de resolver o problema da chave esta abordagem também apresenta uma desvantagem: se comparado com os algoritmos simétricos são bem mais lentos. Isto acaba sendo um problema considerável, pois obtém-se segurança porém o custo é de um desempenho baixo.

- Algoritmos Criptográficos Híbridos: as abordagens apresentadas acima possuem vantagens e desvantagens. A idéia dos algoritmos criptográficos híbridos é de se aproveitar a vantagem de ambos. Assim, são utilizados as duas abordagens acima no processo de comunicação. Funciona da seguinte forma: 


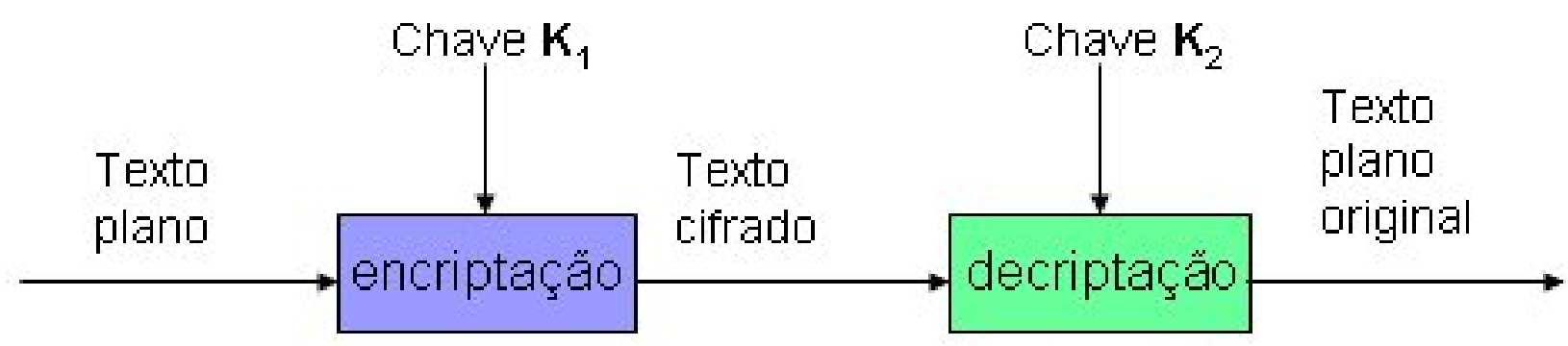

Figura 3.2: Criptografia Assimétrica

- Gera-se a chave de um algoritmo simétrico que será utilizado para a comunicação

- Utiliza-se um algoritmo assimétrico entre o grupo participante da comunicação para efetuar a troca dessa chave.

- Após efetuar a troca de chaves do algoritmo simétrico por meio do algoritmo assimétrico, descarta-se este último e passa-se a utilizar apenas o primeiro, obtendo-se assim um desempenho melhor.

- Algoritmos hash one-way: também conhecidos como funções de compressão, funções de contração, verificação da integridade da mensagem (Message Integrity Check - MIC) e código de detecção de manipulação (Manipulation Detection Code - MDC), entre outros. Exerecem um papel central na criptografia moderna e são usadas em muitos protocolos. Uma função hash é uma função que recebe como entrada uma cadeia de tamanho variável e produz como saída uma cadeia de tamanho fixo, geralmente de tamanho menor, chamado de valor hash. As funções hash one-way são algoritmos que criptografam uma cadeia mas torna-se impossível fazer o processo inverso, ou seja, decriptar. São muito utilizados para armazenamento de senhas, cartões de crédito, assinatura digital, etc. A função hashing analisa toda a informação e com base em um complexo algoritmo matemático gera um valor de tamanho fixo para o arquivo. Esse valor é calculado com base nos caracteres da cadeia. Com isso, qualquer mudança no texto original, mesmo que seja de apenas um único bit, fará com que o valor hash seja diferente.

Outro conceito relacionado com funções hash é o código de autenticação de mensagem (MAC). Também conhecido como Código de Autenticação de Dados (DAC) é uma função hash one-way que faz uso de uma chave secreta. O valor hash é uma função tanto da cadeia de dados quanto da chave. A fundamentação teórica é a mesma da de função hash, exceto que apenas alguém de posse da chave pode verificar o valor de hash.

Outros conceitos relacionados a criptografia são a assinatura digital e o certificado digital. Uma das maneiras de se realizar uma assinatura digital é realizada com criptografia assimétrica na qual um usuário (que pode ser uma pessoa física ou uma instituição qualquer) criptografa a mensagem utilizando sua chave privada que é única e exclusiva. A outra parte da comunicação utiliza a chave 
pública do usuário para decriptar a mensagem. Outra maneira de assinar digitalmente uma mensagem é utilizando uma função hash. Como o uso de um sistema criptográfico assimétrico pode se tornar muito lento, o sistema hash se mostrou bastante eficaz para se assinar digitalmente um documento. Isso deixa claro que o arquivo em si não precisa, pelo menos teoricamente, ser criptografado (caso não seja algo secreto), mas sim acompanhado do valor hash. Com isso, qualquer mudança no arquivo original fará com que o documento se torne inválido. A assinatura digital garante, assim, um dos princípios da segurança que é a não-repudiação.

Para se obter uma assinatura digital é necessário procurar uma entidade que faça esse serviço, isto é, deve-se procurar uma Autoridade Certificadora (AC). Uma AC tem a função de verificar a identidade de um usuário e associar a ele uma chave pública e privada. Essas informações são então inseridas em um documento conhecido como certificado digital. Um certificado digital contém a chave pública do usuário e os dados necessários para informar sua identidade. Esse certificado pode ser distribuído para qualquer usuário na Internet. Deste modo, permite-se a qualquer pessoa ou instituição que queira certificar-se que a assinatura digital de um documento é válida obtendo-se o certificado digital correspondente. Todavia certificados digitais não são usados exclusivamente em conjuntos com assinaturas digitais. Outra informação relevante é que a transmissão de certificados digitais deve ser feita através de uma conexão segura, como as que usam o protocolo SSL (Secure Socket Layer), que é próprio para o envio de informações criptografadas pela Internet.

\subsubsection{Modos de Operação}

Cada algoritmo criptográfico pode operar em diferentes modos, divergindo nos métodos que os algoritmos utilizam para trabalhar com o bloco de dados. De acordo com uma publicação do NIST (NIST, 2001) há 5 modos nos quais cada algoritmo pode operar. São eles:

1. ECB Eletronic Codebook Mode: é o modo mais simples de se criptografar. No modo ECB a mensagem é dividida em blocos de $\mathrm{n}$ bits e cada bloco é encriptado independente dos outros blocos. Cada bloco pode ser visto como um valor que é substituído por outro valor; é daí que recebe o nome de codebook. Sua fraqueza está exatamente em sua caracterísitica, pois mensagens com padrões de repetição podem se revelar no texto cifrado. Em outras palavras, blocos idênticos de texto de entrada produzem blocos de saída idênticos se a mesma chave for utilizada. Para se decriptografar um texto, basta aplicar a função em cada bloco cifrado separadamente. Uma vantagem destacada é no caso de ocorrer um erro: caso um bit esteja errado em um bloco, apenas aquele bloco se tornará inválido. Os outros estarão corretamente criptografados, ou seja, o erro não se propaga de um bloco para outro.

2. CBC Cipher Block Chaining Mode: neste modo, a entrada para o algoritmo de cifragem é o resultado de uma operação ou-exclusivo dos dados a cifrar com o bloco cifrado anteriormente, sendo cada bloco de $\mathrm{n}$ bits. Esse bloco é criptografado usando uma chave $\mathrm{K} \mathrm{e}$ enviado para entrar no processo do próximo bloco. Assim, cada novo bloco a ser cifrado 

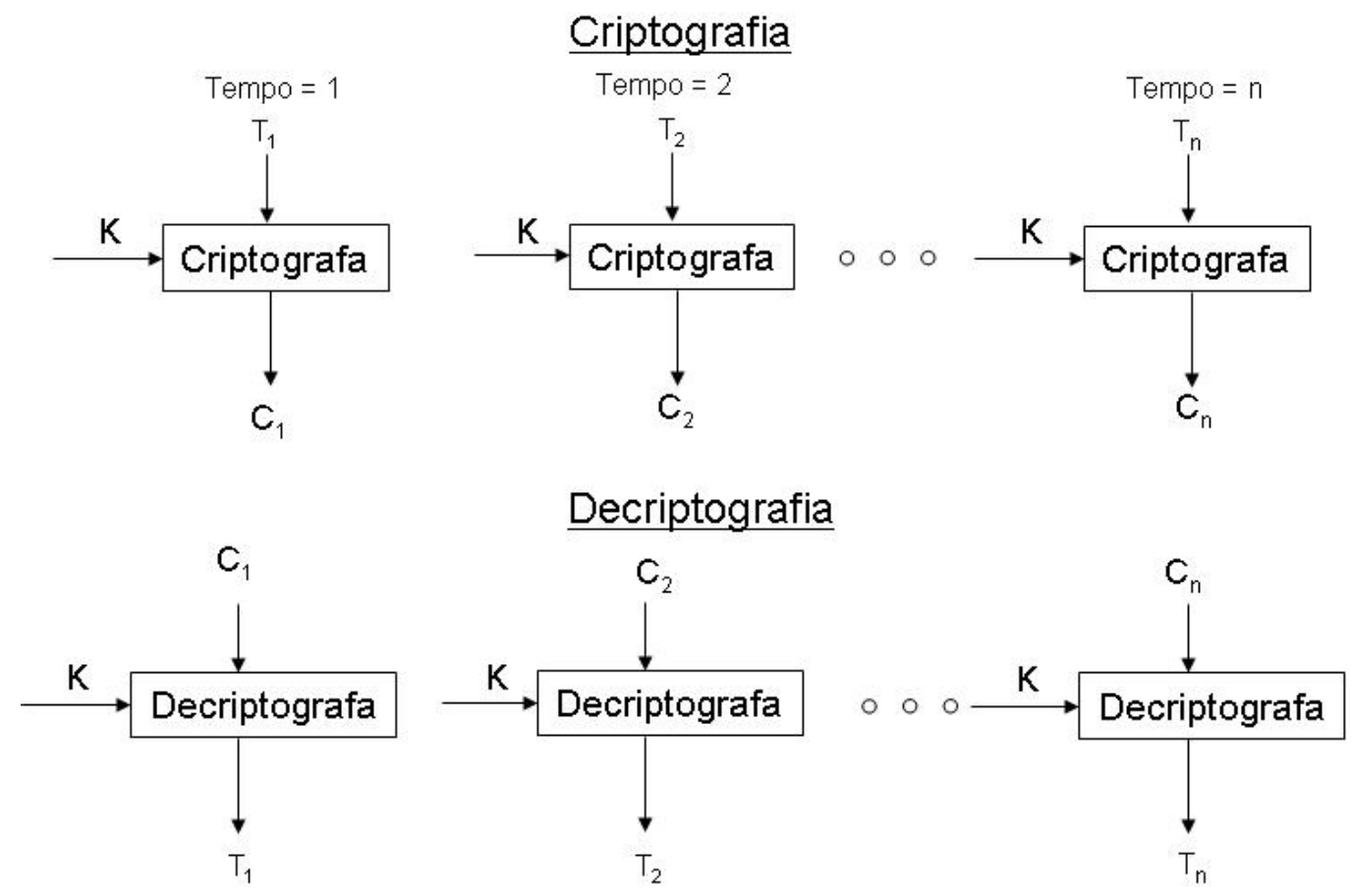

Figura 3.3: Diagrama de funcionamento do modo ECB

depende dos blocos anteriormente processados conforme pode ser visto na figura 3.4. Isto faz com que uma alteração em um bloco de texto não cifrado provoque alteração no bloco cifrado e em todos os blocos subsequentes. Para o funcionamento do algoritmo neste modo, é necessário um vetor de inicialização (IV), o qual é um valor inicial, que faz com que cada mensagem seja única. Este IV não deve ser enviado para o receptor sem estar devidamente criptografado. Neste caso, uma solução comum é se utilizar o modo ECB para se enviar o vetor de inicialização.

No processo de decriptografia, os dados são decriptografados usando a mesma chave K. O valor obtido é passado por um ou-exclusivo com o penúltimo valor de entrada criptografado. Com apenas dois blocos de dados adjacentes é possível se recuperar o texto original, fazendo com que a decriptografia possa ser paralelizada. De todos os modos de criptografia existente, o CBC é o que tem sido o modo mais comumente utilizado. As desvantagens desse método é que a criptografia não pode ser paralelizada, ou seja, é sequencial, e que se for necessário fazer um padding na mensagem ele deve ser do tamanho de um múltiplo do bloco de entrada. Qualquer modificação em um bloco de texto, mesmo que seja um único bit, é propagado para todos os blocos subsequentes.

3. CFB Cipher Feedback Mode: neste modo cada bloco é tratado como uma stream de bits, ou seja, o bloco de entrada possui s bits, sendo $\mathrm{s}<\mathrm{n}$. O estágio seguinte usa a realimentação do estágio anterior para alimentar o seu bloco de cifragem, conforme pode ser visto na figura 3.5. O padrão permite um feedback com qualquer número de bits $(1,8,16$, etc) denominados CFB-1, CFB-8, CFB-16. É normalmente utilizado para autenticação e cifragem de streams. 


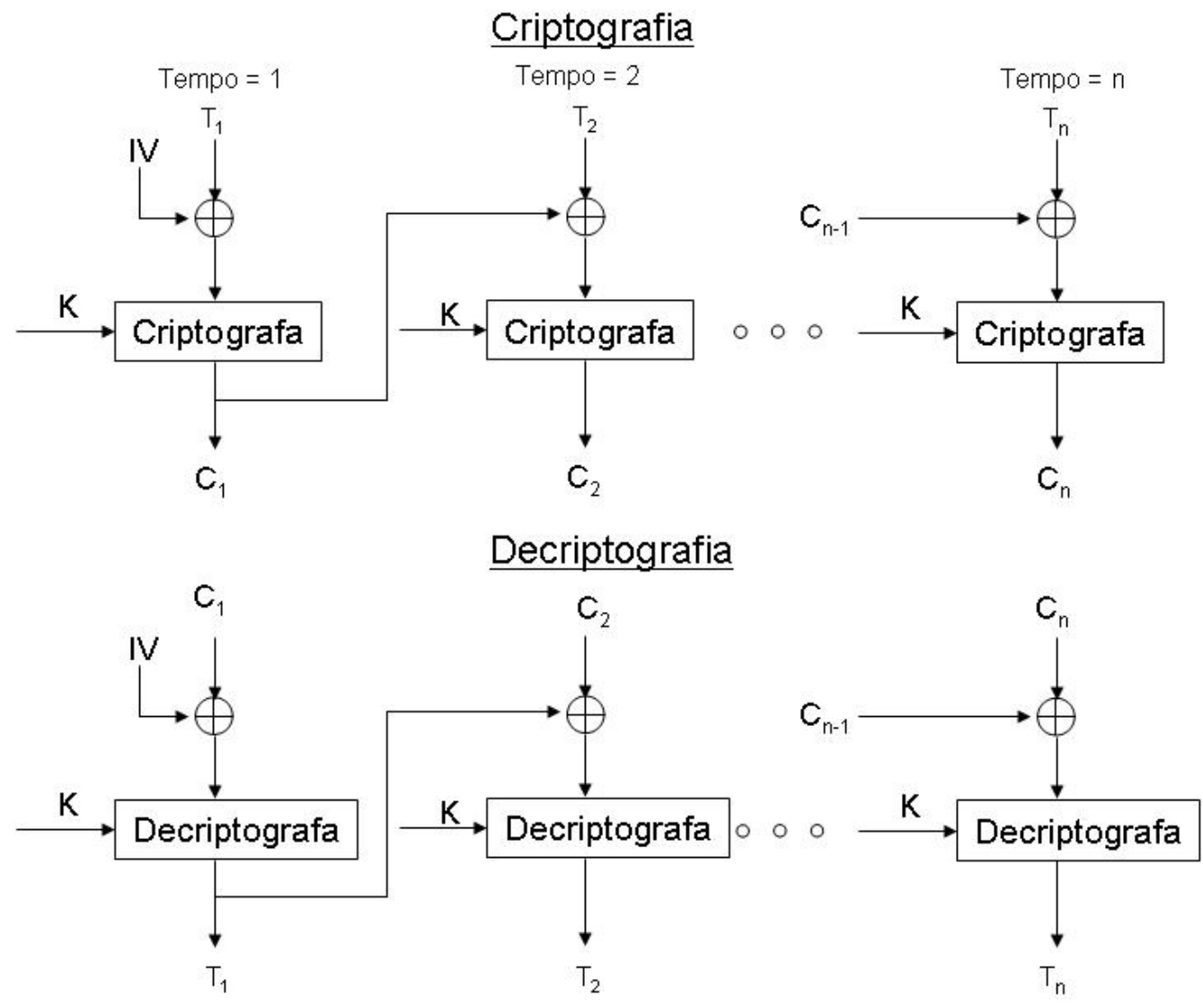

Figura 3.4: Diagrama de funcionamento do modo CBC

Há alguns aspectos semelhantes ao modo CBC, como por exemplo a propagação de erros para todos os blocos subsequentes e a criptografia que não pode ser paralelizada. Já a decriptografia é praticamente idêntica a decriptografia do modo $\mathrm{CBC}$, sendo que a diferença é que ela é realizada ao contrário, podendo também ser paralelizada. Uma vantagem do CFB que também vale para os modos OFB e CTR, é que por serem modos que trabalham com cadeia de bits ao invés de bloco de dados, o padding pode ser feito com qualquer quantidade de bits.

4. OFB Output Feedback Mode: Este modo é semelhante ao modo CFB, como pode ser visto no diagrama da figura 3.6. Os dados também são tratados como uma cadeia de $s$ bits, ao invés de ter um bloco fixo $n$, sendo $s<n$. Ele usa a função de encriptação para gerar um bloco cifrado apenas com a chave e com o vetor de inicialização, no caso do primeiro bloco, ou entre a chave e o bloco anterior, nos passos subsequentes. A esse valor, também chamado de keystream, é aplicada uma função ou-exclusiva com o texto original para gerar o texto cifrado. Cada operação de cifragem depende do bloco anterior e portanto não se pode realizá-las em paralelo.

5. CTR Counter Mode: também conhecido como Contador Inteiro Segmentado (SIC), este modo gera a keystream realizando a operação de criptografia com o incremento sucessivo 

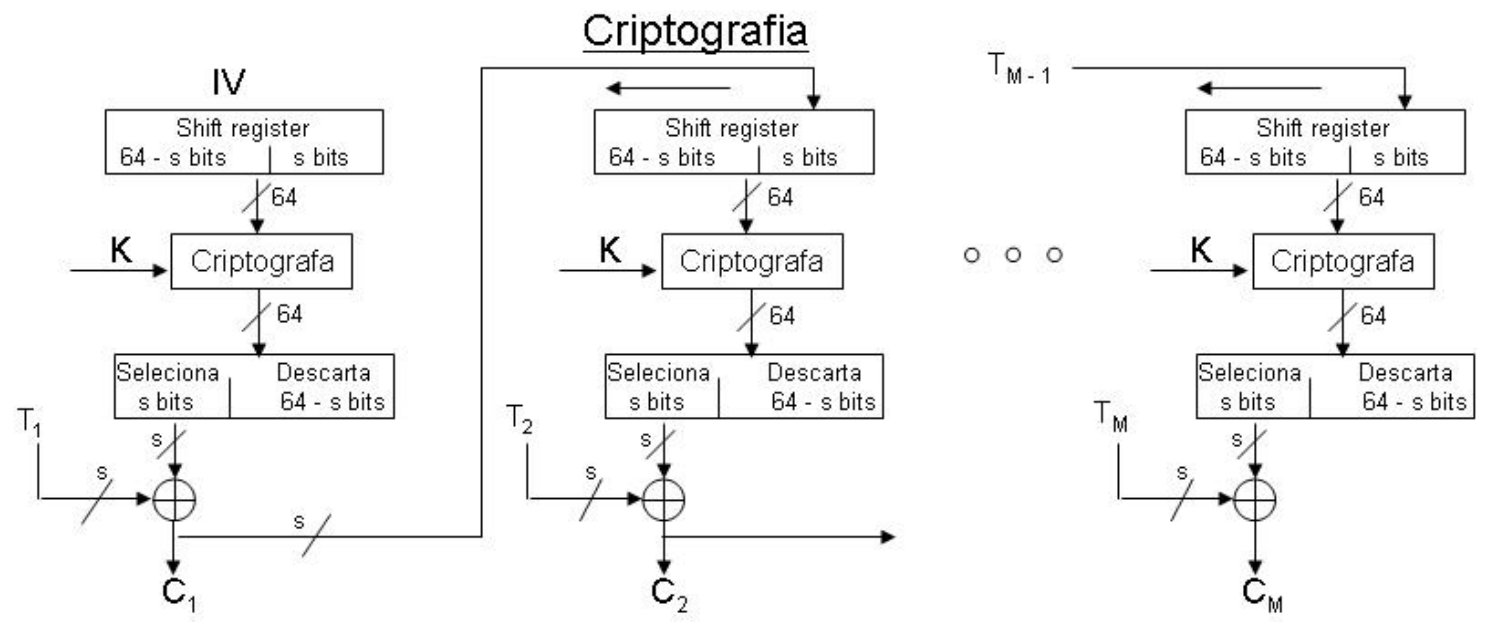

\section{Decriptografia}
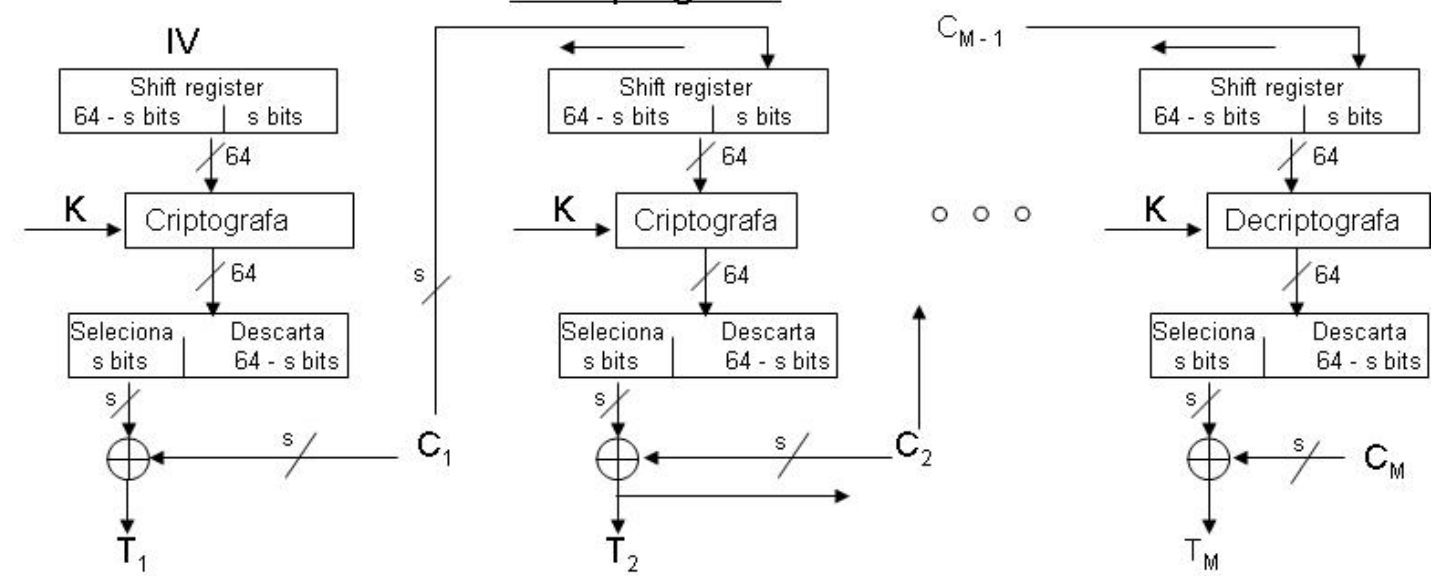

Figura 3.5: Diagrama de funcionamento do modo CFB

dos valores de um contador e a chave utilizada. Ao resultado obtido é aplicado uma função ou-exclusiva junto com o texto original para gerar o texto cifrado, conforme pode ser visto na figura 3.7. O contador pode ser qualquer função que produz uma seqüência que não se repetirá por um longo período de tempo.

\subsection{Aplicações para VPN}

Diversos são os casos onde podem ser empregadas as VPNs. A aplicação mais simples é demonstrada na figura 3.8:

Neste caso, duas máquinas, servidores ou estações, são interligados via Internet usando uma $V P N$. A figura 3.9 apresenta um segundo caso de uso de $V P N s$ o qual seria entre um ou vários usuários remotos e uma rede. Neste caso, o usuário faz uma conexão para um ISP (Internet Service Provider) ou provedor de acesso, recebe autorização para utilizar a Internet por esse provedor e recebe um endereço IP válido e dinâmico para trafegar pela rede. Por meio desse canal com a Internet é possível se estabelecer uma $V P N$ entre o usuário remoto e o gateway da $V P N$ que protege uma filial ou empresa. Geralmente, esta conexão não é transparente pois é necessário uma 


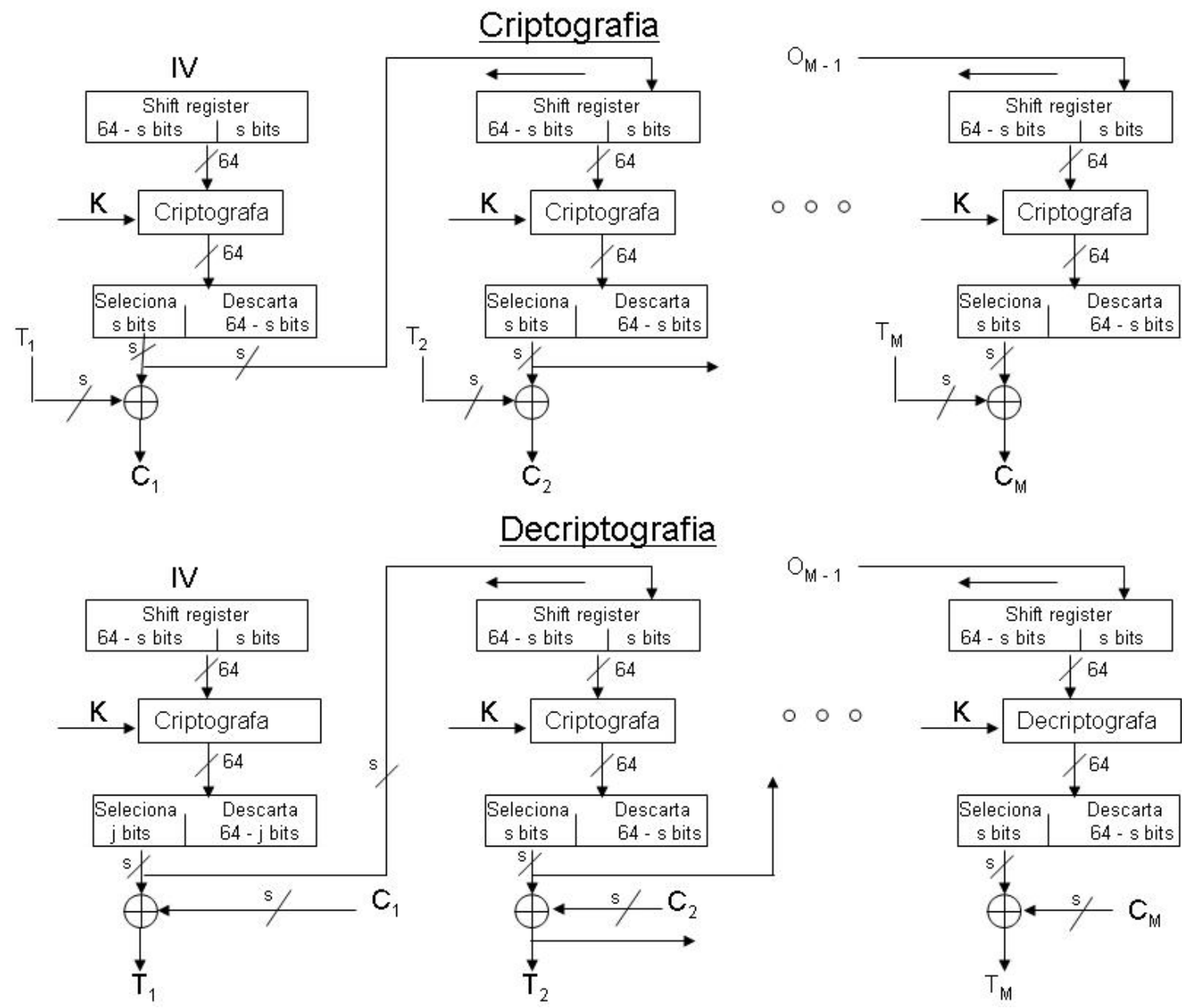

Figura 3.6: Diagrama de funcionamento do modo OFB

fase de estabelecimento de sessão entre o equipamento do usuário e o servidor com o qual se deseja estabelecer a $V P N$. O usuário pode acessar qualquer página da Internet de uma forma insegura e somente utilizará o túnel $V P N$, estabelecido na fase de sessão, quando for acessar uma máquina dentro da rede protegida pelo gateway.

Um terceiro caso de uso seria entre duas redes como mostra a figura 3.10. Este é um caso típico de ligação entre duas empresas formando uma extranet. Cabe ao gateway da VPN definir quais computadores terão acesso a Internet e, dentre estes, quais irão inscrever-se no túnel da $V P N$. Diferentemente de usuários remotos, o tráfego protegido pelo túnel VPN é totalmente transparente ao usuário de dentro da rede. Nesta topologia, o tráfego seguro ocorre somente entre os gateways da $V P N$. Na grande maioria dos casos, esta topologia é suficiente, mas caso necessite aumentar o grau de segurança de um determinado servidor, pode-se colocar outro gateway VPN dentro da rede, formando-se assim uma nova barreira entre este servidor e a rede da empresa ou filial.

Um quarto caso seria entre duas redes com acesso remoto, como demonstrado na figura 3.11. Esta topologia se aplica a empresas maiores que possuam duas ou mais filiais, ou entre empresas, e permite acesso de usuários remotos a determinados sites ou filiais. Neste caso, os usuários remotos fazendo uma conexão para um provedor de acesso à Internet e por meio deste canal é 


\section{Criptografia}
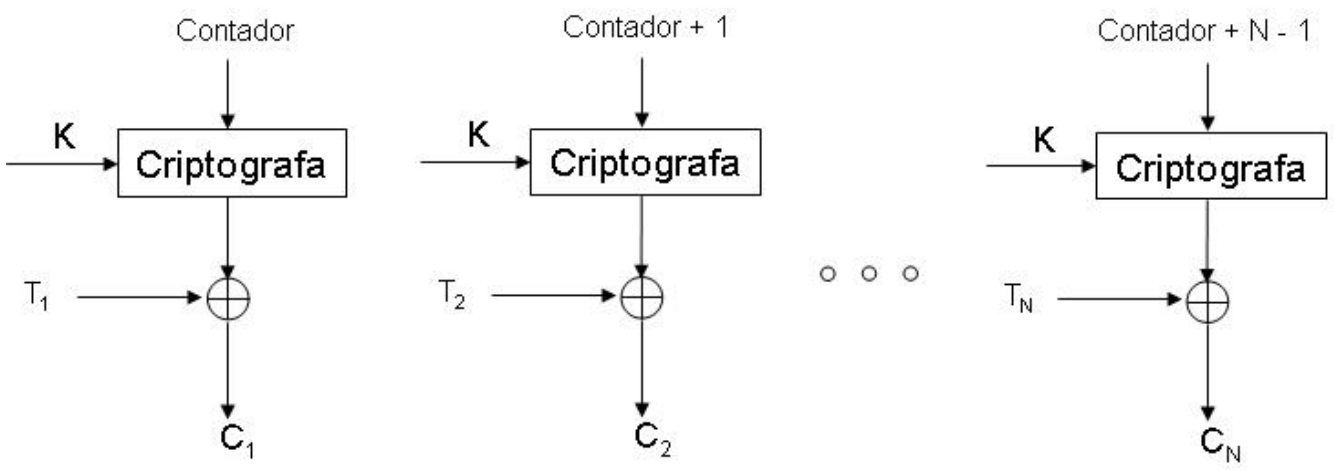

\section{Decriptografia}
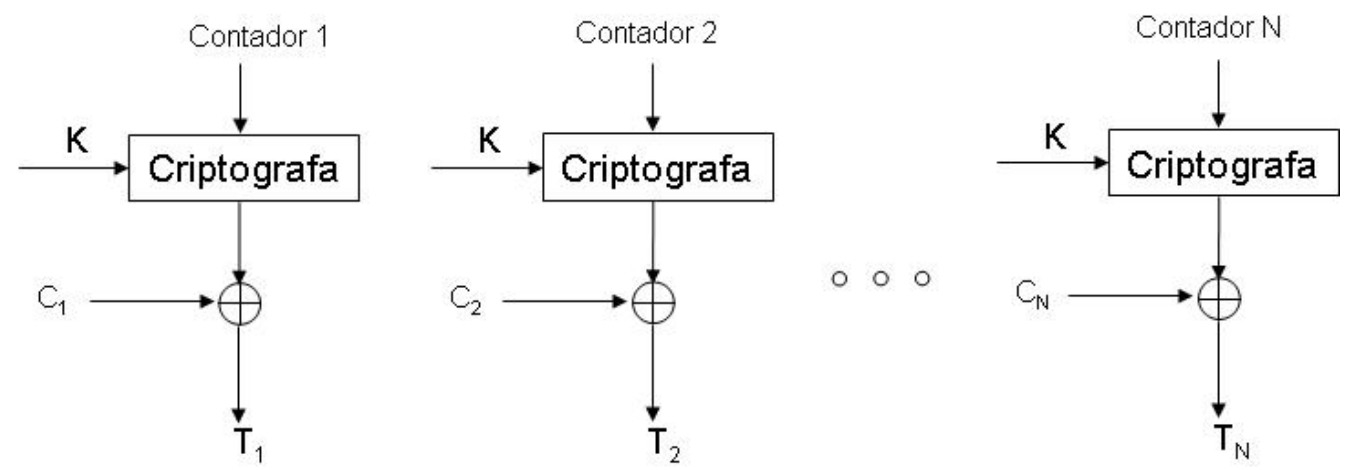

Figura 3.7: Diagrama de funcionamento do modo CTR

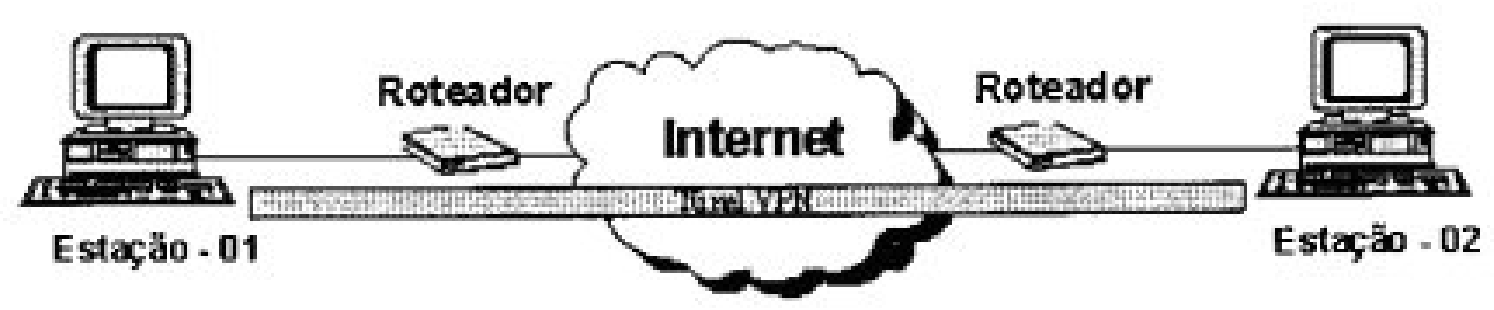

Figura 3.8: VPN de Cliente/Servidor a Cliente/Servidor

possível estabelecer uma VPN com os gateways da VPN que protegem uma filial. Cabe ao gateway estabelecer a permissão ou negação dos usuários remotos ou de outra filial para dentro da rede protegida por esse gateway. Neste exemplo, o usuário Remoto-01 pode fechar uma rede virtual com o gateway da Filal-B, mas não poderá acessar dados protegidos pelo gateway da Filial-A. Por outro lado, o usuário Remoto-02 só poderá estabelecer uma rede com a Filial-A e não com a FilialB. Poderia-se permitir, por exemplo, que a Filial-A tenha uma rede com a Filial-B ou que o usuário Remoto-02 possa estabelecer um túnel com a Filial-B. Essas políticas de acesso são configuradas no gateway que irá permitir ou bloquear estes usuários.

No caso do trabalho em questão foi criada uma VPN para conexão com o robô que vem sendo desenvolvido no Laboratório de Computação Reconfigurável da Usp. A idéia é permitir uma 


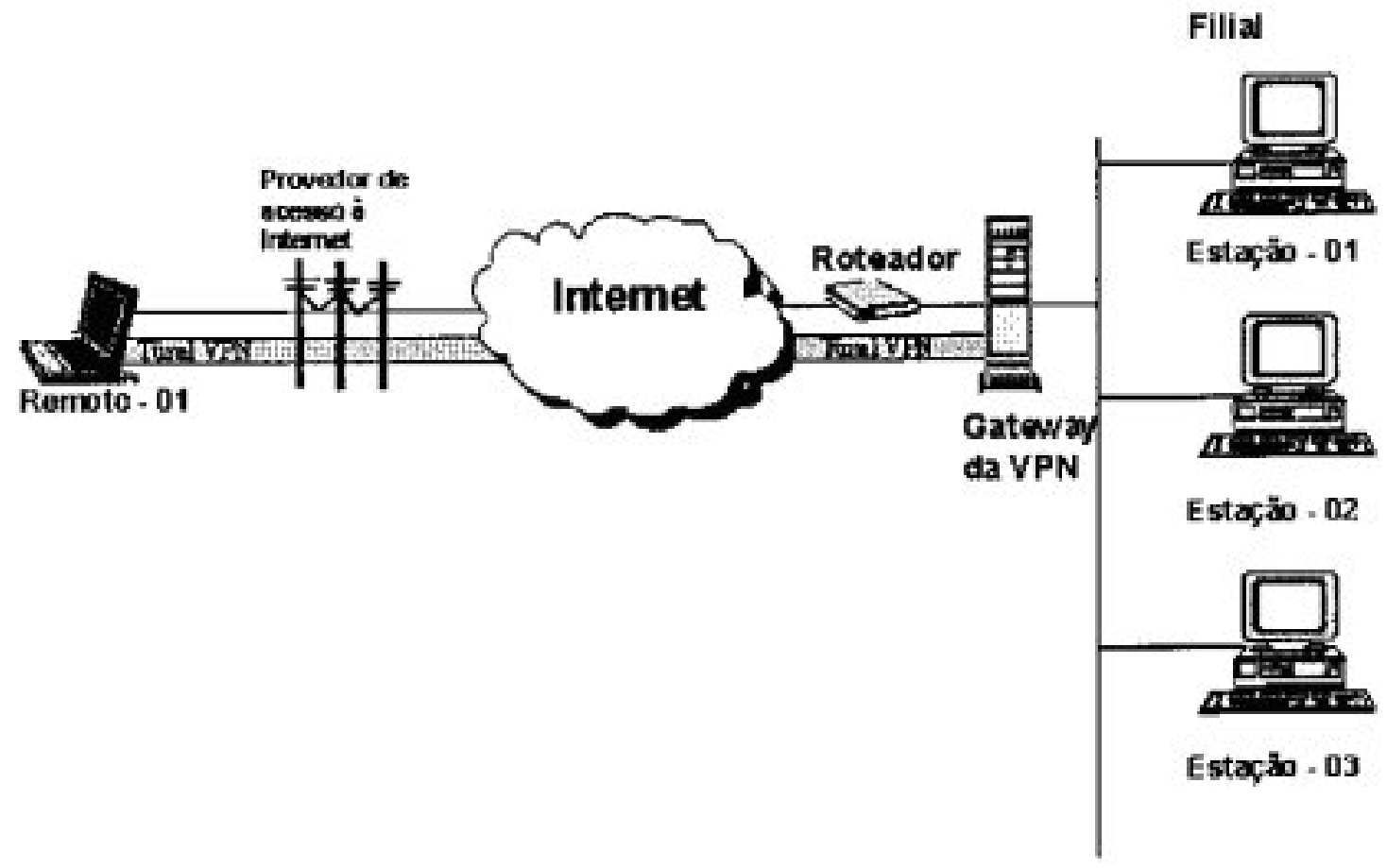

Figura 3.9: VPN entre um Usuário Remoto e uma Rede

Filial - A

Filial - B

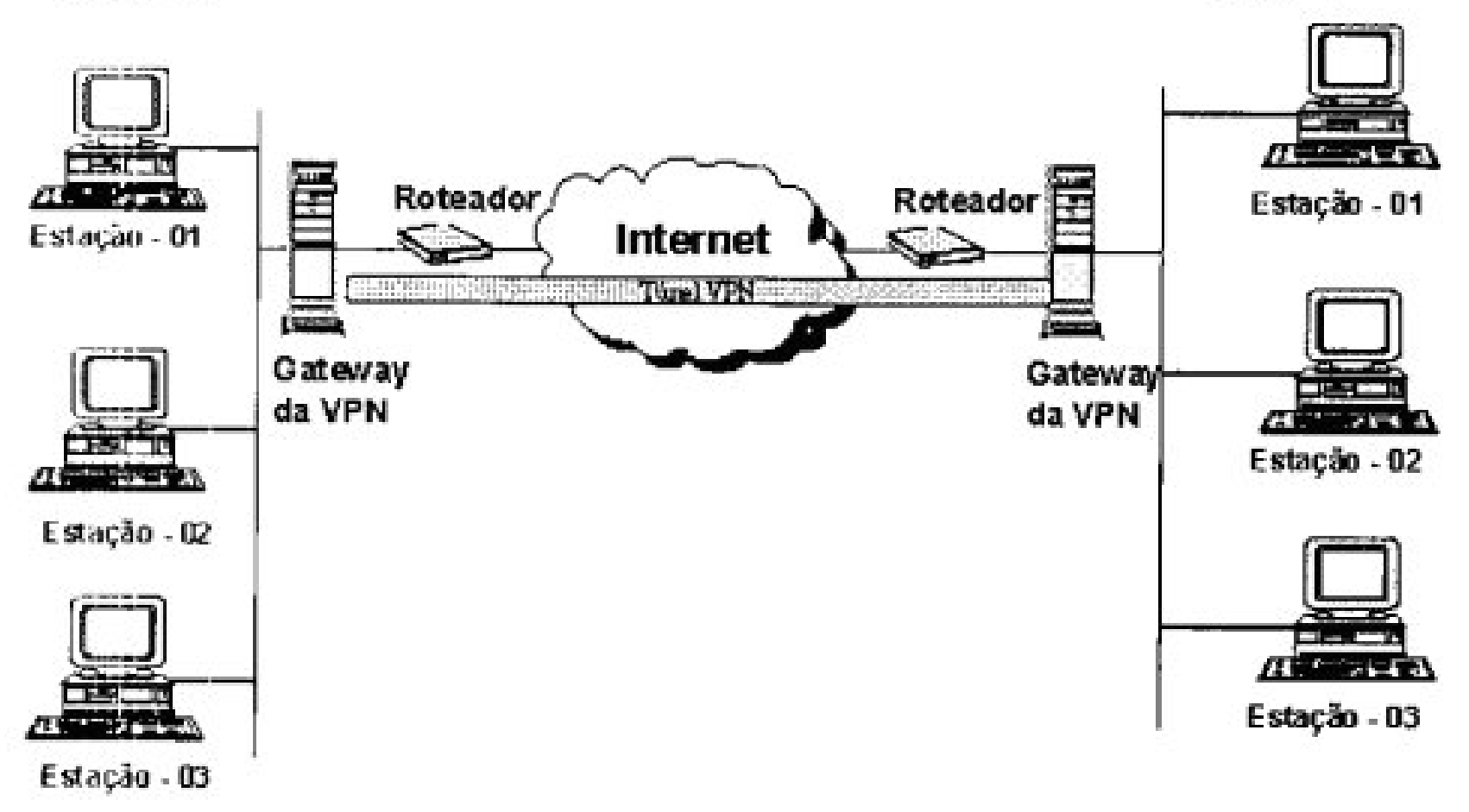

Figura 3.10: VPN entre Redes

conexão de rede com o robô (com ou sem fio) de forma segura e de qualquer localização possível, já que pode-se utilizar a Internet para esta comunicação. 


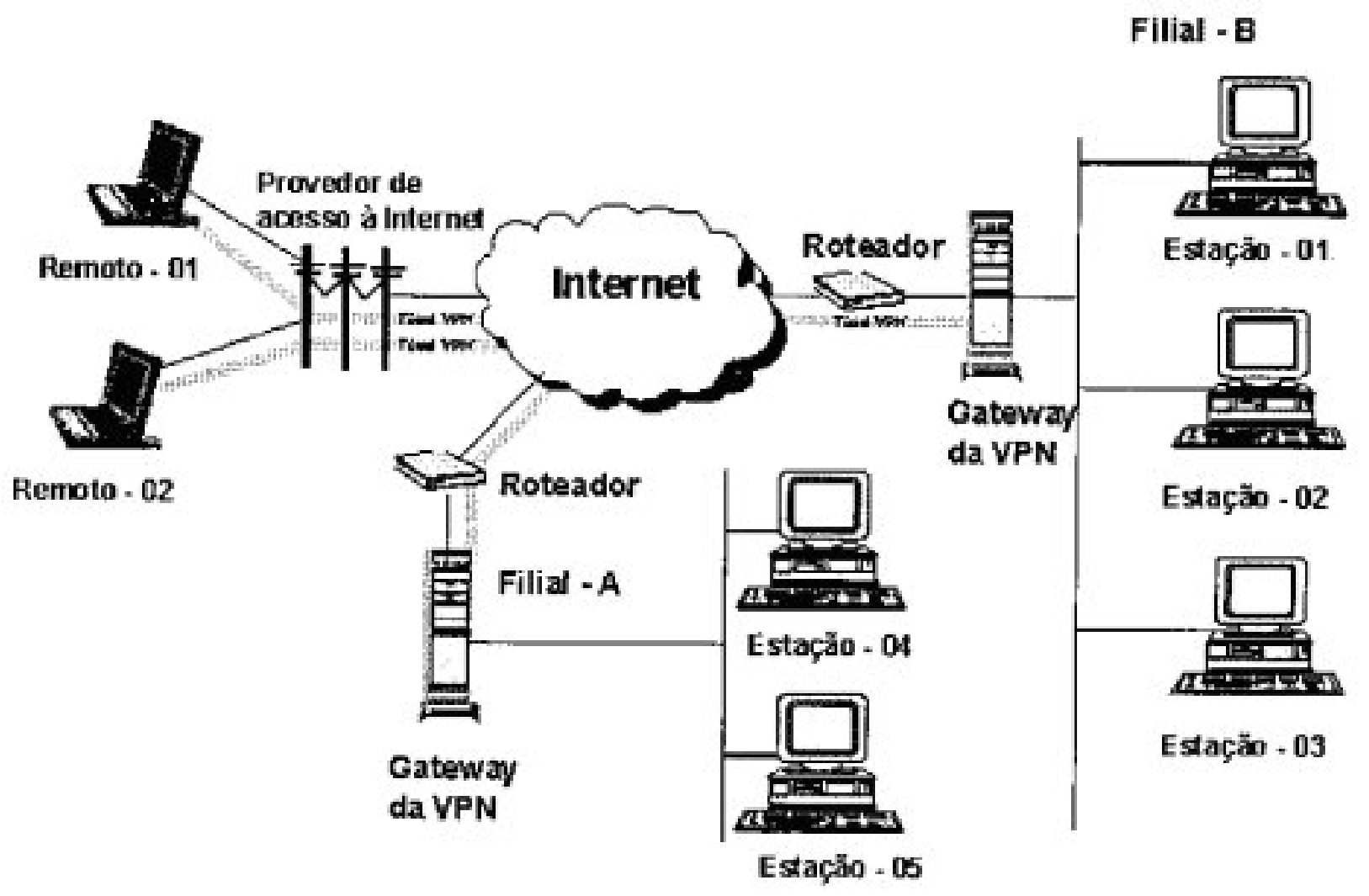

Figura 3.11: VPN com situações mistas

\subsection{Encapsulamento e Criptografia}

As redes privadas virtuais utilizam a técnica de tunelamento que é anterior ao surgimento das $V P N s$. Tunelamento é uma técnica que consiste em encapsular um protocolo dentro de um outro qualquer. Desta forma, podemos utilizar esta técnica para que seja possível que um pacote dentro de uma rede que não usa o protocolo IP (como por exemplo IPX da Novell, SNA da IBM, NetBEUI da Microsoft) possa trafegar pela Internet. Pode-se usar o mesmo mecanismo de tunelamento até para protocolos $I P$. Neste caso utilizamos para esconder o endereço $I P$ de origem que pode ser um endereço não válido dentro da Internet.

Para garantir privacidade na comunicação, devemos utilizar uma das soluções abaixo:

- Ou utilizar uma segmentação de rede, onde o segmento será privado a determinados usuários, como ATM, Frame Relay, MPLS, etc;

- Ou utilizar tunelamento com a criptografia para tornar o canal de comunicação privado.

Como deseja-se fazer uso das VPNs através da Internet, este trabalho utiliza a segunda solução. Desta forma, deve-se criptografar os pacotes antes de encapsulá-los. O pacote criptografado tornase ilegível caso seja interceptado durante seu transporte. Uma vez criptografado o pacote é encapsulado através do protocolo de tunelamento. No caso de um protocolo $I P$, temos um cabeçalho 
(ou header) e os dados (ou payload). No cabeçalho se encontra o protocolo de payload (geralmente é $T C P$ ou $U D P$ ), endereço $I P$ de origem e de destino, etc. $\mathrm{O}$ encapsulamento consiste em gerar um novo cabeçalho com o datagrama original como payload.

Após serem encapsulados os pacotes são roteados entre as extremidades do túnel na rede intermediária. Túnel é a denominação do caminho lógico percorrido pelo pacote ao longo da rede intermediária. Após alcançar o seu destino na rede intermediária, o pacote é desencapsulado e encaminhado ao seu destino final. A rede intermediária por onde o pacote trafegará pode ser qualquer rede pública ou privada (CHIN, 1998). A figura 3.12 demonstra o túnel criado pela Internet:

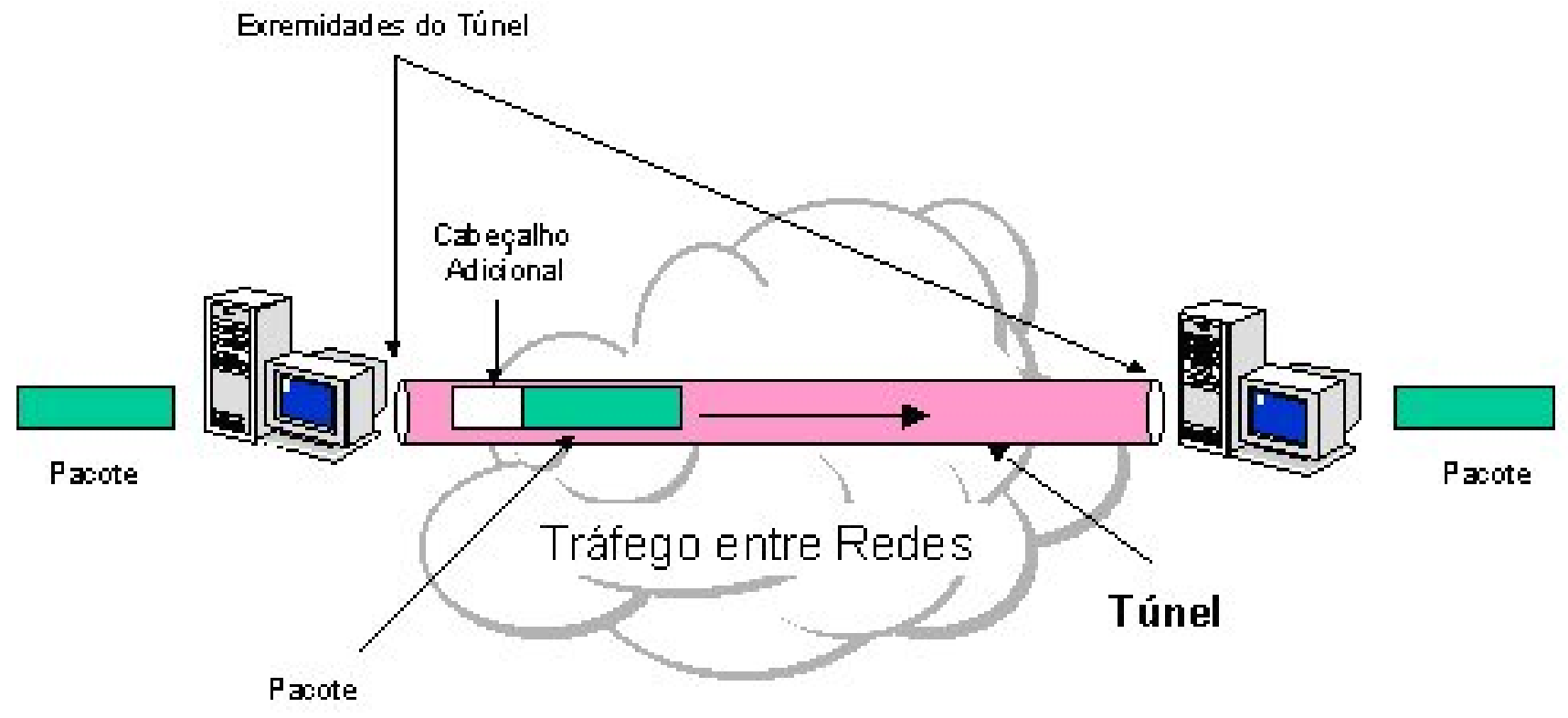

Figura 3.12: Túnel criado pela Internet (CHIN, 1998)

Mais especificamente, no caso deste trabalho, existe uma VPN entre um robô móvel e um PC/Notebook conforme ilustra a figura 3.13.

\subsection{Protocolos de Encapsulamento}

Os protocolos servem para definir como os pacotes serão encapsulados, como a chave de criptografia será compartilhada e outros métodos de autenticação. Para que se tenha um túnel, é necessário que as extremidades utilizem o mesmo protocolo de tunelamento. Há protocolos que fazem apenas o tunelamento, outros agregam criptografia e outras premissas da VPN. Alguns podem atuar na camada 2 ou na camada 3 do modelo ISO/OSI.

Os protocolos que operam no nível 2, o qual corresponde a camada de enlace, transportam protocolos de nível 3 na Internet utilizando quadros como unidade de troca. Estes protocolos encapsulam os protocolos da camada de rede em quadros PPP (Point-to-Point Protocol). São eles:

- PPTP (Point-to-Point Tunneling Protocol): protocolo de tunelamento para acesso discado, tendo como principal desenvolvedor a Microsoft. Para se realizar criptografia necessita-se 


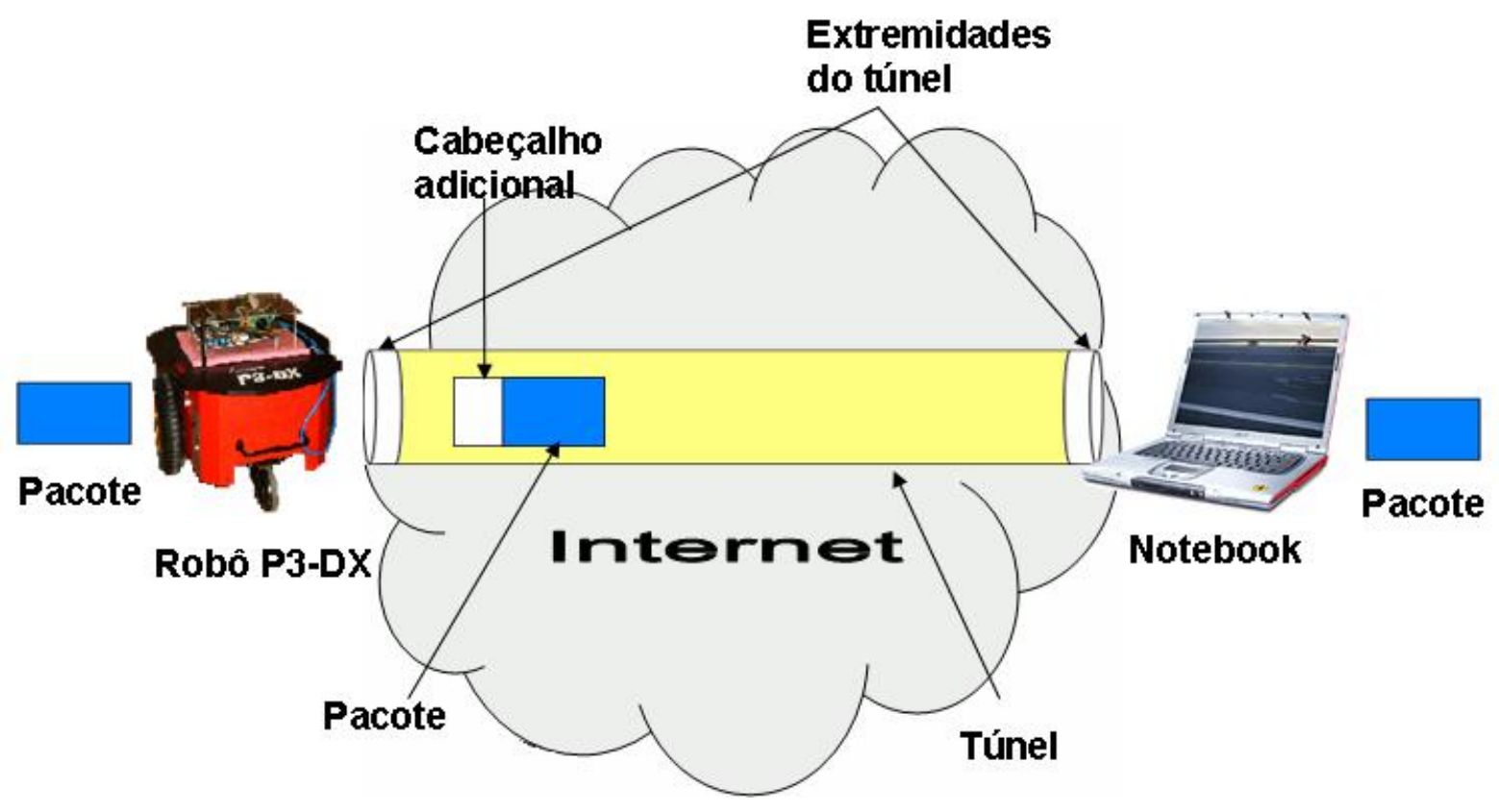

Figura 3.13: VPN entre o robô e um Notebook

de métodos específicos de autenticação em que seja possível a troca de uma chave única, já que a criptografia é simétrica. Não faz autenticação de pacotes. O túnel é construído com computadores remotos, sendo, por isso, chamados de túneis voluntários.

- L2F (Layer-2-Forwarding): protocolo cujo principal desenvolvedor foi a Cisco. Tinha como missão permitir que provedores de acesso ou empresas de telecomunicações oferecessem ao mercado acesso remoto discado para redes privadas. Desta forma, as empresas não necessitariam adquirir modems ou equipamentos de acesso remoto. Neste protocolo o túnel é formado do provedor de acesso e não do computador remoto. Por este motivo são chamados de túneis involuntários ou compulsórios. Após o surgimento do L2TP, os desenvolvedores do $L 2 F$ decidiram por parar com o desenvolvimento deste protocolo.

- L2TP (Layer-2-Tunelling-Protocol): protocolo da IETF que decidiu por um novo padrão de protocolo que uniria o que havia de melhor entre os dois protocolos acima. Só faz criptografia dos dados se forem escolhidos métodos específicos de autenticação em que seja possível a troca de uma chave única, pois a criptografia é simétrica. Não faz autenticação de pacotes. Foi desenvolvido de forma a suportar tanto o tunelamento voluntário quanto o compulsório.

Os protocolos da camada 2 sofrem com a falta de mecanismos sólidos de proteção do túnel. Esses protocolos encapsulam frames $P P P$, herdando assim os mecanismos de segurança como autenticação e criptografia. $P P P$ autentica o cliente junto ao servidor, mas não autentica os pacotes que irão sair do usuário remoto. Além disso, eles não possuem um sistema de gerência de chaves para criptografia e autenticação.

Os protocolos que operam na camada 3 do modelo ISO/OSI encapsulam pacotes dessa camada (como IP, IPX, NETBEUI, SNA) em protocolos IP com um cabeçalho adicional antes de enviá-los 
através da rede. IPSec é um protocolo utilizado nessa camada pelas VPNs. Esse protocolo será apresentado com mais detalhes na seção seguinte.

\subsubsection{IPSec}

O protocolo IP, que é amplamente utilizado devido a sua facilidade de uso e de sua implementação, não foi projetado para ser seguro. De fato é um protocolo que permite a uma entidade mal intencionada facilmente visualizar o tráfego na rede (problema de confidencialidade) e até modificar os dados em curso (problema de integridade). Estes ataques são conhecidos como manin-the-middle attack e não há como saber que os pacotes foram vistos e/ou modificados.

Com a crescente evolução da Internet fez-se necessário soluções para os problemas acima descritos e que mantivessem compatibilidade com toda a infra-estrutura existente. Várias soluções foram propostas e documentadas em requests for comments ou simplesmente RFCs. Até que resoveu-se criar o que hoje denomina-se como IPSec.

IPSec, ou IP Security na verdade, é um conjunto de protocolos de camada 3 do modelo ISO/OSI que define a arquitetura e as especificações para prover serviços de segurança dentro do protocolo IP. Foi desenvolvido pelo IP Security Work Group da IETF (IETF, 2002) e será um padrão utilizado na versão extendida do IPv4, o IPv6. O IPSec foi padronizado para garantir interoperabilidade, mecanismo de criptografia para o IPv4 e também para o IPv6. O IPSec também define um conjunto de serviços de segurança, incluindo integridade dos dados, autenticação, confidencialidade e limite de fluxo de tráfego.

O IPSec fornece estes serviços independentemente do algoritmo de criptografia usado, ou seja, IPSec possui uma arquitetura aberta no sentido de possibilitar a inclusão de outros algoritmos de autenticação e criptografia. Apesar de ser conhecido como protocolo IPSec, ele é na verdade um conjunto de protocolos de segurança de tráfego de dados, de autenticação de cabeçalho, de encapsulamento seguro do dados e de procedimentos e protocolos de gerência de chaves.

O IPSec pode ser utilizado para proteger um canal de comunicação entre dois sistemas finais diretamente conectados ou entre dois sistemas intermediários, os quais são chamados de gateways de segurança nos quais os sitemas finais estão conectados. Os serviços de segurança do IPSec são oferecidos por meio de dois protocolos de segurança, o Authentication Header (Autenticação de Cabeçalho - AH) e o Encapsulating Security Payload (Encapsulamento Seguro do Dado - ESP).

Os protocolos AH e ESP fazem parte da arquitetura básica do IPSec e, por questões de garantia de interoperabilidade, estes protocolos estabelecem que todas as implementações IPSec suportem alguns algoritmos pré-definidos. Os algoritmos obrigatórios, na época da proposta, eram: DES e 3-DES para criptografar e HMAC, MD5 e SHA-1 para autenticação.

Como o IPSec é uma proposta aberta podendo-se adicionar protocolos e serviços ao longo de sua maturação e necessidade, novos algoritmos foram adicionados. Atualmente a lista de protocolos disponíveis (não necessariamente implementado por todos os fornecedores) de IPSec são: 
- Para Criptografia:

- DES, Blowfish, 3-DES, CAST, AES, SEPENT, TWOFISH

- Para Autenticação

- HMAC, MD5, SHA1, SHA2

\section{Associações de Segurança}

Um dos conceitos fundamentais do IPSec é o de Associação de Segurança (Security Association - SA). Uma SA define os tipos de medidas de segurança que devem ser aplicadas aos pacotes baseado em quem está enviando os pacotes, para onde eles estão indo e que tipo de dados estão conduzindo. O conjunto de serviços de segurança oferecidos pela SA depende do protocolo de segurança, das opções escolhidas e do modo na qual a SA irá trabalhar.

Assim, uma associação de segurança é uma espécie de conexão que viabiliza o tráfego de serviços seguros. Esses serviços são oferecidos por uma SA por meio dos protocolos AH ou ESP. Uma SA é identificada por três parâmetros, consistindo de um SPI(Security Parameter Index), um endereço IP de destino e um identificador do protocolo de segurança (AH ou ESP). O SPI é um valor de 32 bits que identifica uma Associação de Segurança, sendo definido durante uma negociação que antecede o estabelecimento da mesma. O endereço IP de destino (IPv4 ou IPv6) é assumido como unicast, mas sua definição pode ser extendida para os casos de broadcast e multicast. O identificador de protocolo especifica o protocolo de segurança que será aplicado ao tráfego dentro de uma SA.

Uma SA pode operar de duas maneiras: modo transporte e modo túnel. No modo de transporte, em uma SA entre duas entidades, somente o segmento da camada de transporte é criptografado e autenticado. O cabeçalho do protocolo de segurança (AH ou ESP) aparece imediatamente após o cabeçalho IP e antes dos protocolos das camadas superiores. O endereço IP de origem e destino ainda estão abertos para verificação, no caso dos pacotes serem interceptados.

No modo túnel, o tráfego IP gerado pelas entidades são capturados por um gateway de segurança e são criptografados. Esses pacotes são encapsulados novamente em pacotes IP, com endereços de origem e destino dos gateways de segurança, e enviados pela rede para um outro gateway de segurança, que irá desencapsular a informação e a enviará para o destino. As figuras 3.14 e 3.15 apresentam a VPN estabelecida com o robô em modo transporte e modo túnel, respectivamente.

As informações da SA que irão fazer parte da $V P N$ podem ser trocadas dinamicamente entre as entidades que irão usar as informações da SA no momento que as entidades quiserem utilizar um ou mais serviços de segurança oferecidos pelo IPSec. Existe também a possibilidade do administrador de rede estabelecer SAs fixas para cada entidade que irá participar da $V P N$. Os serviços IPSec compartilham chaves secretas que são utilizadas para autenticação, integridade e 


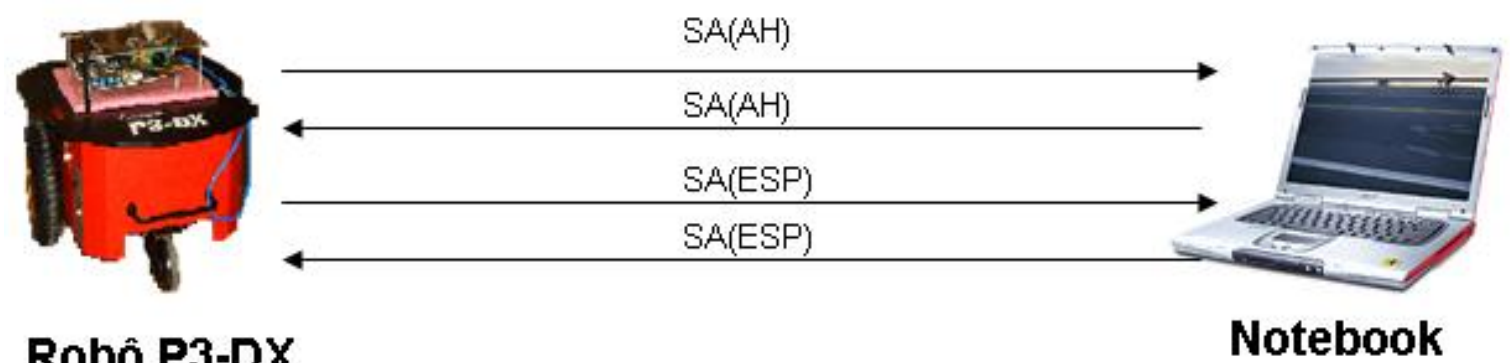

Figura 3.14: Uma VPN com o robô em modo transporte

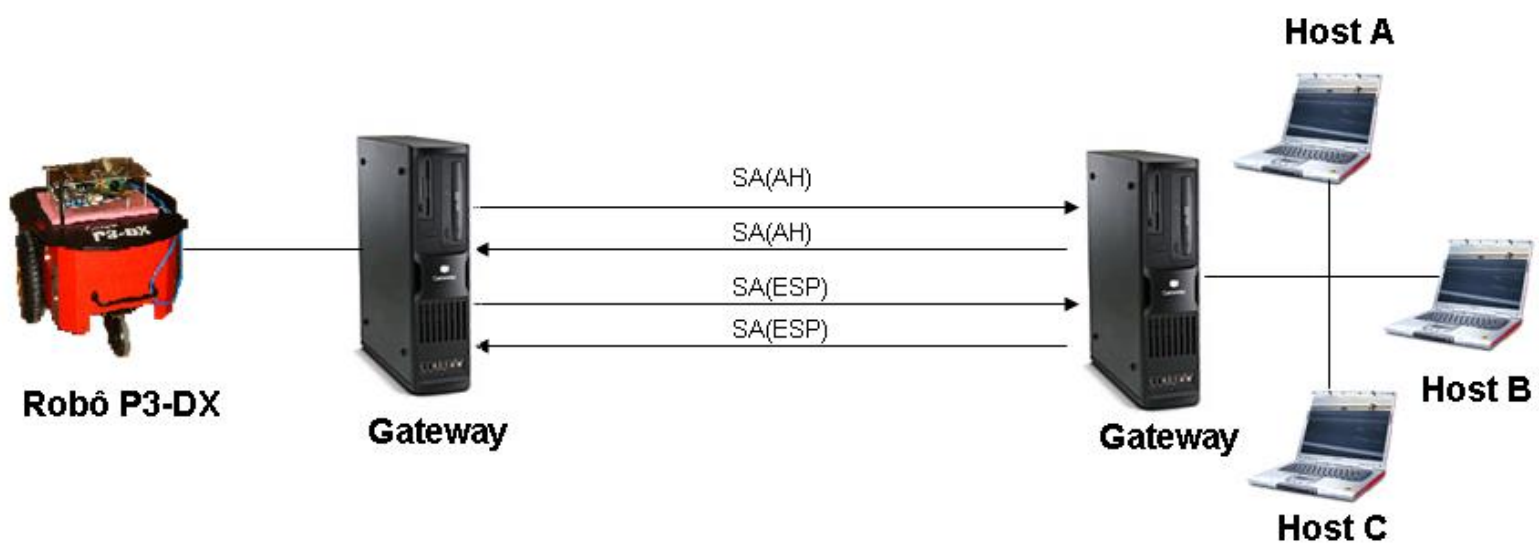

Figura 3.15: Uma VPN com o robô em modo túnel

criptografia. Deste modo, as especificações IPSec definem um conjunto separado de mecanismos para o gerenciamento de chaves com suporte para distribuição automática ou manual das chaves. Para essa distribuição de chaves foram especificados procedimentos baseados em chaves públicas, sendo possível utilizar o ISAKMP/OAKLEY (Internet Security Association and Key Management Protocol). O ISAKMP define o método de distribuição da chave e o OAKLEY define como as chaves serão determinadas. Esta técnica combinada passou a ser chamada simplesmente de Internet Key Exchange - IKE. IKE é definida nos RFCs 2407, 2408 e 2409. (PIPER, 1998) (MAUGHAN et al., 1998) (HARKINS e CARREL, 1998)

Na implementação do IPSec nativa do Linux há um novo socket, chamado $P F \_K E Y$ usado por aplicações que gerenciam chaves para se comunicar com a estrutra interna de gerenciamento de chaves do sistema operacional. Essa estrutura interna é conhecida como Key Engine ou Base de dados de uma Associação de Segurança (SADB). A Key Engine e suas estruturas incorporam os atributos de segurança necessários para uma sessão e são instâncias da Associação de Segurança.

\section{Os protocolos AH e ESP}

O protocolo AH é utilizado para oferecer autenticação aos datagramas IP. No modo de transporte, o cabeçalho AH é inserido após o cabeçalho IP e antes dos protocolos das camadas superiores, ou antes de qualquer outro cabeçalho IPSec inserido anteriormente. No modo túnel, 
o cabeçalho IP interno (IP2 na figura 3.17), protegido, carrega os reais endereços de origem e destino dos pacotes, enquanto o cabeçalho IP mais externo (IP1 na figura 3.17) pode conter os endereços, por exemplo, dos gateways de segurança. O novo cabeçalho IP é gerado com o valor 51 para o seu campo de protocolo, para designar que este datagrama possui um cabeçalho AH. Assim, nos roteadores e sistemas intermediários esses pacotes são considerados pacotes normais e quando chegam ao destino eles são processados pelo IPSec (KENT e ATKINSON, 1998). A figura 3.16 apresenta a disposição dos dados em um pacote $\mathrm{AH}$.

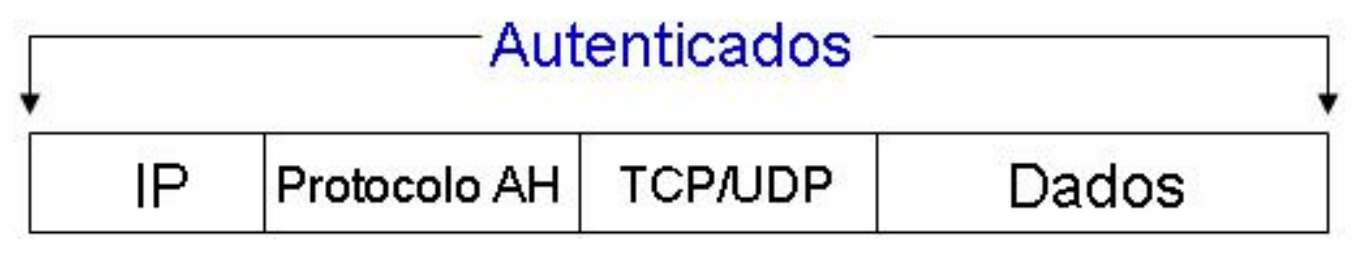

Figura 3.16: Disposição dos dados em um pacote $\mathrm{AH}$

O cabeçalho AH possuí além de um SPI, um campo chamado Autenticação de dados, que contém um resumo da mensagem e uma assinatura digital. O resumo da mensagem é calculado em cima do datagrama IP original, fornecendo, desse modo, autenticação do sistema de origem e integridade ao datagrama IP. A assinatura digital é processada utilizando o algoritmo de autenticação especificado na associação de segurança.

O protocolo ESP (Encapsulating Security Payload) foi projetado para oferecer um conjunto de serviços de segurança para o IPv6 e IPv4, como autenticação e confidencialidade através de criptografia. Esses serviços dependem das opções selecionadas no estabelecimento da AS.

Como pode-se ver na figura 3.17 , um datagrama seguro é criado envolvendo o datagrama IP original com campos de cabeçalho e de trailer e, em seguida, inserindo esses dados encapsulados no campo de dados de um novo datagrama IP. Semelhante ao protocolo AH, o cabeçalho ESP possuí um valor de SPI para identificar a associação de segurança e um número de sequência de datagramas para evitar possíveis ataques de reprodução. O valor presente no cabeçalho de trailer indica qual é o próximo protocolo (UDP, TCP, entre outros). Após o trailer há o campo de autenticação de dados do ESP que é semelhante ao campo de mesmo nome do cabeçalho AH (KENT, 1998c).

O campo de protocolo do cabeçalho IP externo conterá o valor 50, indicando que o datagrama possuí um cabeçalho ESP e um trailer ESP. O datagrama IP original e o trailer são criptografados, não sendo possível saber o tipo de protocolo de transporte que está sendo utilizado, evitando que monitoramentos cheguem a conclusões sobre o tráfego. A figura 3.17 apresenta a disposição dos dados em um pacote ESP. 


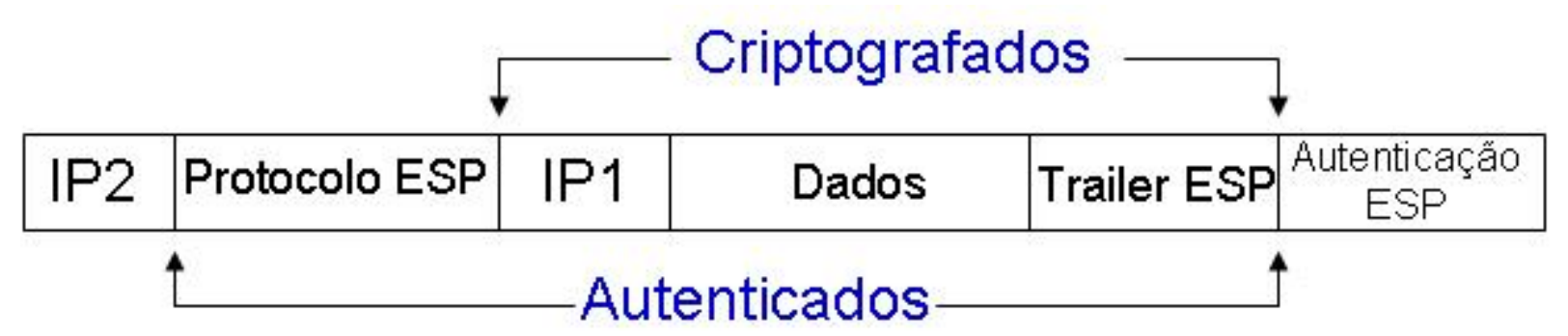

Figura 3.17: Disposição dos dados em um pacote ESP

\subsubsection{Uma outra solução de VPN}

Uma outra solução de VPN é a implementação nas camadas 2 e 3 do modelo ISO/OSI usando os protocolos SSL/TLS. Também chamada de SSL Virtual Private Network é uma forma de VPN que pode ser usada com um navegador Web padrão. Em contraste ao IPSec, uma SSL VPN pode ou não requerer a instalação de programas especializados em computadores que estabelecerão a comunicação. O protocolo SSL Secure Socket Layer e seu sucessor Transport Layer Security são protocolos criptográficos que provêem comunicação segura entre redes para serviços como http, smtp, entre outros. Assim, o protocolo SSL provê integridade e confidencialidade entre duas aplicações que estejam se comunicando pela Internet. Isto é possível graças a autenticação das partes envolvidas e da criptografia dos dados transmitidos entre as partes.

Atualmente, grande parte dos sistemas de segurança de e-commerce, home-banking e diversas outras aplicações na Internet, utilizam-se do SSL para garantir a autenticidade e confidencialidade das transações. Uma outra característica do SSL é o suporte a Public Key Infrastructure (PKI), o qual é possível em sistemas criptográficos assimétricos, e que melhora bastante a distribuição das chaves. Uma implementação completa de código aberto, licenciado sobre a GPL, utilizando essa metodologia é a OpenVPN (OPENVPN, 2002) (YONAN, 2003) (HOSNER, 2004).

\subsection{Considerações Finais}

Desta forma encerra-se este capítulo que procurou apresentar os conceitos sobre VPN bem como os protocolos existentes. Foram também apresentados conceitos fundamentais de segurança e alguns conceitos de criptografia os quais são importantes para a implementação de algoritmos criptográficos, como os que serão utilizados nesta dissertação, caso do AES. Além disso, foram apresentados diferentes protocolos para se realizar uma VPN. 
CAPÍtULO

4

Material e Metodologia

\subsection{Definição Geral}

O projeto foi elaborado utilizando a infra-estrutura fornecida pela Instituto de Ciências Matemáticas e de Computação (ICMC) da Universidade de São Paulo. O ICMC dispõe de um Laboratório de Computação Reconfigurável (LCR) que permite a implementação do sistema na arquitetura de FPGA. Além do laboratório, há uma biblioteca de computação que dispõe de material bibliográfico, trabalhos científicos, revistas, acesso à Internet e parceria com outras bibliotecas de outra universidades, ampliando o potencial de pesquisa oferecido.

A implementação do projeto foi realizada através da plataforma de prototipação para sistemas SoPC, utilizando-se do Kit Stratix II fornecido pela Altera (ALTERA, 2005) que se encontra disponível no LCR. Esta plataforma é composta por uma FPGA da Altera e por vários dispositivos periféricos, como memórias, displays, interfaces, conectores, dentre outros. A configuração da FPGA foi realizada através do porto de comunicação existente entre a plataforma e o porto usb do computador, o qual é chamado de USB Blaster. Outro componente interessante que acompanha o kit é i processador baseado em software, definido como softcore, da Altera que será utilizado para a implementação da VPN, trata-se do NIOS II (NIOSII, 2004). O processador irá executa o sistema operacional $\mu$ Clinux(MICROTRONIX, 2000), pois o software da VPN foi portado/desenvolvido sobre este sistema operacional.

A VPN foi implementada utilizando-se o Protocolo IPSec que é um protocolo bastante apropriado para segurança conforme discutido anteriormente. Além disso, por se tratar de um protocolo aberto permite a implementação de diferentes algoritmos para criptografia e autenticação, caso seja necessário. 
Por último, o LCR dispõe de equipamentos de teste e medição (analisador lógico 136 canais, etc...) de última geração da HP para a depuração do hardware proposto.

\subsection{O processador NIOS II}

Este é um processador softcore de 32 bits desenvolvido pela Altera que utiliza tecnologia RISC (Reduction Instruction Set Computer) e que se encontra atualmente em sua segunda geração. O processador foi projetado sobre a arquitetura Harvard, com barramentos distintos para acessar a memória de dados e de instruções baseado na arquitetura de processadores RISC MIPS desenvolvido pela universidade de Stanford.

A figura 4.1 apresenta um diagrama em blocos do processador NIOS II implementado em um kit Stratix e os recursos que a CPU pode explorar.

As principais características do processador NIOS II são:

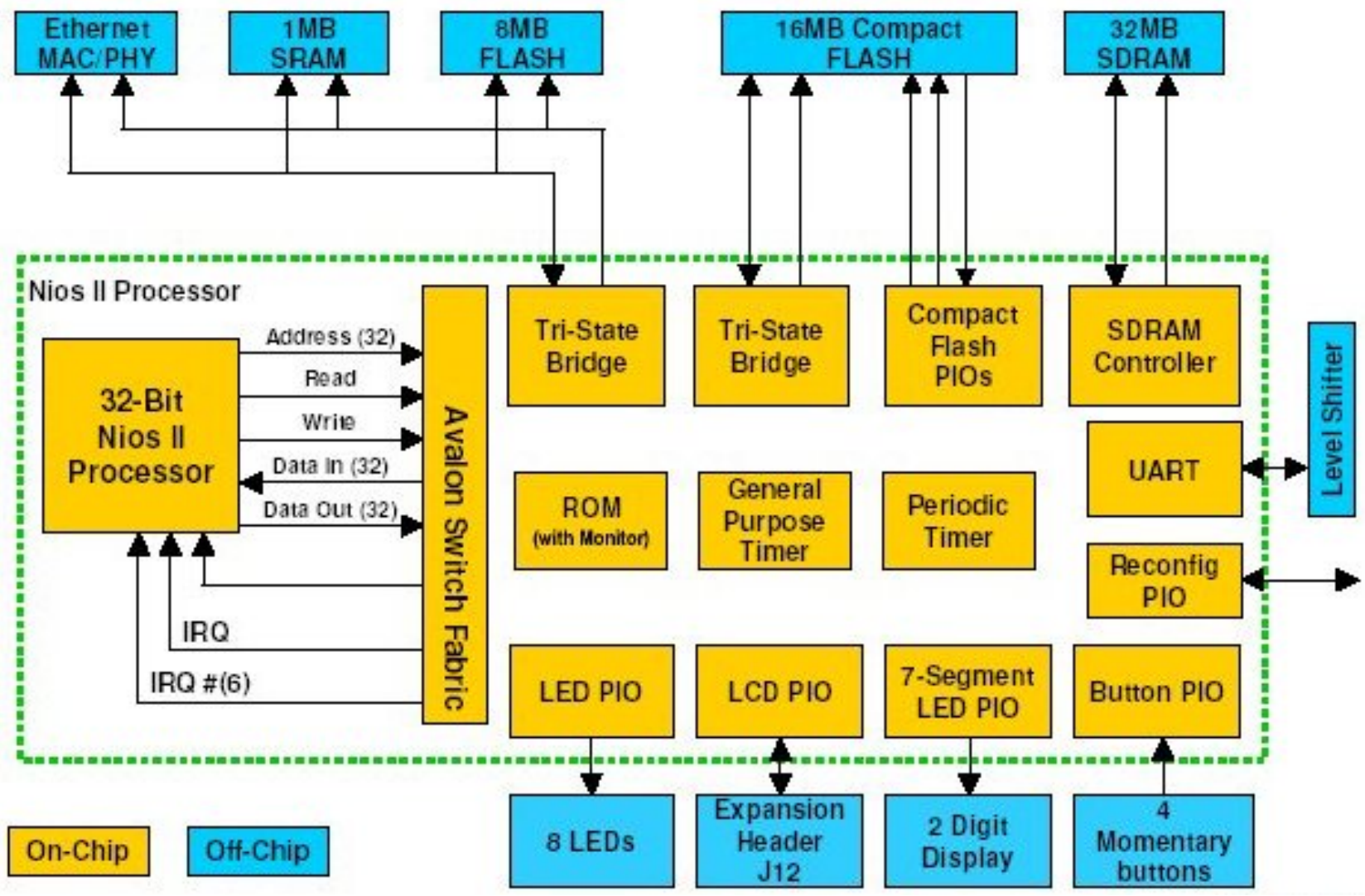

Figura 4.1: Diagrama de blocos de um sistema com o processador NIOS II

- Arquitetura RISC implementada em pipeline

- Instruções de 32 bits

- Barramento de dados de 32 bits 
- Usa o conceito de arquivos de registradores baseado no Flat

- 32 interrupções priorizadas

- Predição de Salto

- Arquitetura Harvard verdadeira com barramentos independentes de dados e de instruções suportadas por interfaces ao barramento AVALON independentes.

- Memória cache de dados e instruções configuráveis

- Permite instruções customizadas definidas pelo projetista do hardware de modo a acelerar alguma funcionalidade específica em um determinado software. Quando uma destas instruções for executada a CPU substitui sua Unidade Lógica e Aritmética por um circuito definido pelo projetista para implementar aquela instrução.

- Dispõe-se em 3 versões sendo elas: rápida, padrão ou econômica. Isto permite ao projetista de hardware, adequar o processador ao chip que ele estiver usando. A diferença consiste em se ter um maior desempenho a um custo maior de elementos lógicos ou menor desempenho permitindo sua implantação mesmo em FPGAs com recursos mais escassos (com menos elementos lógicos, por exemplo). A Tabela 4.1 apresenta as principais diferenças entre as diferentes versões do NIOS II.

\begin{tabular}{|c|c|c|c|c|}
\hline \multirow{2}{*}{\multicolumn{2}{|c|}{ Características }} & \multicolumn{3}{|c|}{ Distribuição do Processador } \\
\hline & & NIOS II/e & NIOS II/s & NIOS II/f \\
\hline \multirow[t]{3}{*}{ Desempenho } & $\mathrm{DMIPS} / \mathrm{MHz}$ & 0,16 & 0,75 & 1,17 \\
\hline & DMIPS Máximo & 28 & 120 & 200 \\
\hline & Freqüência Máxima (MHz) & 150 & 135 & 135 \\
\hline \multicolumn{2}{|c|}{ Tamanho aproximado } & 600 & 1300 & 1800 \\
\hline \multicolumn{2}{|c|}{ Estágios de pipeline } & - & 5 & 6 \\
\hline \multicolumn{2}{|c|}{ Endereçamento Externo } & $2 \mathrm{~GB}$ & $5 \mathrm{~GB}$ & $6 \mathrm{~GB}$ \\
\hline \multirow[t]{2}{*}{ Instrução } & Cache & - & 512Bytes / 64KBytes & 512Bytes / 64KBytes \\
\hline & Previsão de Desvio & - & Estática & Dinâmica \\
\hline Dados & Cache & - & - & 512Bytes / 64KBytes \\
\hline \multirow[t]{3}{*}{ ULA } & Multiplicação & - & 3 ciclos & 1 ciclo \\
\hline & Divisão & - & - & Opcional \\
\hline & Deslocamento & 1 ciclo/bit & 3 ciclos & 1 ciclo \\
\hline \multicolumn{2}{|c|}{ Suporte a Instruções Customizadas } & \multicolumn{3}{|c|}{256} \\
\hline
\end{tabular}

Tabela 4.1: Características das diferentes versões do NIOS II

\subsection{O Barramento Avalon}

Um sistema completo de hardware em um chip programável (SOPC) necessita dos mesmos componentes de um sistema comum: além da CPU ser incluída no projeto, deve-se ter os peri- 
féricos que farão parte do sistema além de um barramento para interligação dos componentes ao processador. No NIOS II, o barramento padrão é o AVALON, mas nada impede de se utilizar outros barramentos como $o$ WISHBONE (SILICORE, 2001) ou o AMBA (ARM, 1999). A figura 4.2 apresenta um sistema SOPC baseado no processador NIOS II e no barramento AVALON.

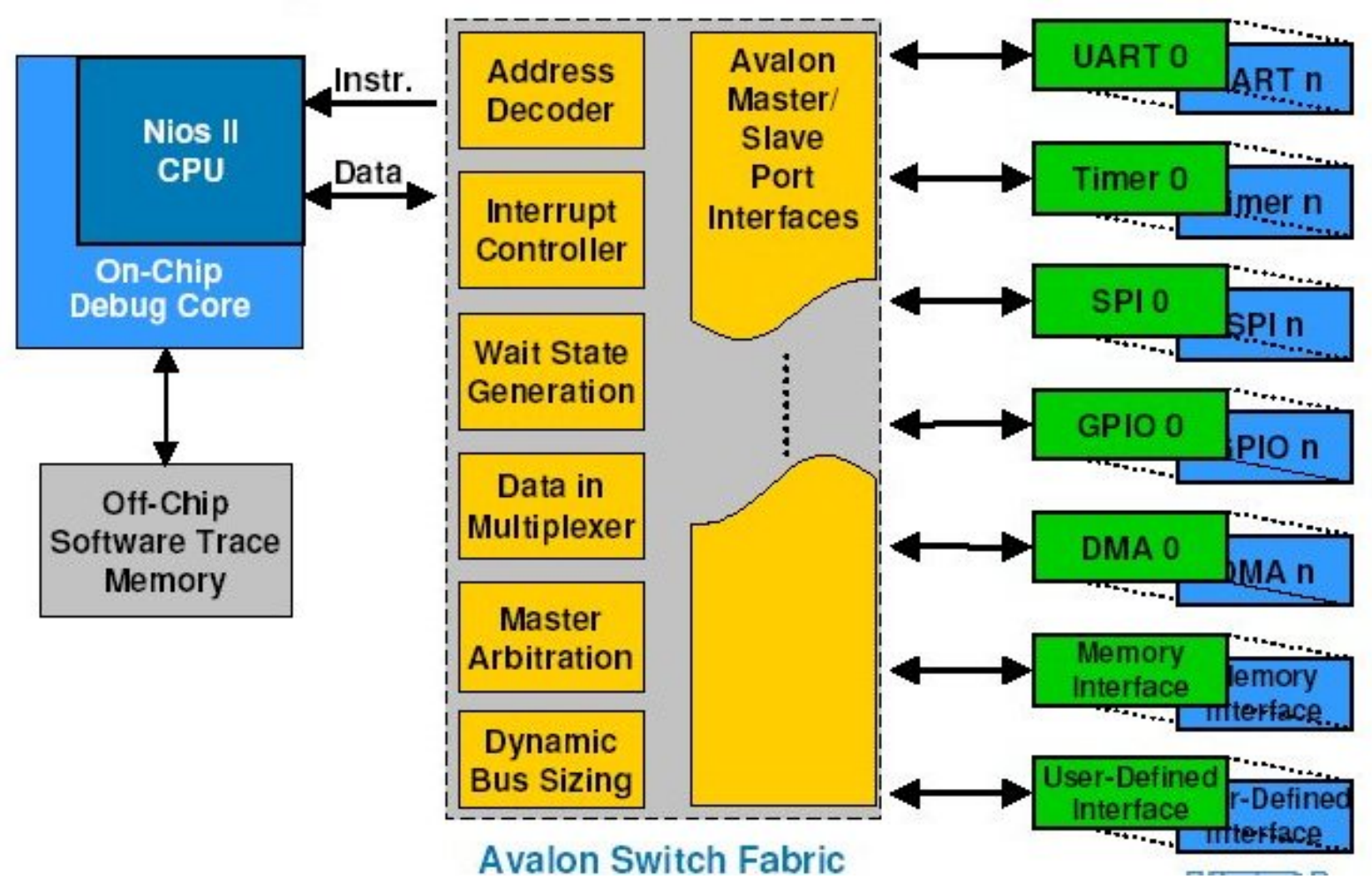

Figura 4.2: Sistema destacando o barramento AVALON

Na figura 4.2 pode-se verificar os componentes de um sistema SOPC sendo que os componentes em verde e azul são definidos e configurados pelo usuário e os em amarelos são gerados automaticamente para o sistema pelo SOPC Builder.

Os periféricos podem ser definidos e configurados ou ainda desenvolvidos pelos usuários. Existem também inúmeros periféricos fornecidos pela própria Altera dos quais pode-se citar o controlador de interface RS-232 Serial, controlador de memória SRAM, SDRAM, DDRAM e FLASH, interface para dispositivos Ethernet, interface SPI, Active Serial Memory Interface (ASMI), que são acompanham o pacote de software do SOPC Builder. Existem também empresas especializadas em desenvolvimento de cores que são vendidos na forma de IPs. Dentre estes pode-se citar a interface $P C I$, interface $U S B, M A C$ Ethernet, sistemas criptográficos completos como o $R S A$, $D E S$, etc. Há ainda sítios na Internet com sistemas inteiros abertos e livres para os usuários, como no caso do OpenCores (OPENCORES, 2004) que disponibiliza processadores e periféricos no geral de forma gratuita. O barramento $A V A L O N$ é gerado automaticamente pelo sistema quando se coloca o processador NIOS II e periféricos no projeto de hardware. Este barramento implementa as seguintes funcionalidades: 
- Controlador de Interrupções: gera uma interrupção codificada, composta de um número de IRQ e de um sinal, para o processador por meio de fontes de interrupção do sistema e do número da interrupção selecionada pelo usuário para cada periférico.

- Decodificação de endereço: gera um sinal de seleção para cada periférico tomando como entrada o endereço inicial definido pelo usuário para o periférico e a área de memória que este irá ocupar.

- Multiplexação de dados: por existir várias possíveis fontes de dados em decorrência de que cada periférico gera um dado diferente a qualquer instante, o sistema AVALON se encarrega de selecionar qual o dado pertinente em um determinado momento para ser enviado ao processador.

- Arbitração MASTER do sistema: o barramento AVALON oferece a opção de que mais de um MASTER possa controlá-lo. O controlador MASTER pode ser um processador, como o NIOS II, um sistema de DMA ou ainda um outro periférico definido pelo usuário. Para que tudo funcione adequadamente o sistema $A V A L O N$ foi projetado de forma que ele prioriza o acesso ao barramento de dados e de endereços e define que em um determinado instante exista apenas um MASTER controlando as linhas de dados e de endereço.

- Configuração Dinâmica da Largura do Barramento: pode ser definido um barramento de 32 bits e o sistema possuir periféricos de 32 bits, 64 bits ou 128 bits. Para que isto funcione adequadamente o barramento se encarrega de fazer vários acessos as transferências entre $\mathrm{o}(\mathrm{s})$ processador(es) e os periféricos de largura diferente.

- Sistema de geração de dados de espera (wait state): por poder possuir vários periféricos com diferentes clocks, o barramento se encarrega de enviar automaticamente para a CPU sinais de espera, mantendo o processador inativo até o periférico estar pronto para concluir a transferência.

\subsection{O sistema operacional $\mu$ Clinux}

Com a consolidação do sistema operacional Linux tanto para servidores quanto para desktops torna-se cada vez mais interessante somar esforços na viabilização deste para sistemas embarcados, ou seja, sistema físicos que empregam uso de um controle computacional para um objetivo específico preferencialmente a um objetivo geral. (HAMACHER et al., 2002)

Baseado nisto, foram desenvolvidos alguns sistemas operacionais baseados no Linux para sistemas embarcados para serem executados em uma grande quantidade de processadores que possuem determinadas limitações. Dentre estes sistemas, os mais importantes e mais usados são o $e$ Cos (REDHAT, 2003) e o $\mu$ Clinux (MICROTRONIX, 2000). 
Centenas de desenvolvedores em todo o mundo estão utilizando estas variações do sistema operacional Linux para seus sistemas embarcados. Isto se deve em grande parte à robustez do Linux e a toda filosofia na qual está baseado o sistema; filosofia esta que determina que o código seja aberto, totalmente livre e permite a reutilização do mesmo (mantendo os devidos créditos) (HOLLABAUGH, 2002).

Pensando nisso, a Microtronix decidiu portar o Sistema Operacional Linux com Kernel versão 2.6 do projeto $\mu$ CLinux para o processador NIOS II da Altera, mantendo suas características principais. Trata-se de um sistema Linux projetado para sistemas que não possuam uma $M M U$. Este sistema baseia-se em uma proposta diferente dos demais Sistemas Operacionais disponíveis para a CPU NIOS II, disponibilizando boa parte das funcionalidades pertinentes a sistemas Linux.

A Microtronix disponibiliza a distribuição NIOS II Linux sobre os termos e condições da Licença Pública Geral (GPL) - GNU, que é uma licença que foi criada com o objetivo de possibilitar ao usuário adquirir um código fonte aberto, modificá-lo e distribuí-lo sem custos para outros desenvolvedores (GPL, 1991). Uma característica importante inerente a distribuição NIOS II Linux da Microtronix é que ela é totalmente integrada ao ambiente de desenvolvimento NIOS II IDE, facilitando o uso e diminuindo o tempo de projeto (MICROTRONIX, 2004). Para que se possa utilizar a distribuição $\mu$ Clinux basta que se tenha a ferramenta NIOS II IDE (a qual será apresentada na próxima seção), fazer download ${ }^{1}$ e instalar a distribuição desejada sobre o sistema operacional do computador utilizado para o projeto ${ }^{2}$. A distribuição já vem preparada para se integrar com a ferramenta de desenvolvimento NIOS II IDE disponibilizando assim que um projeto com o sistema operacional $\mu$ Clinux possa ser corretamente configurado para ser executado na placa da Altera.

\subsubsection{Ferramenta NIOS II IDE}

A ferramenta NIOS II IDE acompanha o pacote de software que vem com o kit NIOS II. Por meio desta ferramenta podem ser criadas aplicações, bem como se colocar um sistema operacional para serem executados sobre a $C P U$ em questão.

Faz parte também do conjunto de ferramentas a shell cygwin que é uma shell Linux com compiladores baseados no GCC (GNU, 1987) com modificações para gerar arquivos para o hardware em questão. Trata-se do compilador nios2-gcc que gera arquivos binários do tipo FLAT (formato para sistemas embarcados) ao invés do ELF (formato geral do sistema Linux).

Para que um projeto com o processador NIOS II possa executar o sistema operacional $\mu$ Clinux, este deve ser instalado para que possa ser disponibilizado pela plataforma conforme a figura 4.3 demonstra. Pode-ser ver também as opções que a ferramenta Microtronix NIOS II disponibiliza na criação de um novo projeto.

\footnotetext{
${ }^{1}$ O Nios Fórum - http://www.niosforum.com/forum.htm - possui as últimas versões do $\mu$ Clinux para o processador NIOS II bem como documentações sobre o mesmo.

${ }^{2}$ Há versões disponíveis atualmente para Windows e para Linux
} 
New Project

Select

Create a project that will generate a Nios II Linux kernel.

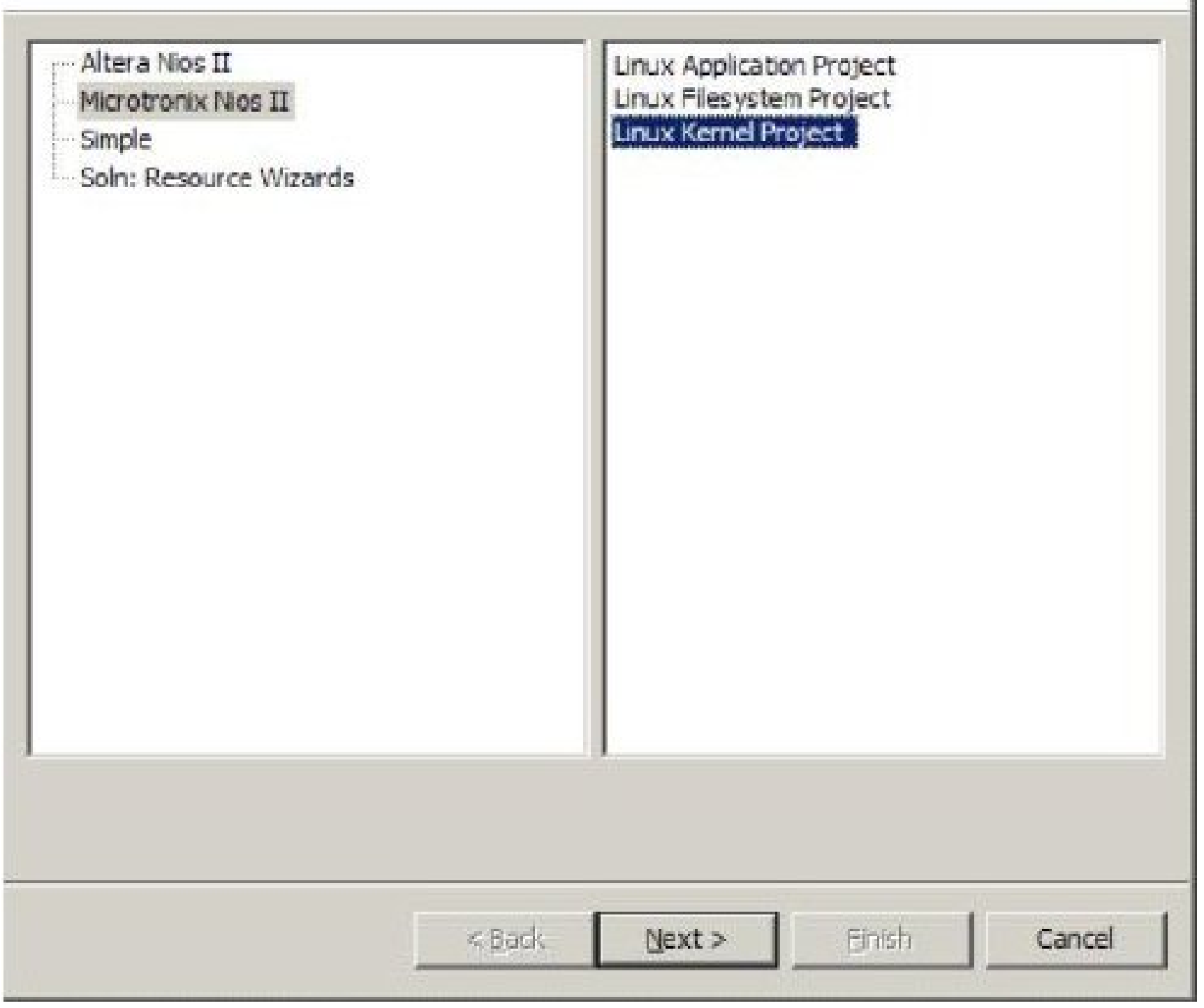

Figura 4.3: Criação de um novo projeto utilizando o NIOS II $\mu$ Clinux

A distribuição Microtronix NIOS II Linux oferece suporte à criação de três tipos de projetos os quais são projeto do kernel, projeto de um sistema de arquivos e projeto de uma aplicação.

A criação do kernel do Sistema Operacional Linux é similar à criação de um kernel para um sistema em um computador pessoal, com a diferença dos recursos gráficos da ferramenta da Microtronix que facilitam a tarefa do projetista. O usuário indica, através de um alto grau de abstração, como pode ser visto na Figura 4.4, qual será a placa de desenvolvimento utilizada, e em qual dispositivo de armazenamento será carregado e executado o Kernel.

Após esta etapa, deve-se fazer a configuração do Kernel que deve ser realizada através da plataforma de desenvolvimento do NIOS II IDE. A configuração é idêntica à tela de configuração 
New Project

Hardware/Software Options

Configure Hardware/Software Options

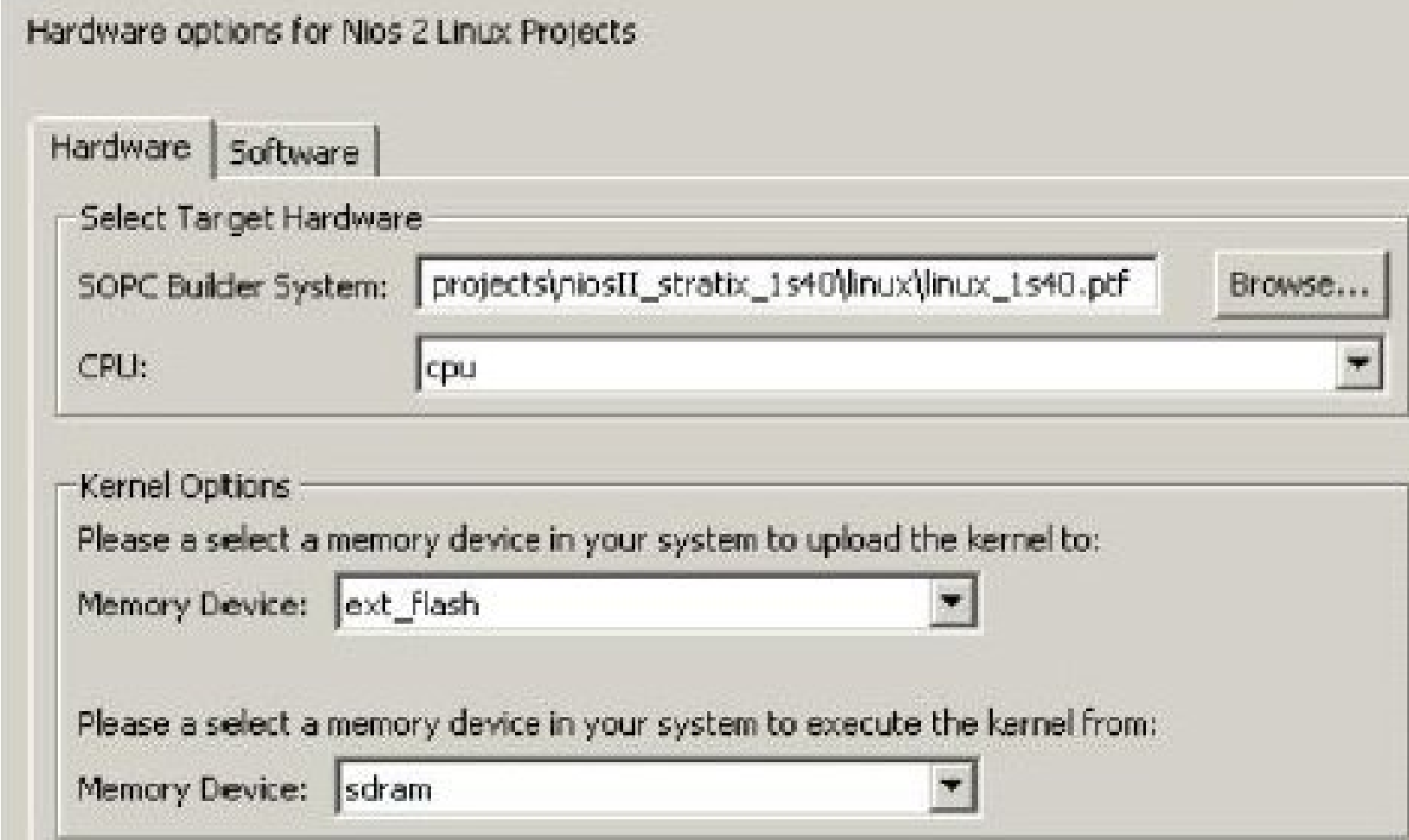

Figura 4.4: Opções para configurar Hardware e Software

de um sistema Linux para computadores pessoais, preservando as devidas limitações. Após o usuário ter configurado o Kernel, retorna-se ao ambiente de desenvolvimento, onde através da NIOS II IDE é possivel construir o Kernel e enviá-lo para a placa de desenvolvimento utilizandose apenas do mouse.

A criação de um sistema de arquivos Linux também é uma tarefa extremamente simples. Após o usuário selecionar a opção Linux Filesystem Project na tela de criação de um novo projeto, ele escolhe a placa de desenvolvimento a ser utilizada e logo após é direcionado para uma tela para seleção de pacotes que ele necessite no sistema de arquivos. 
Finalmente, com um simples clique no mouse o usuário pode construir o sistema de arquivos e carregá-lo na placa de desenvolvimento. Neste ponto, o sistema já deve estar executando podendo ser inicializado pela placa e devidamente testado.

Este sistema gera uma versão simplificada do $\mu$ CLinux que foi portado pela Microtronix. Essa versão não possui várias implementações no Kernel, como por exemplo, recursos de criptografia e suporte ao IPSec nativo. Considerou-se, inicialmente neste trabalho, em se desenvolver todo o código do IPSec para executá-lo sobre esse sistema operacional. Todavia, os desenvolvedores do $\mu$ CLinux em conjunto com a Microtronix portaram uma versão nova mais completa deste sistema operacional para o Nios II sem MMU. Esta versâo possui também vários utilitários portados para o $\mu$ CLinux como a busybox e outros programas.

Para se utilizar esse sistema, é necessário que se tenha uma máquina com Linux, gcc versão 3.2 e um sistema completo de compilação cruzada com as bibliotecas apropriadas para o $\mu$ CLinux, a $\mu$ CLibc.

O sistema funciona da seguinte forma: o SOPC Builder gera um arquivo ${ }^{3}$ com todas as configurações dos endereços de memória dos diversos componentes configurados. Através de uma diretiva especial no Makefile, o sistema gera os arquivos de hardware específicos necessários de acordo com o que foi configurado no SOPC Builder. Ao se configurar o sistema, há opções específicas para sistemas embarcados fazendo com que a configuração tenha 3 etapas distintas.

Na primeira etapa deve-se selecionar o fabricante das placas alvo, o processador embarcado, as bibliotecas que se desejam utilizar, a versão do Kernel que se deseja compilar (apesar de haver outras opções, o Nios II só funciona com o Kernel versão 2.6.x), como pode ser visto na figura 4.5 .

A segunda etapa envolve a configuração do Kernel do $\mu$ CLinux. Esta etapa é semelhante a configuração de um sistema Linux comum, considerando as devidas restrições de hardware. A figura 4.6 apresenta esse quadro.

A terceira e última etapa de configuração serve para selecionar os aplicativos para o sistema operacional, de forma a montar o sistema de arquivos. Há algumas aplicações portadas mas nem todas funcionam para um hardware sem MMU como é o caso do Nios II. Cabe ressaltar que essa versão do $\mu$ CLinux foi elaborada para sistemas embarcados, porém cada sistema possui uma particularidade sendo que diversas aplicações podem funcionar adequadamente em um determinado hardware e podem nem compilar em outro.

Após a última etapa o sistema está devidamente configurado e pronto para ser compilado. A compilação segue os padrões de um sistema Linux normal, porém com alguma diferenças que são apresentadas no Apêndice B.

\footnotetext{
${ }^{3}$ Arquivo do tipo PTF com todas as configurações de hardware
} 


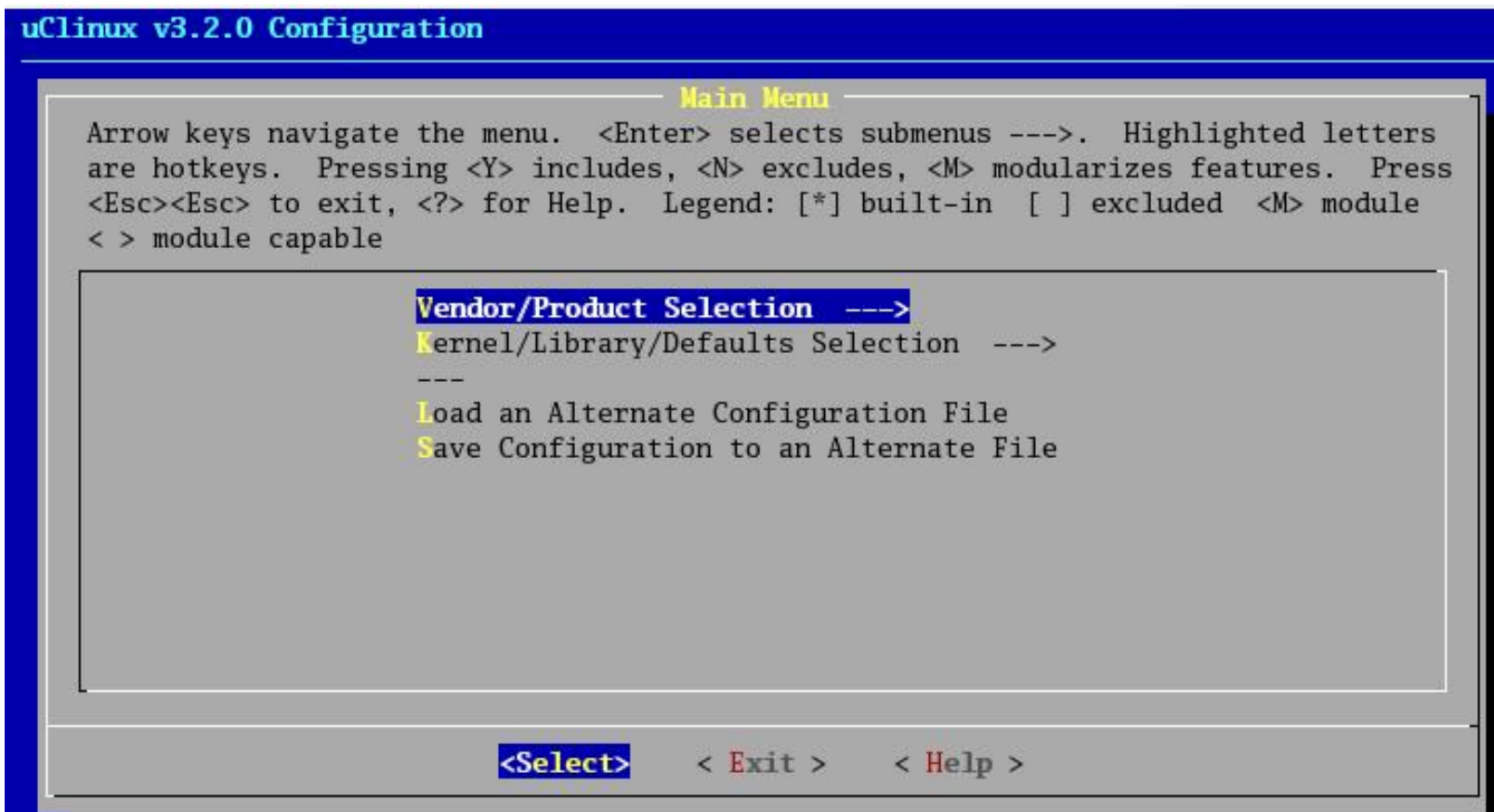

Figura 4.5: Primeira etapa de configuração do $\mu$ CLinux

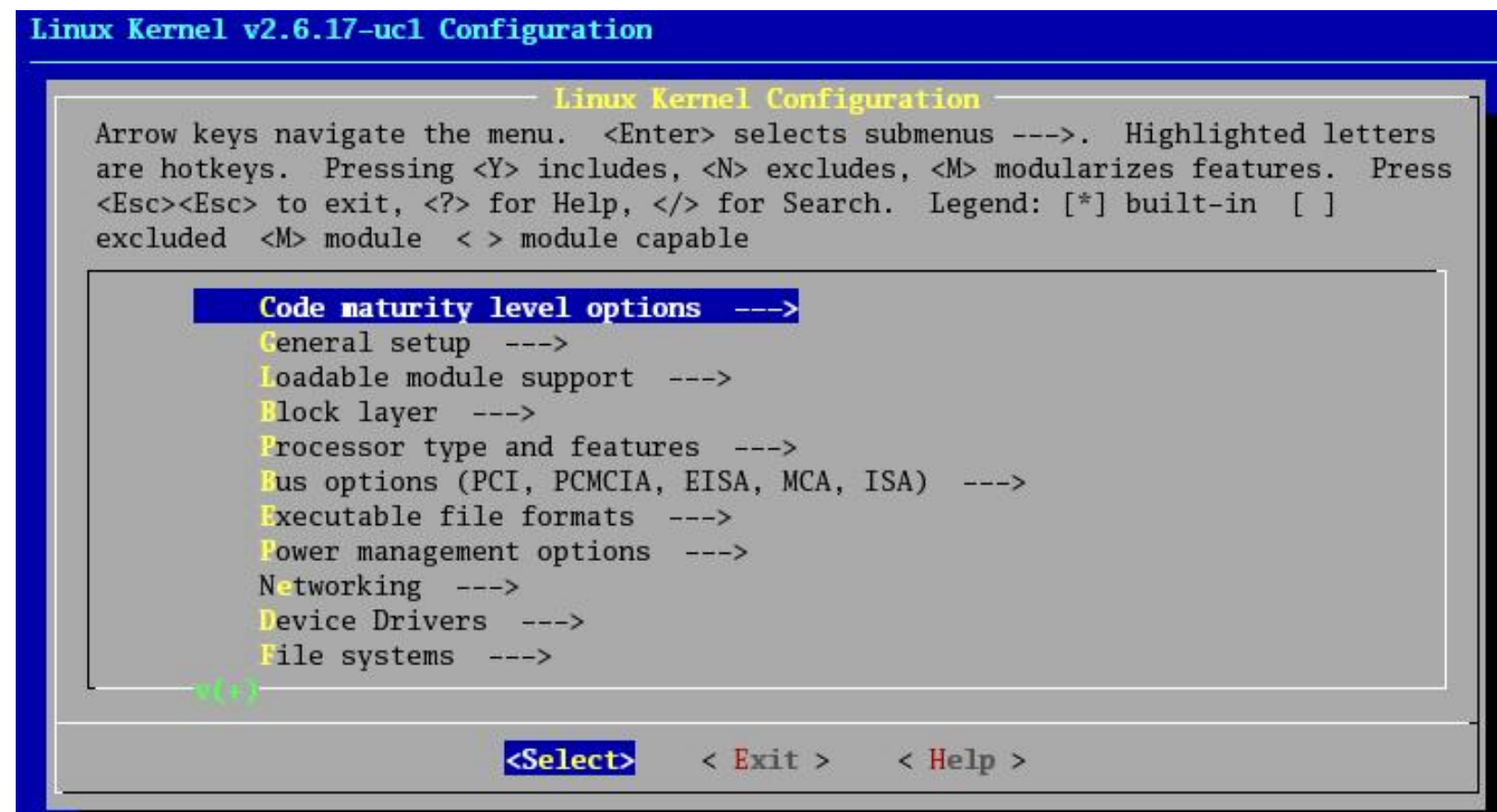

Figura 4.6: Segunda etapa de configuração do $\mu$ CLinux

\subsection{Ferramentas de Software}

Além das ferramentas utilizadas para hardware há algumas ferramentas de software que foram utilizadas com a finalidade de se se verificar/constatar o funcionamento da VPN. São elas: 


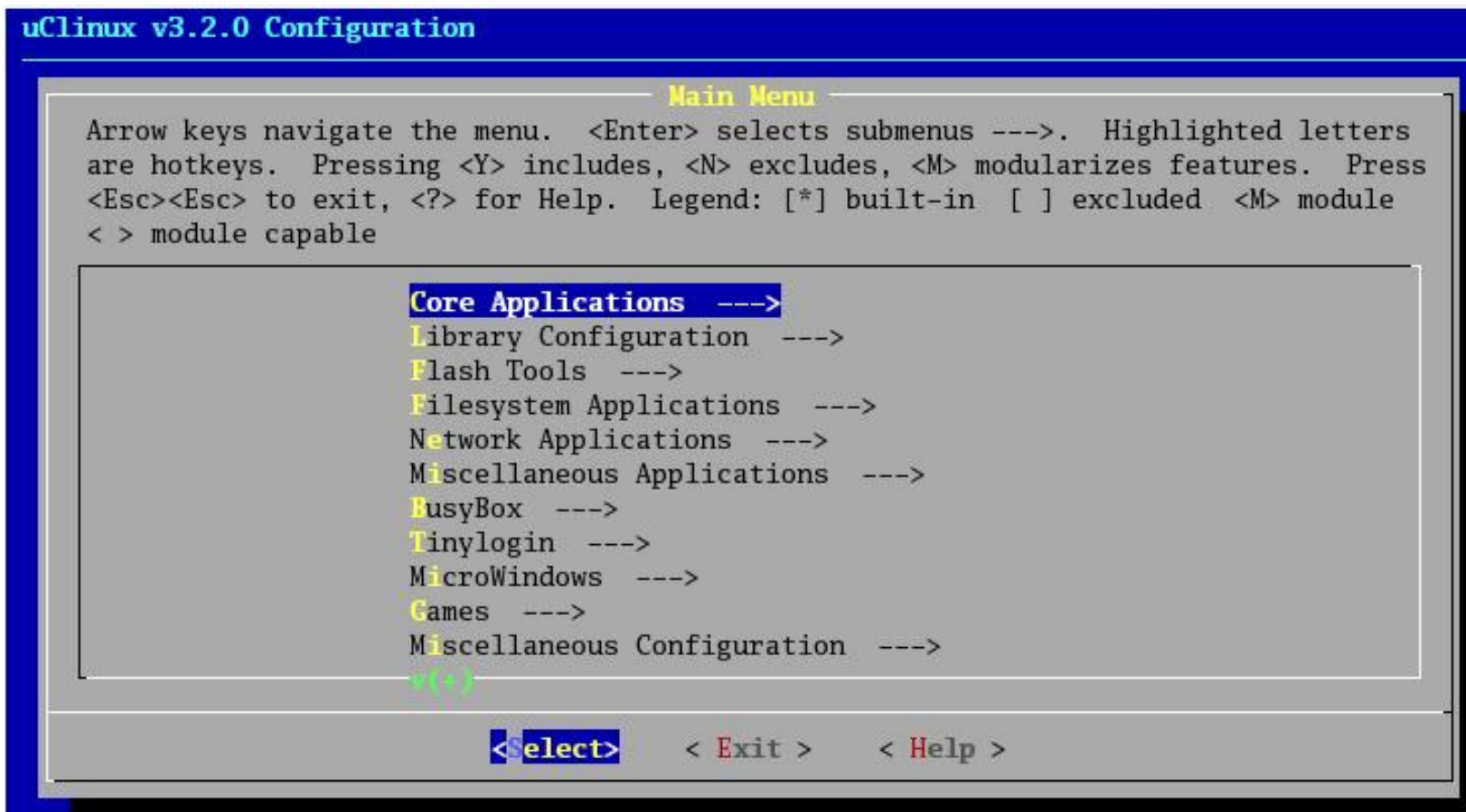

Figura 4.7: Terceira etapa de configuração do $\mu$ CLinux

- TCPDump (TCPDUMP, 1997): trata-se de uma ferramenta da GNU que roda em linha de comando utilizada normalmente para depuração em uma rede. A ferramenta analisa uma interface de rede permitindo interceptar os pacotes TCP/IP e outros pacotes transmitidos/recebidos e imprime os cabeçalhos destes pacotes que estão de acordo com uma expressão booleana. Para se executar esse programa, um usuário deve ter privilégios de administrador pois ela funciona em modo promíscuo, ou seja, intercepta todos os pacotes que passam por essa interface ao invés de simplesmente os pacotes que são endereçadas a mesma.

- Ethereal (ETHEREAL, 1998): trata-se de outra ferramenta para redes utilizado para analisar pacotes, resolver problemas de conexão, desenvolvimento de protocolos, dentre outras finalidades. Sua funcionalidade é bem parecida com a do TCPDump, a diferença é que opera em uma interface gráfica (GUI) e possui mais opções de filtragem e ordenação dos pacotes. Também funciona no modo promíscuo capturando todos os pacotes de uma rede.

- Iperf (NLANR/DAST, 2003): esta é um ferramenta para se realizar benchmarks de rede. O Iperf foi desenvolvido para ser uma moderna alternativa para se medir o desempenho de conexões TCP e UDP.

\subsection{Algoritmos Criptográficos}

O algoritmo implementado em hardware para fazer o processamento dos pacotes ESP é o AES (DUARTE, 2004). Trata-se um algoritmo de chave simétrica, desenvolvido para o governo 
americano, que é o algoritmo padrão para criptografia não-militar. o algoritmo AES foi selecionado pelo National Institute of Standards and Technology (NIST) dentre um conjunto de 15 algoritmos propostos em 1997, e declarado vencedor em Outubro de 2000 (CSRC, 2000), sendo publicado pelo Federal Information Processing Standards Publications (FIPS PUBS) em novembro de 2000 com o título FIPS-197. (NIST, 2000)

Dentre alguns sistemas comerciais que utilizam o AES para criptografia de dados podemos citar softwares como o PGP (PGP, 2007), o DriveCrypt (GMBH, 2007) e a própria VPN, motivo principal desta dissertação.

O algoritmo AES foi especificado para chaves de 128, 192 e 256 bits, sendo denominado respectivamente, AES-128, AES-192 e AES-256 dependendo do número de bits usados para definir a chave. Já o número de bits do bloco de dados é sempre 128. No caso do coprocessador criptográfico AES utilizado nesta dissertação (DUARTE, 2004) foi implementado o AES-128 no modo ECB e gentilmente fornecido pelo autor para este trabalho.

Outros algoritmos criptográficos utilizados nessa dissertãção são para se fazer autenticação dos pacotes (protocolo AH) e para a troca de chaves automaticamente (protocolo IKE). Nesse caso, não há restrição para qual algoritmo utilizar, bastando escolher um dos algoritmos definidos por padrão pelo IPSec na seção 3.6.1.

\subsection{Considerações Finais}

Neste capítulo foi abordada a metodologia que foi utilizada bem como ferramentas pertinentes para o desenvolvimento do projeto. O processador NIOS II, escolhido para esta dissertação é o processador oficial para os dispositivos da Altera. O $\mu$ clinux se mostrou como o sistema operacional mais adequado pelas razões explicitadas e é o que foi utilizado na construção deste trabalho. Sobre as ferramentas de desenvolvimento, elas possuem grau de complexidade compatível com o conhecimento de um projetista de hardware. 


\section{5}

\section{Implementação e Resultados}

\subsection{Justificativa}

A proposta deste trabalho foi de se construir uma VPN utilizando-se computação reconfigurável, mais especificamente FPGA para se utilizar em um robô móvel. Com o auxílio da computação reconfigurável pode-se ter uma $V P N$ que utiliza toda a flexibilidade do software com a robustez do hardware. Assim, por meio deste trabalho foi possível contribuir com a evolução do ambiente para projeto e implementação de controle evolucionário embarcado de robôs móveis reconfiguráveis dinamicamente. Este projeto é parte de um amplo trabalho que vem sendo desenvolvido pelo Laboratório de Computação Reconfigurável - LCR do Instituto de Ciências Matemáticas e de Computação da Universidade de São Paulo.

Como pode ser visto na figura 5.1, é possível uma comunicação com os robôs tanto em ambientes com fio quanto sem fio através da Internet de forma segura e rápida. Segura, por utilizar o conceito de VPN que implementa um túnel criptografado através da Internet obtendo assim três aspectos fundamentais da segurança: autenticação, integridade e confidencialidade. Rápida por utilizar todo o poder da computação reconfigurável, utilizando-se, por exemplo, de hardware para criptografar dados com a flexibilidade do software.

Este trabalho particularmente vem para complementar o projeto e fornecer uma solução capaz de aliar segurança com desempenho na comunicação com o robô. 


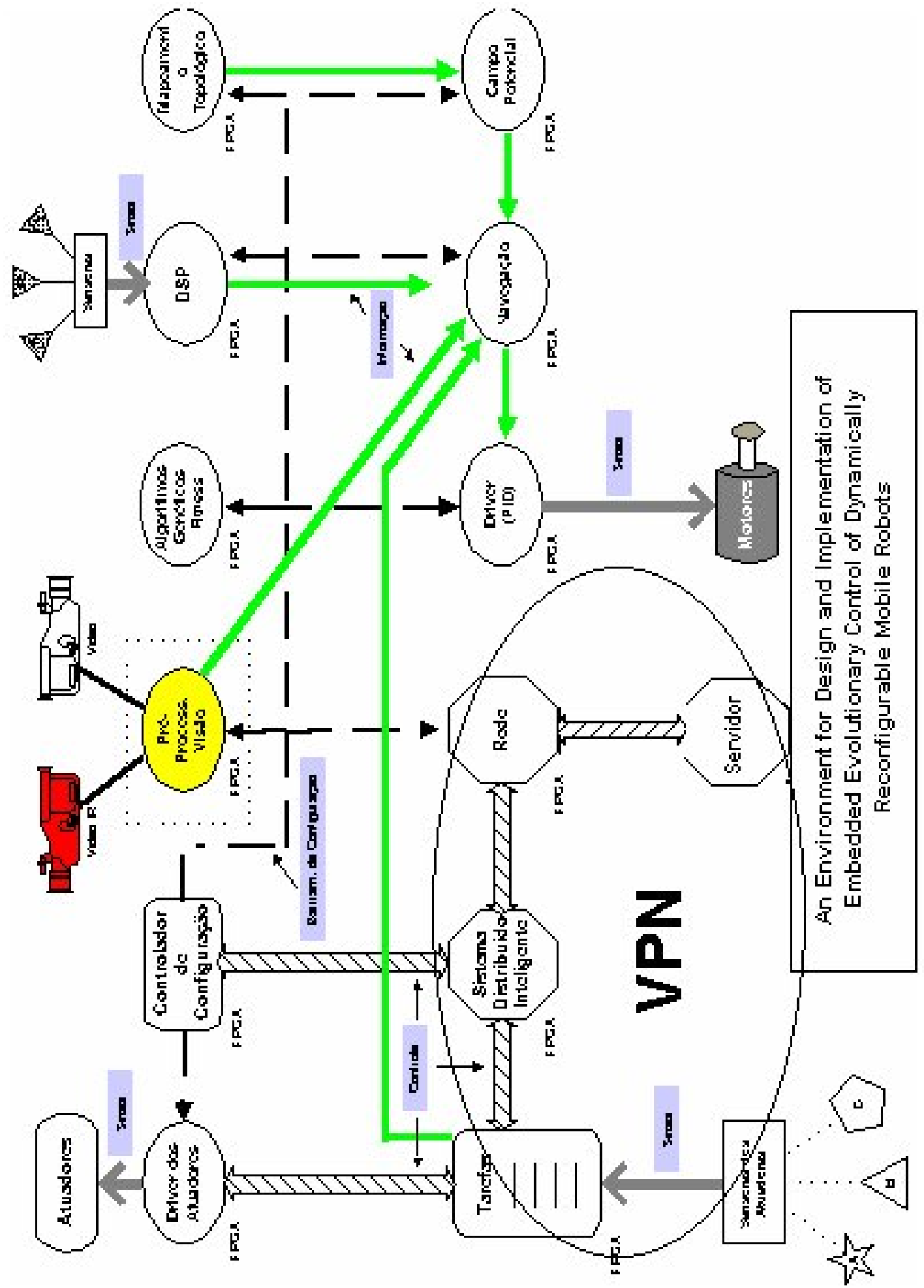

Figura 5.1: Ambiente de desenvolvimento do robô do LCR

\subsection{Metodologia}

O desafio deste trabalho está em portar as diversas ferramentas relacionadas a IPSec para o $\mu$ Clinux que executará sobre uma plataforma embarcada baseada no processador softcore Nios II 
e ainda fazer uma interface dessas ferramentas com o coprocessador criptografico AES de forma a acelerar a criptografia e decriptografia dos blocos de dados. De modo a resolver o problema geral, o trabalho foi dividido em basicamente três partes:

1. Portar o conjunto de ferramentas ipsec-tools para o $\mu$ Clinux;

2. Portar o coprocessador criptográfico AES para a placa utilizada nesta dissertação;

3. Construção de um modelo no qual o conjunto ipsec-tools utilize o coprocessador AES;

Para a construção do trabalho foi utilizada uma máquina Athlon 2200+ com 1GB de memória RAM. Nesta máquina foi instalado o Sistema Operacional Windows 2003 Server e sobre esse sistema os softwares da Altera: Quartus 6.01 com service pack 1 e Nios II Development Kit 6.01 com service pack 1. A partir daí foi instalada uma máquina virtual com Linux Fedora Core 5 para se construir e configurar o software do sistema embarcado e para funcionar como uma entidade que participa da VPN. Na máquina virtual foi instalado um novo Kernel versão 2.6.17.4 (no qual foram feitas modificações necessárias a estrutura da VPN utilizada) e o conjunto de ferramentas ipsectools versão 0.6.6 modificado para executar o algoritmo AES no modo ECB. Já no sistema embarcado, foi carregado na placa a configuração do hardware desejado, o qual se trata do processador softcore Nios II com o coprocessador criptográfico AES. O software para o hardware proposto é o sistema operacional $\mu$ Clinux com kernel versão 2.6.17 e diversas aplicações portadas para o mesmo. Foi, então, aplicado um patch no Kernel com o novo framework de criptografia utilizado, a Assynchronous Crypto Layer (POLYAKOV, 2005) e portado o coprocessador criptográfico AES para esta camada do Kernel do $\mu$ Clinux. Finalmente foi modificado e portado o conjunto de ferramentas ipsec-tools para o sistema embarcado. Construídas as soluções de hardware e software em ambos os participantes da VPN, o sistema pode finalmente estabelecer a comunicação privada. Este resumo geral, é apresentado na figura 5.2. Essas etapas serão descritas com mais detalhes nas seções seguintes.

\subsection{Ipsec-tools no $\mu$ Clinux}

Para a resolução da primeira etapa do trabalho várias considerações foram feitas a respeito das ferramentas que poderiam ser utilizadas. Todas as ferramentas que foram utilizadas nesta dissertação não estavam prontas ainda para serem executadas no $\mu$ Clinux, necessitando conhecimento do sistema operacional e do sistema embarcado para portá-las. Dentre as aplicações para Ipsec existentes para um sistema Linux Desktop comum, pode-se destacar:

- FreeS/Wan (GILMORE, 1996): projeto iniciado em 1996 por por John Gilmore e inicialmente levava o nome de S/Wan, Secure Wide Area Network. Sobre licença GPL, recebeu depois o nome de FreeS/Wan para diferenciá-lo de outras implementações pagas. Pretendia-se 


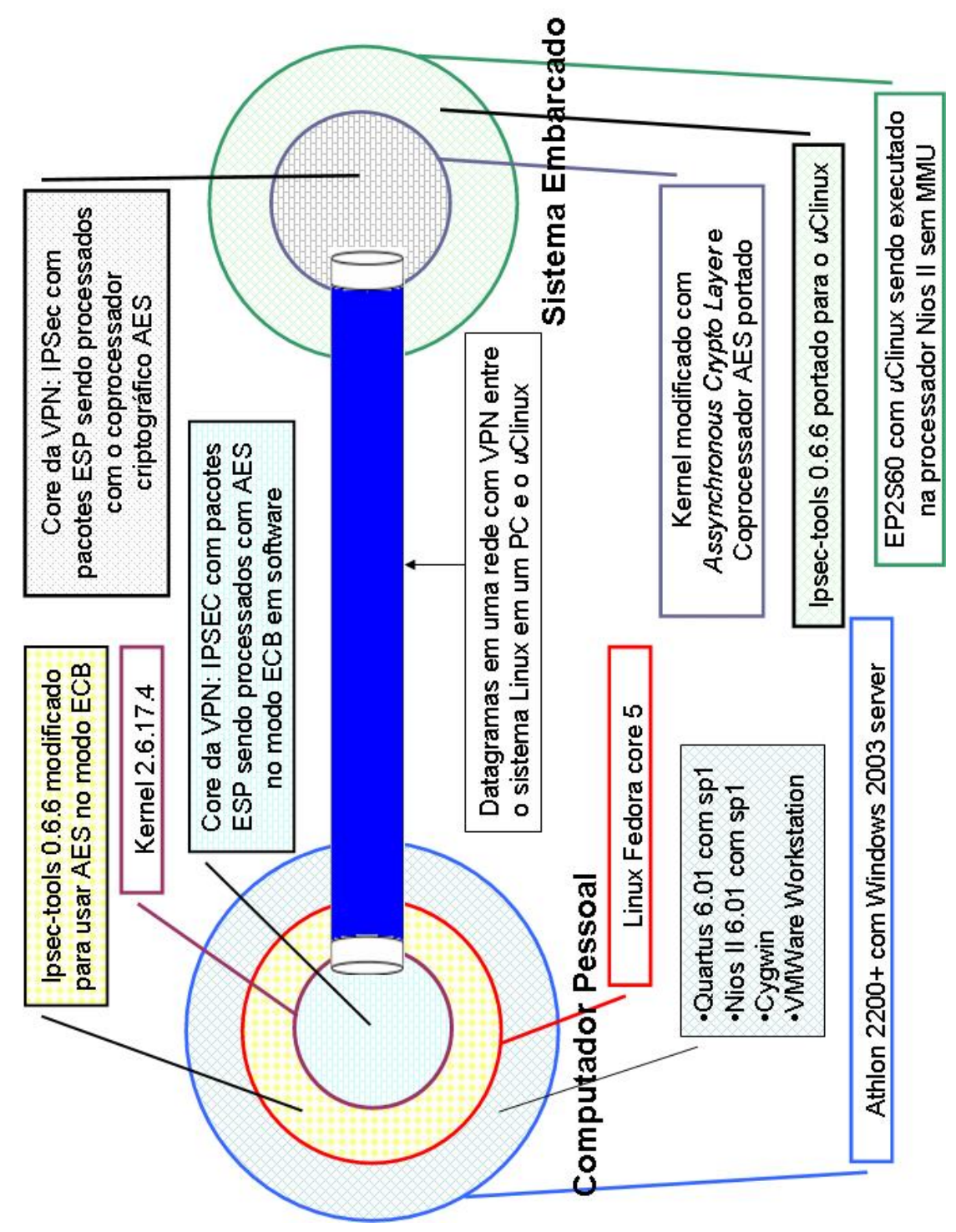

Figura 5.2: Visão geral do sistema

com o projeto que 5\% do tráfego da Internet fosse seguro contra monitoramentos de pacotes. Isto não foi possível em 1996 e continuou-se o projeto em 1999. Esperava-se os mesmos 5\% em 1999 ou 2000, 20\% no próximo ano e $80 \%$ no ano posterior. A primeira versão para Linux foi disponibilizada para ser utilizada com o Kernel 2.0.36. Atualmente, o projeto FreeS/Wan não existe mais e isso motivou o surgimento de duas novas vertentes baseadas nele: o OpenSwan e o StrongSwan. Um dos motivos alegados para o fim do projeto, é que foi escolhido outra implementação do IPSec para o código nativo do Linux.

- OpenSwan (OPENSWAN, 2003): projeto iniciado em 2003, partindo da implementação do FreeS/Wan, por alguns desenvolvedores do próprio FreeS/Wan que não estavam de acordo com as políticas do projeto anterior. Funciona sobre o Kernel 2.4 e 2.6 do Linux. Dentre os patrocinadores do OpenSwan estão estão a Novell, a Suse e a Astaro. 
- StrongSwan (STEFFEN, 2003): outro projeto que partiu do FreeS/Wan. Possui algumas características especiais como atribuir certificado às partes envolvidas, gerenciamento de Autoridades de Certificação (com suporte ao protocolo OCSP) e Cache Local de CRL.

- Ipsec-tunnel (RINGSTROM, 2002): projeto iniciado em 2002 que tinha por base ser uma implementação bastante simples do conjunto de protocolos IPSec de acordo com as normas RFC. A idéia é de que seria fácil para qualquer usuário estabelecer uma VPN entre clientes sem necessitar de um patch no Kernel do Linux. Para realizar a criptografia e a decriptografia, utiliza-se a CryptoAPI (que até então também não estava incorporada ao Kernel). Não implementa o procoloco AH, apenas o ESP para processamento de pacotes. O projeto terminou com a chegada do Kernel 2.6, pois este já vinha com uma implementação do IPSec nativa no Kernel do Linux.

- Ipsec-tools (KAME, 2002): a partir da versão 2.5.47 do Kernel do Linux foi incorporado uma implementação do IPSec de forma nativa. A implementação escolhida foi um porte do projeto Kame para o Linux. O projeto Kame foi um esforço colaborativo de seis empresas japonesas no Japão para providenciar uma pilha de IPv6, IPSec e IPv6 móvel para as variantes do BSD. Ipsec-tools são duas ferramentas que rodam no espaço do usuário que foram feitas pelo projeto Kame. As ferramentas são setkey e racoon. Setkey permite que se estabeleça uma VPN em modo transporte ou modo túnel de forma manual, ou seja, as chaves devem ser trocadas manualmente. Já racoon implementa o protocolo IKE para troca de chaves automaticamente, criando uma VPN em modo transporte ou modo túnel mais facilmente. Por fazer parte nativa do Kernel do Linux, Ipsec-tools foi escolhida para o desenvolvimento deste trabalho.

Como os arquivos binários de um sistema Linux padrão são diferentes dos arquivos binários da arquitetura de destino - o primeiro utiliza ELF e o segundo utiliza FLAT - faz-se necessario um cross compiler capaz de compilar uma aplicação que foi elaborada para um sistema Linux/Desktop padrão para o $\mu$ Clinux sendo executado sobre o processador Nios II. Além do compilador são necessárias bibliotecas específicas para o projeto e que serão compiladas estaticamente. Para compilar essas aplicações está sendo utilizado um conjunto de Makefiles e patches específicos para esta tarefa, chamado de buildroot (ANDERSEN, 2005). O conjunto buildroot, que facilita a compilação cruzada, é distribuido junto com o conjunto de bibliotecas $\mu$ Clibc(ANDERSEN, 2002) que são imprescindíveis para a compilação cruzada das aplicações, do sistemas de arquivos e da imagem para a arquitetura do Nios II. O conjunto de ferramentas ipsec-tools exige outras ferramentas que devem ser devidamente portadas antes de se compilar o projeto principal. Elas são descritas a seguir:

- OpenSSL (OPENSSL, 2000): OpenSSL é um projeto que destina-se a desenvolver uma completa e robusta solução de código aberto para a Secure Sockets Layer(SSL) e Transport 
Layer Security(TLS). Esses protocolos também necessitam de sistemas criptográficos para processamento dos pacotes. OpenSSL fornece uma interface para que outros programas utilizem criptografia no espaço de endereçamente de usuário. Assim, o programa racoon utiliza essa interface para o protocolo IKE, de modo a garantir segurança na troca das chaves entres os clientes que estabelecerão a VPN.

- Flex (FLEX, 1997): Flex é uma ferramenta opensource da GNU que serve para gerar programas que realizam análise léxica em um texto. É utilizada tanto pelo setkey quanto pelo racoon para analisar o arquivo de configuração criado pelo usuário e passar os devidos parâmetros para o Kernel e para a OpenSSL (no caso do racoon).

Essas ferramentas ainda não estão totalmente prontas para serem compiladas diretamente para o $\mu$ Clinux com Nios II, necessitando um certo esforço para a realização da compilação cruzada. Os primeiros problemas envolvem a alteração dos arquivos de configuração para compilar a aplicação para um host específicio, o Nios II. Para tanto, devem ser feitas modificações nos arquivos configure e config.sub que acompanham o programa. O conjunto de ferramentas buildroot introduz um aquivo para configuração chamado config.mk. Nesse arquivo de configuração são definidos os novos compiladores que devem ser usados e as bibliotecas específicas, bem como os seus respectivos paths.

O próximo passo se refere a modificação das bibliotecas compartilhadas que são utilizadas pela ipsec-tools, mas que no caso do $\mu$ Clinux devem ser compiladas estaticamente. Felizmente, a $\mu$ Clibc fornece uma gama de bibliotecas estáticas semelhantes as bibliotecas utilizadas pelo gcc em uma ambiente Linux comum. Basta então, fazer as alterações nos mesmos arquivos de configuração supra-citados. ${ }^{1}$

Continuando o processo para portar estes aplicativos, agora serão necessárias algumas alterações estruturais no código devido a limitações do hardware utilizado. O processador softcore da Altera não possui MMU. Isso significa dizer que não existe via hardware um gerenciamento de memória adequado, um mapeamento de processos na memória, que é necessário para sistemas que são multitarefa, como no caso dos sistemas Linux. Assim, determinadas instruções como fork, daemon, syslog, etc, não existem. Isso faz com que seja necessário soluções alternativas via software que não são tão seguras quanto as de hardware, mas que permitem a manipulação de processos filhos, como por exemplo, em um endereço de memória compartilhado com o processo pai. O compilador cruzado possui uma diretiva de compilação que lida com os forks dos programas substituindo-os por virtual forks, ou seja, os vforks que são responsáveis por realizar esse tipo de operação. Uma vez compilado o programa, foi necessário montar o sistema de arquivos do $\mu$ Clinux e incluir as ferramentas ipsec-tools nesse sistema. O sistema de arquivos não é composto exclusivamente dessas ferramentas. Ao contrário, deve possuir diversas outras ferramentas para manipulação de arquivos, shell e outros utilitários comuns de um sistema operacional. Porém

\footnotetext{
${ }^{1}$ As bibliotecas dinâmicas são arquivos do tipo *.so enquanto que as estáticas são do tipo *.a.
} 
essas ferramentas ocupam um espaço considerável do disco, sendo que a placa utilizada possui apenas 16MB de memória RAM que podem ser utilizadas. Assim, a solução é utilizar o busybox (VLASENKO, 2000). Busybox é uma versão enxuta composta de muitos utilitários de um sistema padrão unix em um único binário. As ferramentas do busybox normalmente tem menos opções que as versões completas implementadas pela GNU em um sistema Linux normal.

A placa alvo deste trabalho não possui disco rígido nem qualquer outro tipo de armazenamento de dados que não seja memória RAM ou memória Flash. Isto fez com que fosse necessário utilizar um conceito que foi incorporado no Kernel do Linux a partir da versão 2.5.49, o qual se chama initramfs. A idéia do initramfs é de anexar arquivos cpio na imagem do Kernel. O sistema final deve ser uma única imagem de boot (inicializável) que será carregado na placa. Quando ocorre o boot, o kernel descompacta o arquivo em um disco baseado em RAM, o qual é montado e usado como sistema de arquivos.

Com a imagem do Kernel construída, utiliza-se o Quartus para carregar a imagem do sistema de hardware gerado, no caso Nios II com o coprocessador criptográfico AES. O Quartus, após compilar o hardware, gera um único arquivo com todas as configurações necessárias ${ }^{2}$ que deve ser carregado para a placa. Após essa etapa, descarrega-se a imagem, zImage, que contém todo o kernel e o sistema de arquivos. Finalmente, a placa está pronta para ser acessada com todo o sistema implementado, visando a utilização da rede VPN para o controle do robô móvel. Para cada arquivo novo que se deseja inserir no $\mu$ Clinux é necessário a criação de uma nova zImage para ser carregada na placa. Com o sistema pronto basta realizar as configurações pertinentes ao tipo de VPN que se deseja estabelecer entre o robô e o notebook/PC.

\subsection{Implementação do Hardware}

Na etapa de resolução do problema proposto, considerou-se qual seria a melhor solução para implementação: um hardware dedicado, como um coprocessador, ou algumas instruções customizadas diretamente no código do processador NIOS II.

Instruções customizadas são interessantes quando se levam poucos ciclos de relógio para se realizar uma operação. Intruções que levam mais de 20 ciclos de relógio para executar uma tarefa não são viáveis de se implementar já que o processador ficará parado - preso nessa instrução até que termine a sua execução - fazendo com que o sistema como um todo passe a ficar mais lento. Já no caso de se ter um hardware dedicado para a execução dessa tarefa, haverá um tempo demandado na comunicação entre o processador principal, o Nios II, e o coprocessador criptográfico. Todavia, o coprocessador criptográfico executará em paralelo com o processador, fazendo com que o sistema possa continuar realizando outras operações normalmente. Quando o algoritmo já estiver criptografado ou decriptografado, apenas será necessário se comunicar novamente com o coprocessador para se obter os dados. Algoritmos criptográficos normalmente necessitam de

\footnotetext{
${ }^{2}$ trata-se de um arquivo do tipo SOF
} 
muitos ciclos de relógio para processar cada bloco de dados. Segundo o projetista do coprocessador AES (DUARTE, 2004) as características do coprocessador operando originalmente em uma placa Cyclone modelo EP1C20F400C8 são as seguintes:

- Freqüência real de operação: $50 \mathrm{MHz}$

- Número de ciclos de relógio necessários para o processamento de um bloco de dados: 12

- Taxa máxima de saída: 533 Mbits/seg

- Capacidade computacional: 4,16 Mblocos/seg

- Número de ciclos de relógio considerando o sistema completo:

Escrita do dado no registrador de entrada: 1 ciclo

Latência até o início do processamento: 1 ciclo

Tempo de processamento do bloco de dados: 12 ciclos

Leitura dos dados ao final do processamento: 1 ciclo

Tempo total de um ciclo completo: 15 ciclos de relógio

- Taxa máxima de saída para o sistema completo: 426,66 Mbits/seg

- Capacidade computacional: 3,33 Mblocos/seg

Deste modo, a melhor solução é a implementação do sistema criptográfico por meio de um coprocessador dedicado em detrimento as instruções customizadas. A implementação do hardware, então, consiste em portar o coprocessador AES para o processador Nios II e para a FPGA que foi utilizada neste projeto, a Stratix EPS2S60. Depois deve-se compilar o hardware pelo Quartus e gerar o arquivo com todas as configurações do sistema SOPC para ser carregado na placa.

Este coprocessador AES possui o código em VHDL permitindo assim modificações, caso necessárias, na estrutura do mesmo. Ele foi utilizado originalmente em uma placa de menor capacidade com recursos diferentes dos que estão sendo utilizados neste trabalho devido as exigências da placa em questão. No projeto inicial foram utilizados dois circuitos de PLL separados do processador e instanciados pelo próprio Quartus. Uma PLL era responsável por gerar o sinal de relógio da SDRAM externa e outra para gerar o sinal de relógio para o sistema SOPC completo. No sistema deste trabalho há apenas uma PLL que é instanciada dentro do próprio SOPC Builder, ligada no barramento avalon, fazendo com que o projeto seja mais conciso.

A seguir uma descrição completa do hardware implementado:

- CPU NIOS II: frequência de $50 \mathrm{MHz}$, com cache de instruções de 4KBytes, predição de salto, multiplicador e divisor em hardware. Possui um desempenho de até 32 DMIPS. 
- Barramento Avalon: barrmento principal do sistema

- Interface com memória SDRAM: Interface com a memória SDRAM de 16 MBytes.

- FLASH externa: Interface com memória FLASH externa de 16 MBytes.

- PLL: para gerar o sinal de relógio adequado para o sistema SOPC completo.

- SRAM Externa: Interface com memória SRAM externa de 1 MBytes, com tempo de acesso à memória de 12 ns.

- Interface Ethernet: Interface com um dispositivo externo de interface Ethernet 10/100 Mbits, LAN91C111 [125], dispositivo contendo uma MAC e a interface física de acesso a Ethernet.

- UART: Interface serial configurável com taxa máxima de transferência de $115 \mathrm{Kbps}$, e que permite que um computador externo carregue software no sistema e receba as mensagens enviadas pelo programa que está sendo executado na placa.

- Interface com display LCD: Interface de onze bits com um display LCD.

- LEDs: Saídas para acionar oito LEDs disponíveis na placa.

- Botões do tipo push-button: Permite a leitura de quatro botões disponíveis na placa.

- Displays de LEDs de sete segmentos: Saídas para acionamento direto de dois displays de sete segmentos de LEDs disponíveis na placa.

- Interface com cartão Compact FLASH: Interface com uma memória do tipo Compact FLASH externa, disponível na placa.

- Pedido de reconfiguração: Pino de saída que, quando colocado em nível lógico 0, inicia a reconfiguração da FPGA. Permite que um programa carregue uma nova configuração de hardware na FLASH serial e reinicialize o hardware da FPGA.

- Interface com o coprocessador AES: Interface com o coprocessador criptográfico AES implementado, com 32 bits de dados, 2 bits de endereço e os sinais de controle de escrita, leitura e seleção do dispositivo.

Na figura 5.3 é apresentado a tela do SOPC Builder com o sistema implementado, mostrando todos os elementos do sistema, o endereço de cada um dos blocos do sistema e a interrupção gerada pelo bloco, quando aplicável.

Na figura 5.4 é apresentada uma imagem do RTL Viewer, ferramenta do Quartus II que permite ver na forma de esquema elétrico o diagrama de blocos do sistema, bem como algumas portas lógicas e registradores que ficam no topo de hierarquia. 


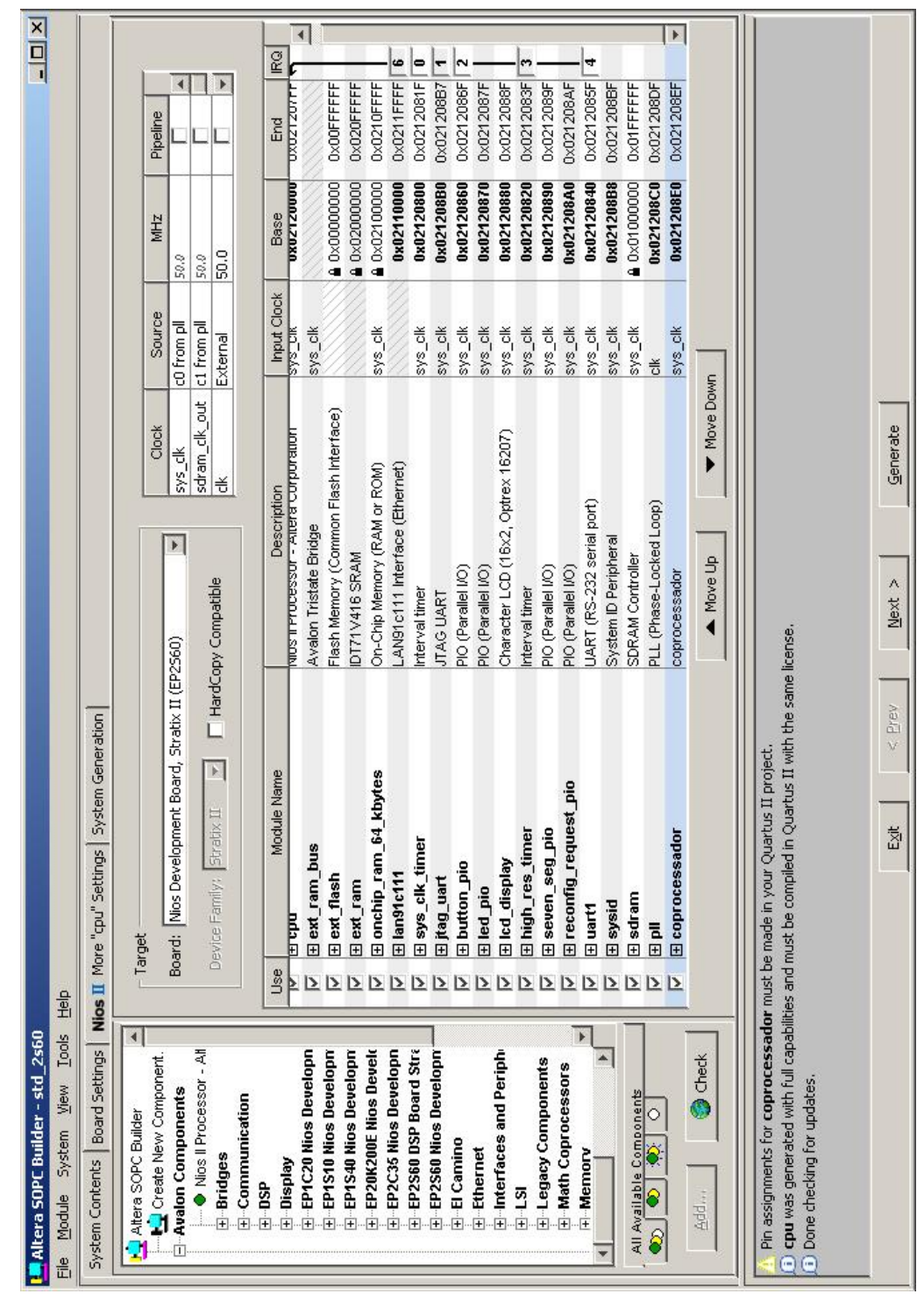

Figura 5.3: SOPC Builder com todo o sistema implementado

Na figura 5.5 é possível verificar os resultados gerados pelo Quartus após a compilação do hardware como um todo. É possível ver, dentre outros aspectos interessantes, a quantidade de ALUTs utilizadas, o número total de pinos necessários, número total de bits de memória e quantidade de DSPs utilizadas.

\subsection{Construção da solução final}

A terceira parte do trabalho envolve a união do coprocessador criptográfico AES com o pacote de software ipsec-tools e as modificações relativas ao processamento de pacotes ESP no Kernel do $\mu$ Clinux. Faz-se necessário, então, uma modificação no Kernel para incluir o código do AES que será realizado pelo coprocessador em detrimento ao algoritmo padrão AES que é executado 


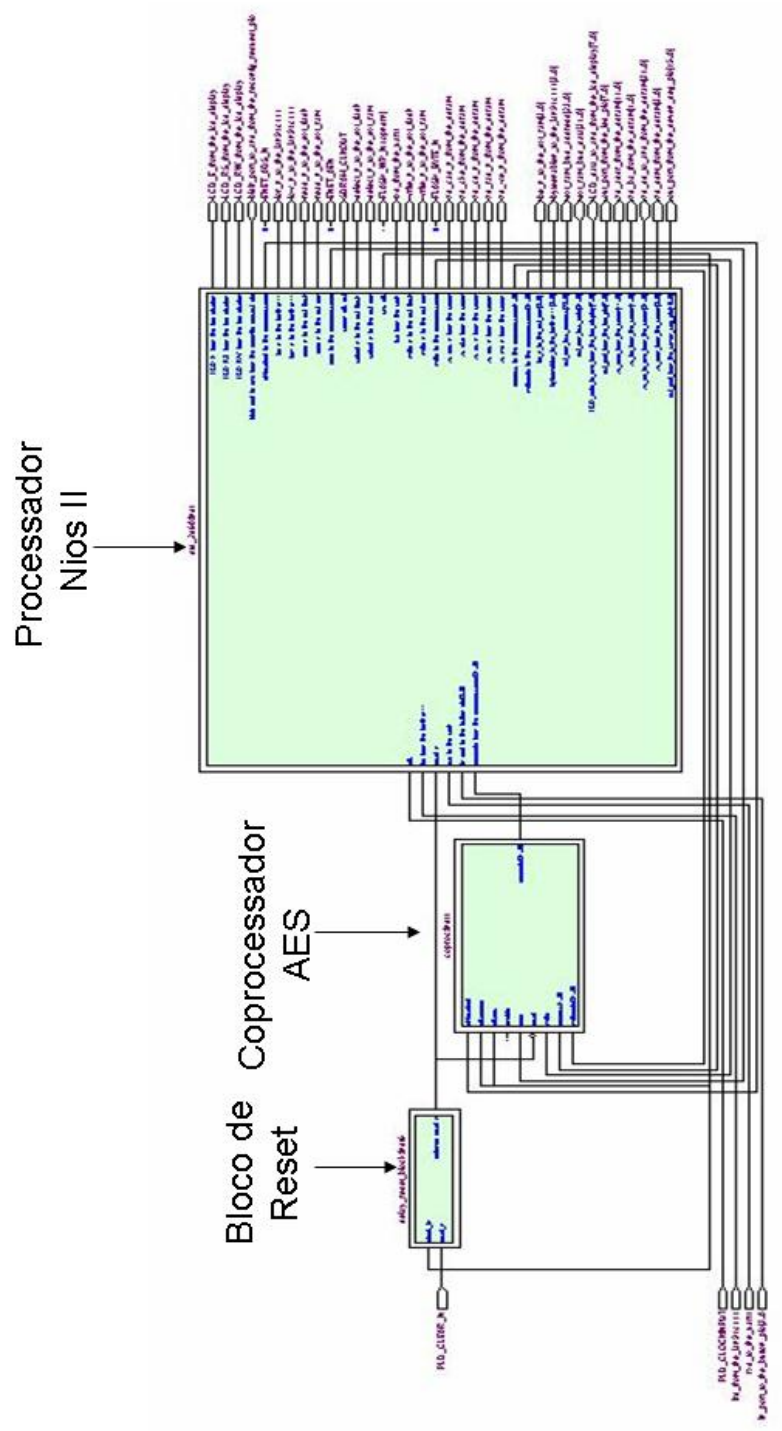

Figura 5.4: Diagrama do sistema completo visto pelo RTL Viewer

via software. Essa última parte visa aumentar consideravelmente o desempenho da VPN como um todo, uma vez que o hardware embarcado é muito inferior ao de um PC/Notebook comum.

O código do AES implementado inicialmente era executado no espaço de endereçamento do usuário, sem qualquer ligação com o Kernel do Linux. Para a realização deste trabalho, o código do AES foi trazido para dentro do Kernel onde é executado o processamento dos pacotes ESP. Nesse caso, algumas questões foram consideradas para a resolução deste problema.

A primeira questão para se resolver foi analisar o framework de criptografia atual utilizado pelo Kernel do Linux. O Kernel versão 2.6 possui todo um sistema de criptografia interno utilizado para várias finalidades como criptografar sistemas de arquivos, área de troca e conexões de rede. Há uma gama de algoritmos disponíveis, os quais são: MD4, MD5, SHA1, SHA256, SHA384, SHA512, HMAC, Whirlpool, Tiger, DES, 3-DES, Blowfish, Twofish, Serpent, AES, CAST5, CAST6, TEA, ARC4, Khazad, Anubis e Michael MIC. Assim, foi portado o código do coprocessador criptográfico AES para o Kernel utilizando o framework de criptografia, seguindo 


$\begin{array}{ll}\text { Flow Status } & \text { Successful - Wed Dec 06 16:00:31 2006 } \\ \text { Quartus II Version } & \text { 6.0 Build 202 06/20/2006 SP 1 SJ Full Version } \\ \text { Revision Name } & \text { standard } \\ \text { Top-level Entity Name } & \text { standard } \\ \text { Family } & \text { Stratix II } \\ \text { Device } & \text { EP2S60F672C5 } \\ \text { Timing Models } & \text { Final } \\ \text { Met timing requirements } & \text { Yes } \\ \text { Total ALUTs } & 5,491 / 48,352(11 \%) \\ \text { Total registers } & 2954 \\ \text { Total pins } & 182 / 493(37 \%) \\ \text { Total virtual pins } & 0 \\ \text { Total memory bits } & 624,384 / 2,544,192(25 \%) \\ \text { DSP block 9-bit elements } & 8 / 288(3 \%) \\ \text { Total PLLs } & 1 / 6(17 \%) \\ \text { Total DLLs } & 0 / 2(0 \%)\end{array}$

Figura 5.5: Resumo das características utilizadas na FPGA após a compilação

todos os padrões inerentes a API. Um problema encontrado teve que ser solucionado: a ordem para se guardar as informações lidas no registrador interno do coprocessador não satisfaziam o sistema de hardware proposto, inviabilizando os resultados obtidos com a criptografia/decriptografia. Em outras palavras, o Kernel realizava a leitura para arquiteturas little endian enquanto o coprocessador utiliza big endian.

Após ser resolvido o problema anterior, partiu-se para próxima etapa na qual envolvia o processamento dos pacotes ESP. Um problema crucial impediu a utilização da solução anteriormente implementada: o Kernel do Linux não foi projetado para execução de algoritmos criptográficos assíncronos, como o são os sistemas de criptografia que utilizam um hardware dedicado. De fato, ao se construir e se incorporar a Crypto API ao Kernel do Linux foi deixado para posterióri uma estrutura capaz de lidar com esses tipos de sistemas. A criptografia funciona isoladamente mas não funciona adequadamente para o processamento dos pacotes ESP, pois não há uma estrutura no IPSec para lidar com o processamento assíncrono. O Linux ainda está caminhando neste sentido para no futuro próximo lidar com essas novas tendências de criptografia via hardware. O FreeBSD, por exemplo, possui uma implementação exclusiva para aceleramento criptográfico por hardware para VPNs, chamado de FAST IPSec, que inclusive foi herdado do OpenBSD. Assim, para o Linux, 
foram criadas soluções não oficiais para atualizarem o Kernel (os chamadospatches) de forma a se resolver essa questão. Há, atualmente, duas soluções existentes:

- $O C F$ (MCCULLOUGH, 2002): trata-se de um porte do framework de criptografia do OpenBSD/FreeBSD. Este sistema implementa uma aceleração criptográfica assíncrona de Hardware e Software para o Kernel do Linux e aplicações rodando sobre o Linux. Os resultados mostram melhoras de até 7 vezes no desempenho dos algoritmos. Não há porém suporte para o IPSec.

- Assynchronous Crypto Layer (POLYAKOV, 2005): trata-se de um framework de criptografia assíncrona desenvolvido especificamente para o Kernel do Linux. Oferece suporte para os pacotes ESP, para o Device-mapper ${ }^{3}$ e possui também uma interface para drivers que utilizam a OCF.

Para este trabalho foi escolhida a Assynchronous Crypto Layer por ser mais completa, oferecendo suporte para os pacotes ESP. A solução, agora, está em re-portar o código do coprocessador criptográfico AES para esta nova camada que foi incorporada ao Kernel do $\mu$ Clinux. O porte completo do código pode ser visto no apêndice A.

Após ser devidamente portado o código, foram necessárias modificações nos arquivos de configuração do Kernel do Linux que são utilizados quando se faz a recompilação do mesmo e se escolhe os recursos que se deseja incorporar ao núcleo do sistema operacional. Em outras palavras, são necessárias modificações em arquivos como o Makefile, Kconfig para incluir suporte quando se faz a configuração do sistema ${ }^{4}$. Assim, o novo sistema é apresentado na figura 5.6 para o usuário.

Tendo o sistema embarcado sido solucionado, as atenções se voltam ao outro lado da comunicação: o PC/Notebook. Neste caso, há um problema que deve ser resolvido: o coprocessador criptográfico AES foi desenvolvido para trabalhar no mo ECB enquanto que as ferramentas ipsectools utilizam o AES exclusivamente no modo CBC. Isto faz com quem os pacotes sejam diferentes após a criptografia e, portanto, inviabilizam a comunicação. Assim, devem ser feitas modificações no sistema para que essas ferramentas passem a utilizar o AES no modo ECB.

O Kernel do Linux, através da camada de criptografia, possui suporte nativo ao algoritmo AES no modo ECB, bastando fazer com que o conjunto ipsec-tools inclua o modo ECB em seu conjunto de algoritmos disponíveis. Para se fazer isso, deve-se modificar o analisador léxico do programa e incluir uma interface entre o conjunto ipsec-tools e o Kernel do Linux para que o software disponibilize a opção para que o usuário possa utililizar o algoritmo AES no modo ECB. No apêndice B há uma explicação para se configurar diferentes modos de VPN com o sistema proposto.

\footnotetext{
${ }^{3}$ uma estrutura que providencia um modo genérico para criar camadas virtuais de dispositivos de bloco presente nas versões do Kernel 2.6

${ }^{4}$ A configuração é realizada via make menuconfig
} 


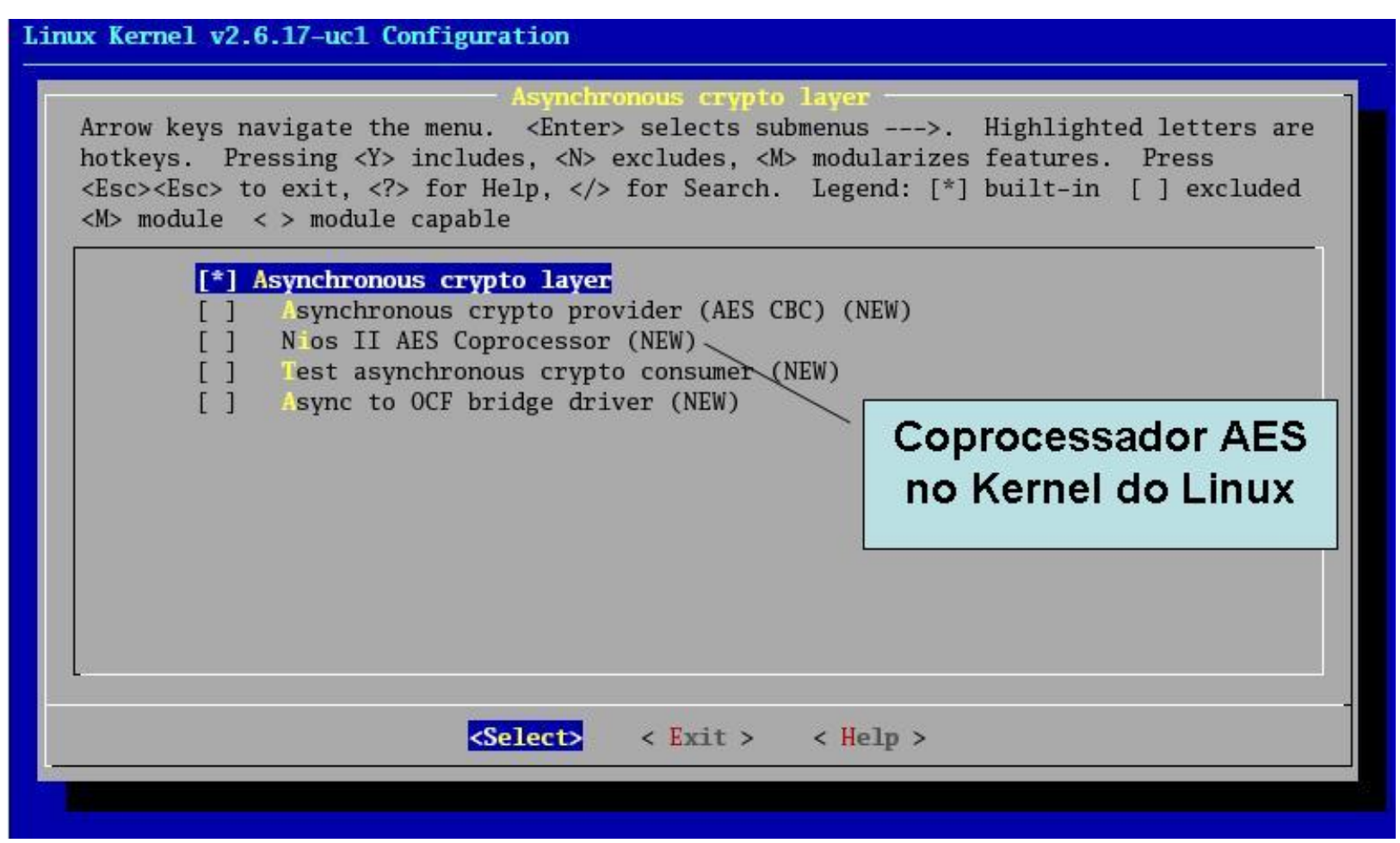

Figura 5.6: Menu para selecionar o coprocessador AES na configuração do Kernel

\subsection{Resultados Obtidos}

Esta seção visa validar os dados obtidos através de análises dos datagramas de rede e do desempenho obtido. Após a conexão ser estabelecida, foi utilizado o programa ping para testar a conexão. Os resultados foram analisados com os programas TCPdump e Ethereal. Os testes foram realizados com e sem o IPSec.

Para o teste apresentados nas figuras 5.7 e 5.9 foi efetuada as seguintes configurações:

1. Sistema embarcado: configurado o IP 192.168.0.3/24

2. Sistema Linux comum: configurado o IP 192.168.0.4/24

Alguns detalhes interessantes podem ser verificados: o TCPDump apresenta o tipo do pacote capturado, Internal Control Message Protocol (ICMP), gerado pelo software ping, bem como dados de controle, indicando claramente que a conexão foi estabelecida e está funcionando. Já o software Ethereal apresenta outros detalhes a se observar, como o tamanho total do pacote (que é de 64 bytes sendo 56 de dados e o restante de controle) e os caracteres enviados. Ao analisar apenas o final do pacote pode-se claramente ver a seguinte string “./0123567" que foi enviada pelo ping a fim de se testar a comunicação.

O próximo teste foi realizado estabelecendo-se a VPN no modo transporte manualmente, entre o computador e o sistema embarcado. Para isso foi utilizado o algoritmo hmac-md5 para se fazer 


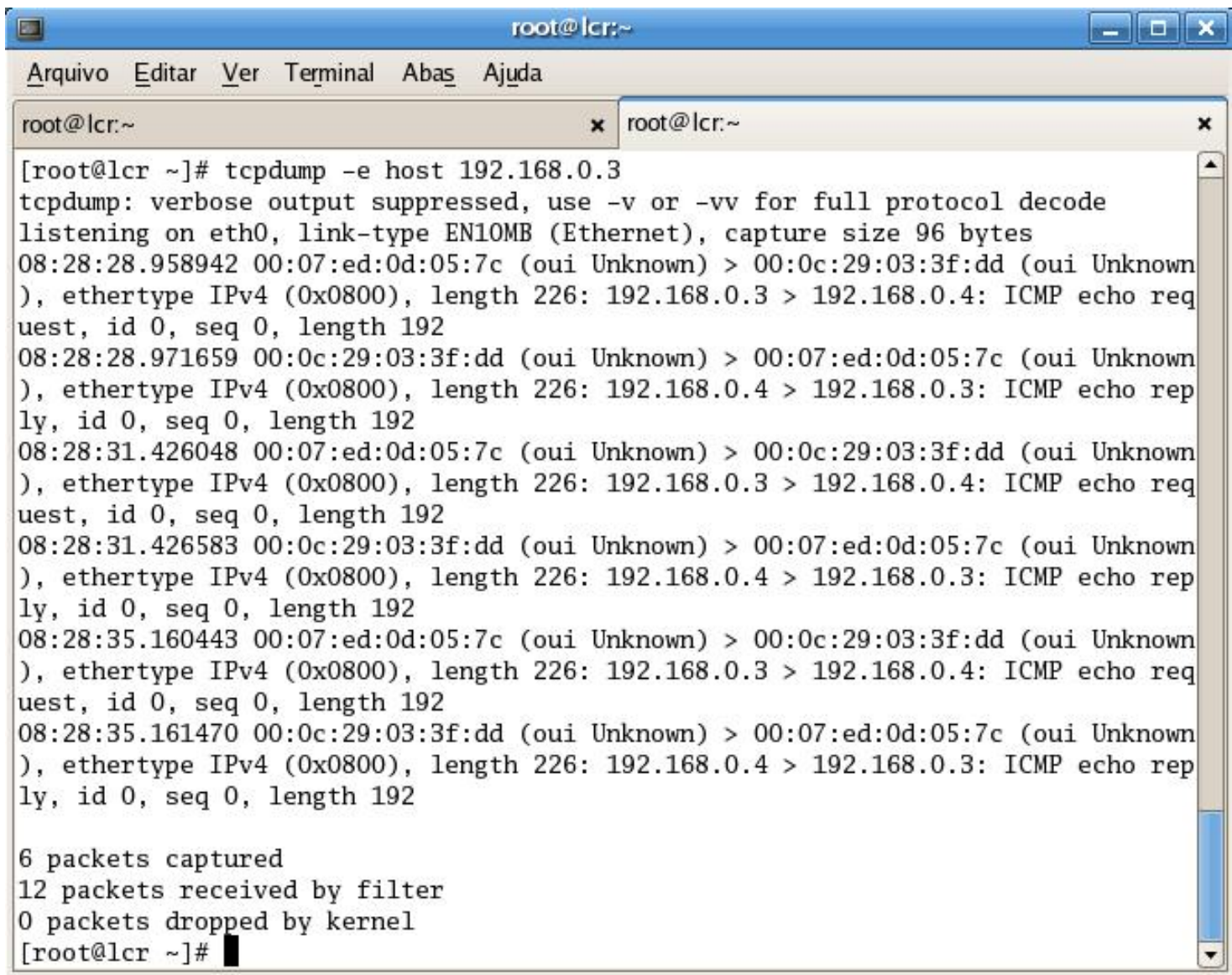

Figura 5.7: Análise dos pacotes ICMP com TCPDump

autenticação e o algoritmo AES no modo ECB sendo executado em hardware no sistema embarcado e em software no PC. O sistema embarcado foi configurado com IP 192.168.0.1/24 e o PC com IP 192.168.0.2/24. O mesmo programa ping com os mesmos parâmetros foi utilizado a fim de se verificar as diferenças obtidas. Os resultados podem ser vistos nas figuras 5.8 e 5.10 .

Pode-se claramente verificar as diferenças analisadas pelo TCPDump e pelo Ethereal nas figuras 5.8 e 5.10. O protoloco destacado é o Encapsulating Security Payload, o ESP. O mesmo pacote do tipo ICMP foi enviado porém agora o tamanho total do pacote é de 88 bytes, sendo 80 bytes de dados. Os caracteres “./0123567” não são mais legíveis, indicando que foram devidamente criptografados antes de transitar pela rede.

Após a verificação da funcionalidade do sistema, foi utilizado o iperf para se realizar testes de desempenho na rede. Os resultados finais obtidos com os testes podem ser vistos na tabela 5.1. Como pode ser visto na tabela 5.1 o desempenho do IPSec é bem inferior ao desempenho de uma conexão usando IP. Isso pode ser explicado por vários motivos, como o encapsulamento do pacote, a autenticação dos dados, o aumento no tamanho dos dados na rede (overhead), etc. Porém esse processamento é acelerado quando se é comparado o desempenho do IPSec com criptografia dos pacotes ESP em hardware e com o processamento em software. O desempenho chega a ser de aproximadamente $110 \%$ superior a versão em software, principalmente em pacotes de dados maiores. 


\begin{tabular}{|c|c|c|}
\hline root@ler: & - & \\
\hline Arquivo Éditar Ver Terminal Abas Ajüda & & \\
\hline root@lcr:/home/marcelo/... x root@lcr: & root@lcr: & $\mathbf{x}$ \\
\hline 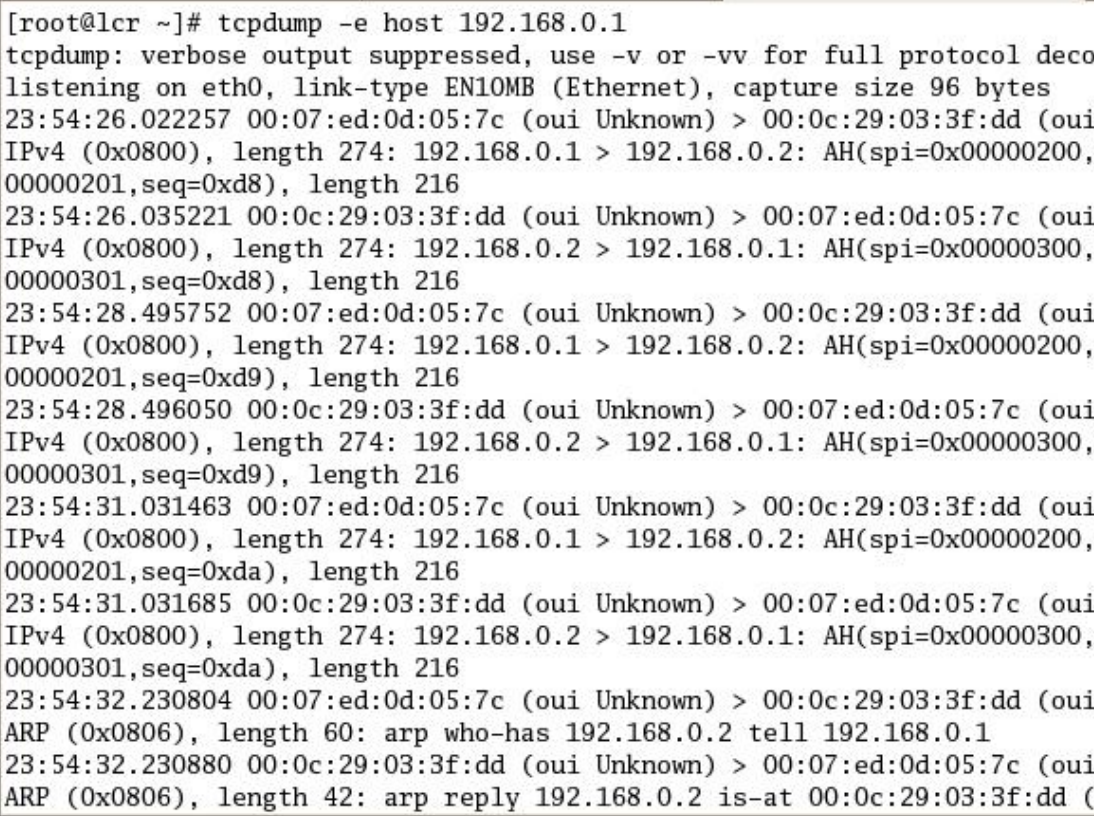 & $\begin{array}{l}\text { ode } \\
\text { i Unknown), ethertype } \\
\text {, seq=0xd8): ESP(spi=0x } \\
\text { i Unknown), ethertype } \\
\text {, seq=0xd8): ESP(spi=0x } \\
\text { i Unknown), ethertype } \\
\text {, seq=0xd9): ESP(spi=0x } \\
\text { i Unknown), ethertype } \\
\text {, seq=0xd9): ESP(spi=0x } \\
\text { i Unknown), ethertype } \\
\text {, seq=0xda): ESP(spi=0x } \\
\text { i Unknown), ethertype } \\
\text {, seq=0xda): ESP(spi=0x } \\
\text { i Unknown), ethertype } \\
\text { i Unknown), ethertype } \\
\text { (oui Unknown) }\end{array}$ & 8 \\
\hline
\end{tabular}

Figura 5.8: Análise dos pacotes ESP com TCPDump

\begin{tabular}{|c|c|c|c|}
\hline \multicolumn{3}{|c|}{ Protocolo TCP } \\
\hline $\begin{array}{c}\text { Tamanho } \\
\text { do pacote }\end{array}$ & $\begin{array}{c}\text { Conexão } \\
\text { sem VPN }\end{array}$ & $\begin{array}{c}\text { VPN com criptografia } \\
\text { em software }\end{array}$ & $\begin{array}{c}\text { VPN com criptografia } \\
\text { em hardware }\end{array}$ \\
\hline $512 \mathrm{~B}$ & $4.48 \mathrm{Mbps}$ & $620 \mathrm{Kbps}$ & $915 \mathrm{Kbps}$ \\
\hline $1 \mathrm{~KB}$ & $5.97 \mathrm{Mbps}$ & $694 \mathrm{Kbps}$ & $936 \mathrm{Kbps}$ \\
\hline $2 \mathrm{~KB}$ & $7.02 \mathrm{Mbps}$ & $716 \mathrm{Kbps}$ & $1.13 \mathrm{Mbps}$ \\
\hline $4 \mathrm{~KB}$ & $7.87 \mathrm{Mbps}$ & $752 \mathrm{Kbps}$ & $1.19 \mathrm{Mbps}$ \\
\hline $8 \mathrm{~KB}$ & $8.31 \mathrm{Mbps}$ & $772 \mathrm{Kbps}$ & $1.25 \mathrm{Mbps}$ \\
\hline $16 \mathrm{~KB}$ & $8.57 \mathrm{Mbps}$ & $771 \mathrm{Kbps}$ & $1.44 \mathrm{Mbps}$ \\
\hline $32 \mathrm{~KB}$ & $8.71 \mathrm{Mbps}$ & $774 \mathrm{Kbps}$ & $1.56 \mathrm{Mbps}$ \\
\hline $64 \mathrm{~KB}$ & $8.76 \mathrm{Mbps}$ & $780 \mathrm{Kbps}$ & $1.62 \mathrm{Mbps}$ \\
\hline $128 \mathrm{~KB}$ & $8.84 \mathrm{Mbps}$ & $781 \mathrm{Kbps}$ & $1.64 \mathrm{Mbps}$ \\
\hline
\end{tabular}

Tabela 5.1: Tabela comparativa de desempenho entre diferentes tipos de conexão

Com base nos experimentos realizados pode-se deduzir que, principalmente com o advento do padrão IPv6, o IPSec com criptografia em hardware deve ser uma das tendências do futuro já que o IPSec por sua própria natureza tornará mais lenta as comunicações em rede. A criptografia em hardware ajuda a diminuir esse gargalo. Isso sem falar nos sistemas embarcados que possuem dispositivos de hardware muito mais limitados e uma solução de VPN sem o aceleramento criptográfico, pode tornar a sua aplicação crítica. 


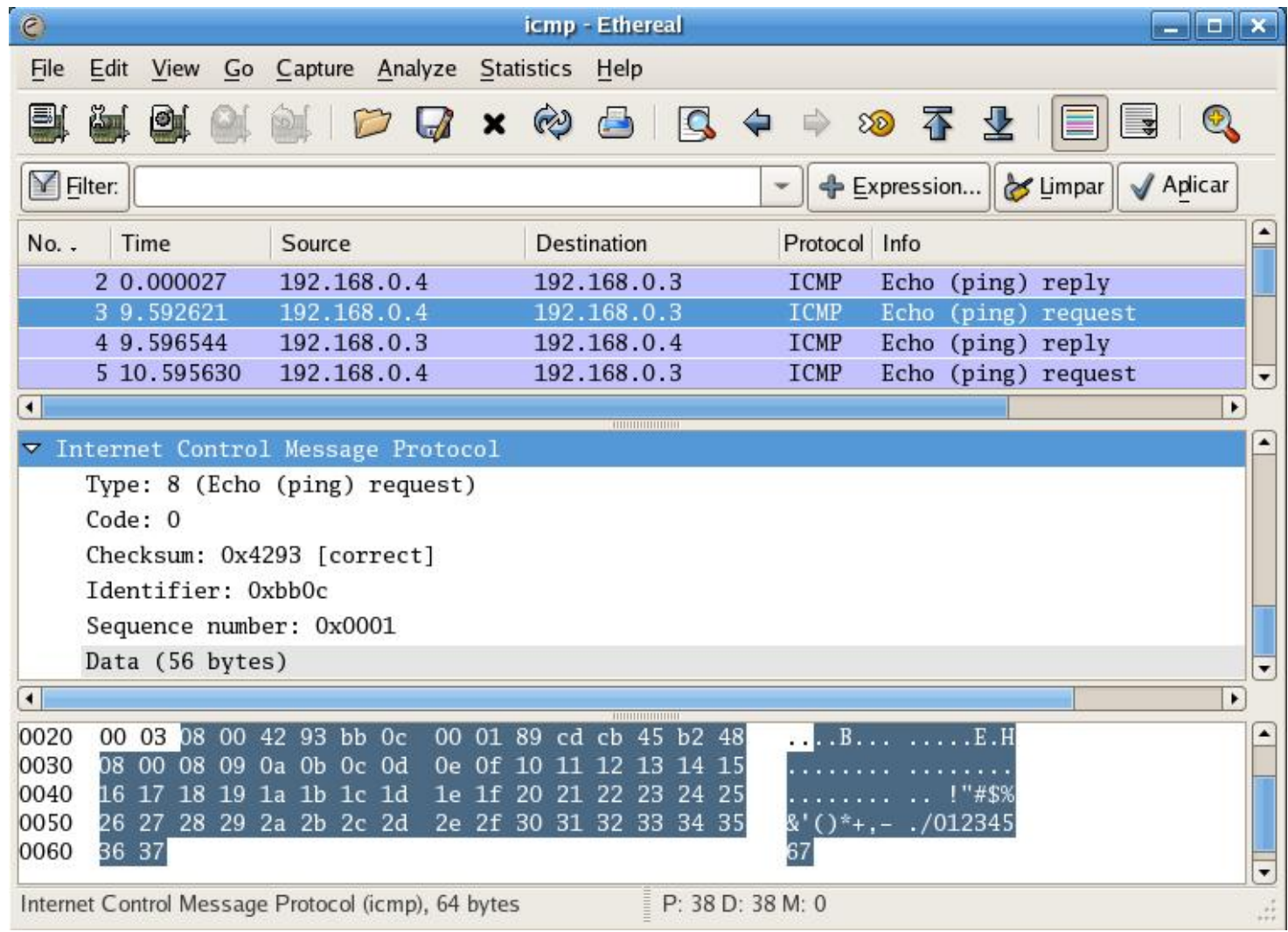

Figura 5.9: Análise de Pacotes ICMP com o Ethereal

\subsection{Considerações Finais}

Desta forma encerra-se este capítulo no qual foi abordado detalhes de implementação em diferentes níveis de abstração. Além disso foram apresentados resultados para validação da implementação por meio dos analisadores de protocolo e executado testes de desempenho. Como o padrão IPv6 utilizará IPSec, soluções de criptografia por hardware principalmente em sistemas embarcados, que são mais limitados, devem ser implementadas. 


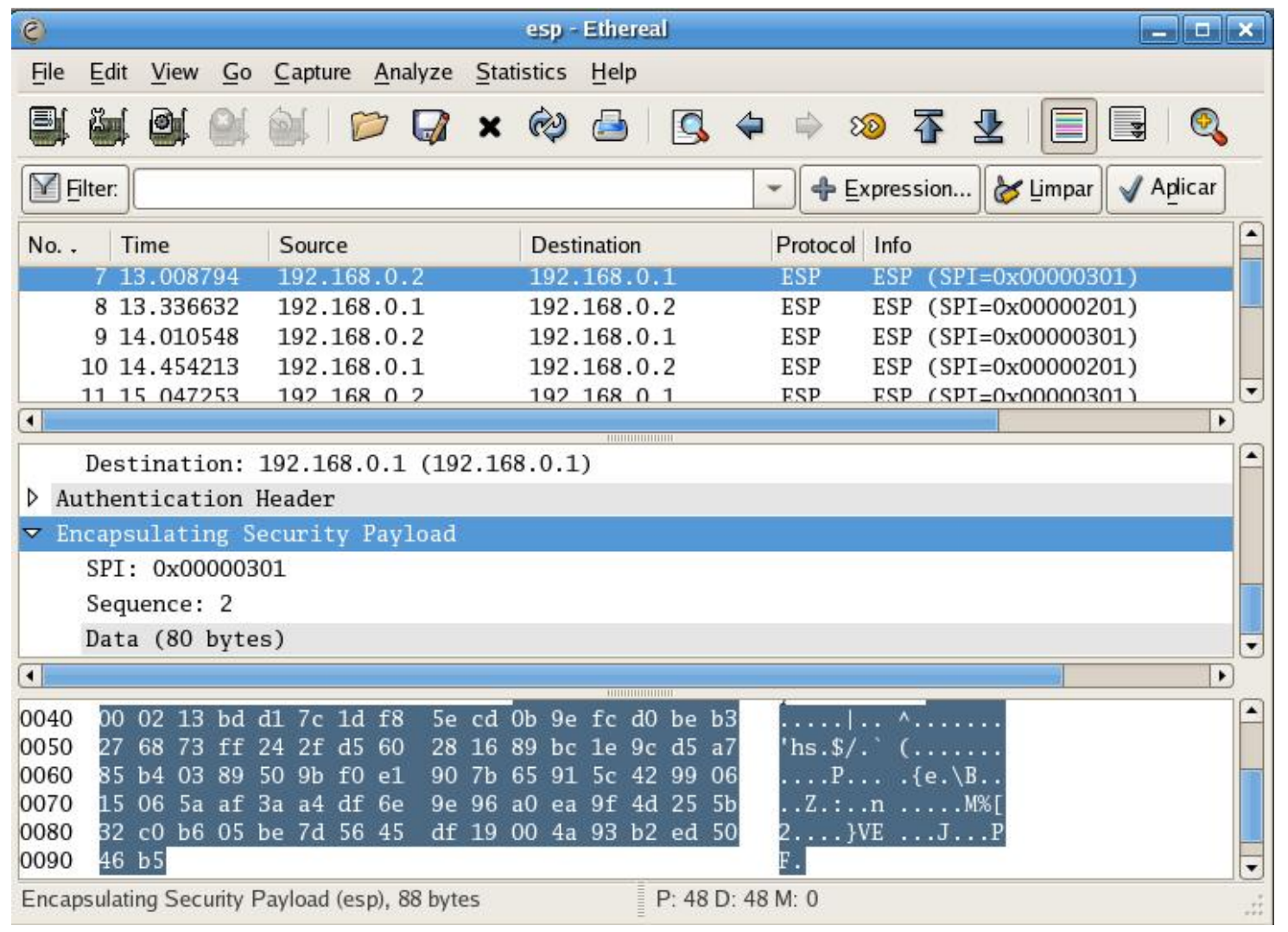

Figura 5.10: Análise dos Pacotes ESP com o IPSec 
CAPÍTULO

6

\section{Conclusão e Trabalhos Futuros}

Nesta dissertação foi apresentada uma proposta de uma rede privada virtual, VPN, implementada sobre um sistema embarcado com aceleração criptográfica via hardware para ser utilizada em um robô móvel. O sistema foi implementado sobre um dispositivo lógico programável do tipo FPGA que possui hardware totalmente customizável.

O sistema final utiliza um dispositivo FPGA com um processador softcore da Altera, o Nios II, um coprocessador criptográfico de 128 bits AES(DUARTE, 2004), o sistema operacional $\mu$ Clinux e o conjunto de ferramentas ipsec-tools, devidamente portado e modificado para utilizar o coprocessador para criptografar os pacotes ESP.

A primeira conclusão obtida é sobre o uso do sistema operacional $\mu$ Clinux. Dentre as diversas opções de sistemas operacionais para plataformas embarcadas, o $\mu$ Clinux se mostrou bastante adequado por ser um sistema aberto, gratuito, e com praticamente todas as funcionalidades de um Linux padrão. No caso do hardware utilizado não há MMU, sendo esta a principal diferença entre um sistema Linux comum e o $\mu$ Clinux. Para aplicações que não são de tempo real, os sistemas Linux se tornam ideais. Já em uma comparação direta com o eCos, o $\mu$ Clinux leva vantagem por possuir muito mais funcionalidades do que o primeiro.

A principal contribuição deste trabalho é que pode-se controlar o robô móvel que existe no laboratório LCR de forma rápida, segura e eficiente de qualquer lugar que possua um ponto de Internet. Além disso o trabalho está pronto para ser utilizado para o novo padrão de IP, o IPv6, que deverá substituir o atual padrão IPv4 em um futuro próximo. Assim, esse trabalho se adequa as tendências do futuro, podendo ser utilizado com o novo padrão da Internet em alguns anos.

O desempenho obtido com a criptografia em hardware mostra outra tendência do futuro: a utilização de coprocessadores específicos em hardware para realizar criptografia. Com isto será 
possível utilizar chaves bem maiores para se criptografar/decriptografar blocos de dados, tornando o sistema mais seguro. De fato, em PCs comuns já existem máquinas, como por exemplo placasmãe com chipset da VIA ${ }^{1}$, com hardware dedicado para se realizar criptografia.

$\mathrm{O}$ sistema foi desenvolvido de modo a não ser restrito à placa utilizada, podendo ser utilizado por quaisquer sistemas embarcados de diferentes fabricantes. Isso se deve ao fato de que o hardware todo é desenvolvido em uma linguagem de descrição universal, a VHDL, podendo ser acoplado em qualquer processador com as devidas modificações pertinentes a cada um. O sistema operacional $\mu$ Clinux já está portado para diversas arquiteturas e pretende-se tornar um padrão para sistemas embarcados. Assim, as aplicações que forem portadas para este sistema operacional podem ser facilmente migradas quando executadas em hardwares diferentes.

Por último, a integração de diversas ferramentas de software em um sistema embarcado baseado em computação reconfigurável demonstrou uma complexidade enorme, cujos desafios inicialmente pareciam insuperáveis. Entretanto, com muito conhecimento e perseverança, o trabalho foi concluído com êxito.

\subsection{Trabalhos Futuros}

Alguns trabalhos que poderiam ser desenvolvidos para se complementar o projeto seriam:

1. Desenvolver o algoritmo de autenticação em hardware. O hmac-md5, utilizado neste trabalho, ou um outro algoritmo como o SHA1 ou ainda SHA2, poderia ser implementado como um outro coprocessador, totalmente em hardware. Com isso, poderíamos acelerar os pacotes $A H$, que utilizam esses algoritmos para fazer autenticação.

2. Desenvolver o algoritmo de criptografia utilizado pelo IKE em hardware. O protocolo IKE utilizado para troca de chaves automaticamente, que o programa em espaço de usuário racoon implementa, faz uso de um algoritmo criptográfico que é atualmente implementado pela OpenSSL. Um desses algoritmos poderia ser desenvolvido em hardware como um novo coprocessador para acelerar o processo de troca de chaves automáticas.

3. Integrar todo o novo sistema. O novo sistema seria composto de um processador e três coprocessadores criptográficos: um para processamento dos pacotes ESP, implementado no Kernel do Linux, outro para processamento dos pacotes AH, que também deverá ser implementado no espaço do Kernel, e outro para troca de chaves, para o protocolo IKE, que deverá ser implementado no espaço de endereçamento do usuário.

4. Desenvolver uma MMU para o Nios II. Com uma MMU haveria proteção de memória e por isso mais segurança da informação no sistema embarcado que será executado no robô. Além disso, estariam disponíveis instruções como fork, daemon, syslog, etc.

\footnotetext{
${ }^{1}$ Os chipsets novos da VIA vem com um hardware dedicado para criptografia AES chamado de VIA padlock AES
} 
5. Integrar a nova VPN com os outros módulos do robô. O sistema do robô é composto de diversos módulos como sistema de processamento de imagens, algoritmos robóticos, etc, conforme pôde ser visto na figura 5.1. A integração de todo o sistema é o estágio final do amplo projeto desenvolvido pelo LCR. 
APÊNDICE

\section{$A$}

Apêndice A

Neste primeiro apêndice é apresentado a parte principal do sistema: o código do coprocessador AES portado para o Framework Assynchronous Crypto Layer do Kernel do $\mu$ Clinux.

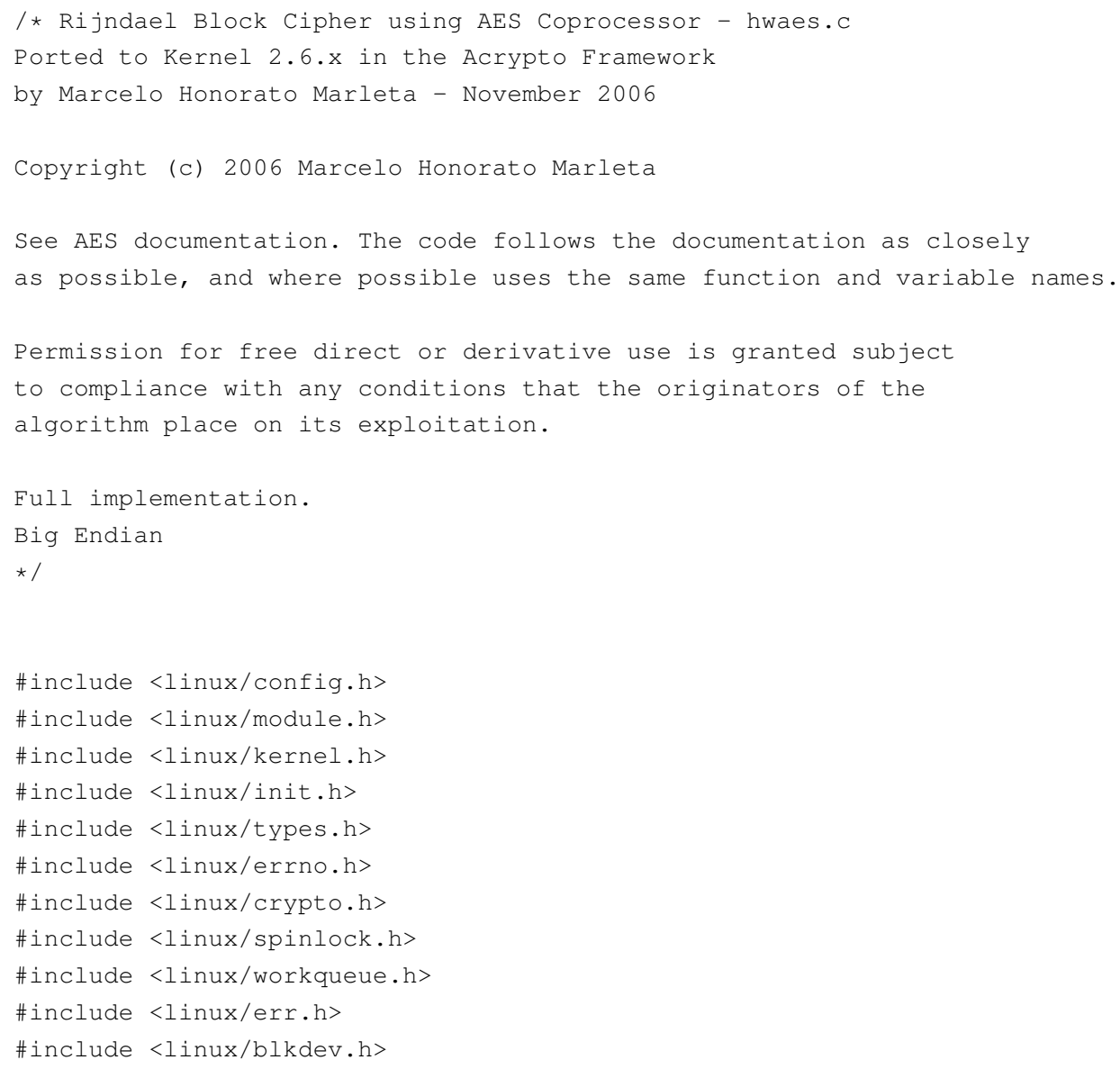


ctx->key_length = key_len;

/* Write the key to be expanded */

coprocaes $->$ np_coprocdata = le32m_to_cpu (key[0]);

coprocaes $\rightarrow$ np_coprocdata = le32m_to_cpu (key[1]);

coprocaes $\rightarrow$ np_coprocdata = le32m_to_cpu(key[2]);

coprocaes $->$ np_coprocdata = le32m_to_cpu(key[3]);

/* Write the key expand command */

controle $=0$;

controle = controle $\mid$ np_coprocctrl_expande_mask;

controle = controle $\mid$ chaveid;

coprocaes $\rightarrow$ np_coprocctrl = controle;

I* Wait for data to be processed */

while ((coprocaes->np_coprocstatus \& np_coprocstatus_chaveok_mask)==0) ; return 0 ;

static void

hwaes_encrypt (void *ctx_arg, u 8 *out, const u 8 *in)

\{

const _le $32 * \operatorname{src}=$ (const _le $32 *$ ) in;

_le $32 *$ dst $=($ _le $32 *)$ out;

I* Prepare the coprocessor to encrypt */

controle $=0$;

controle = controle | np_coprocctrl_operacao_mask;

controle = controle | np_coprocctrl_processa_mask;

controle = controle $\mid$ chaveid;

coprocaes $->$ np_coprocctrl = controle;

/* Write data block to be encrypted * /

coprocaes $->$ np_coprocdata $=$ le32m_to_cpu (src[0]);

coprocaes $\rightarrow$ np_coprocdata = le32m_to_cpu(src[1]);

coprocaes $\rightarrow$ np_coprocdata = le32m_to_cpu(src[2]);

coprocaes -> np_coprocdata = le32m_to_cpu (src[3]);

I* Wait for data to be processed */

while ((coprocaes->np_coprocstatus \& np_coprocstatus_dadook_mask)==0);

/* Read data to internal block */

dst $[0]=$ cpum_to_le32 (coprocaes $\rightarrow$ np_coprocdata);

dst $[1]=$ cpum_to_le32 (coprocaes $->$ np_coprocdata);

dst [2] = cpum_to_le32 (coprocaes $->$ np_coprocdata);

dst [3] = cpum_to_le32 (coprocaes $->$ np_coprocdata);

\}

static void

hwaes_decrypt (void *ctx_arg, us *out, const u 8 *in)

\{

const_le $32 * \operatorname{src}=$ (const_le $32 *$ ) in;

_le $32 *$ dst $=($ _le $32 *)$ out;

controle $=0$

controle = controle | np_coprocctrl_processa_mask;

controle = controle $\mid$ chaveid; 


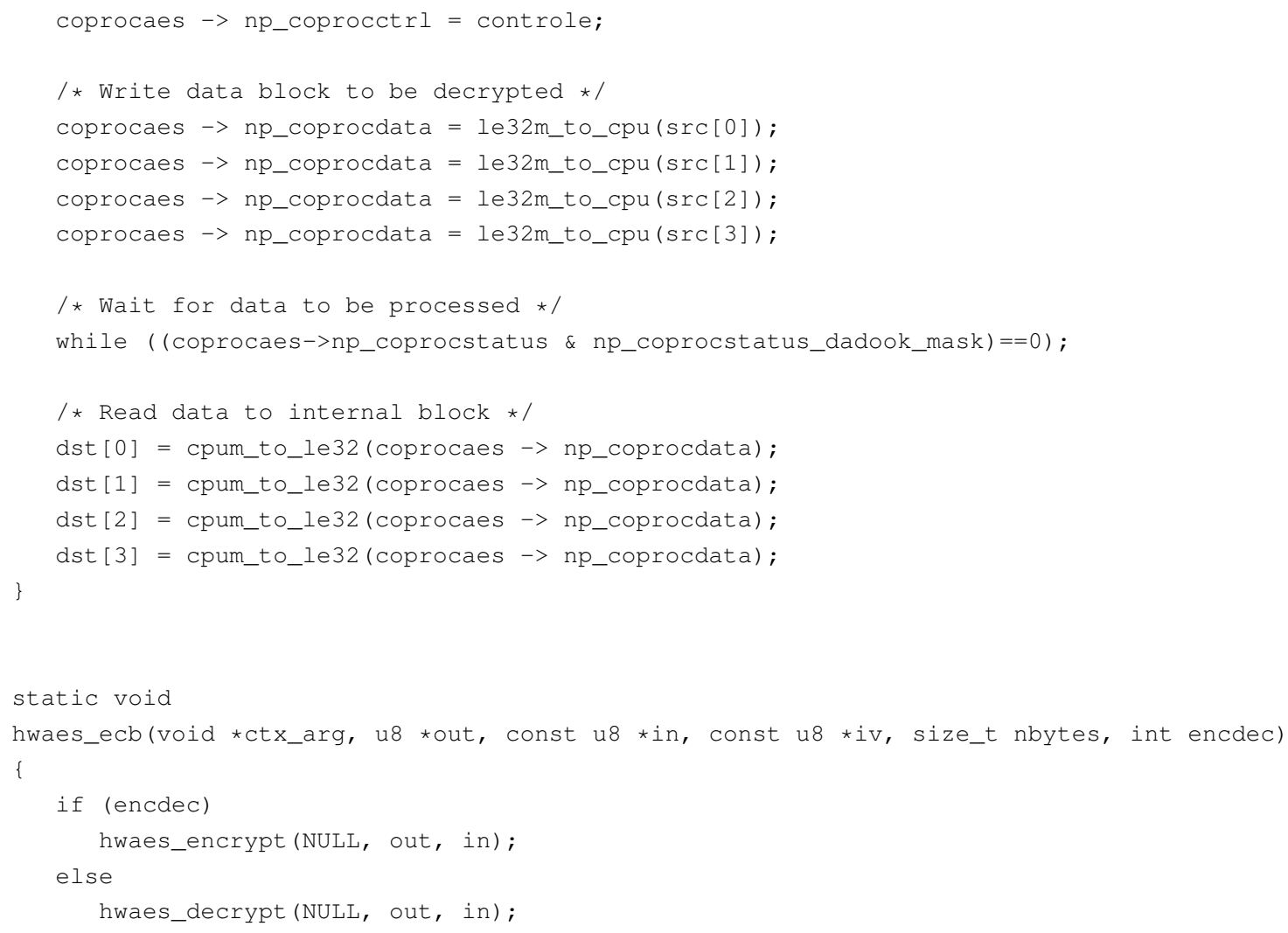


dprintk("Broken session: sg_src_num [\%d] != sg_dst_num [\%d].n", s->data.sg_src_num, s->data.sg_dst_num);

break_session(s);

return;

\}

key $=(($ u $8 *)$ page_address $(s->$ data.sg_key[0].page $))+$ s->data.sg_key[0].offset;

keylen = s->data.sg_key[0].length;

$i v=((u 8 *)$ page_address $(s->$ data.sg_iv[0].page $))+$ s->data.sg_iv[0].offset;

err $=$ hwaes_set_key (s->data.priv, key, keylen);

if (err)

\{

break_session (s);

return;

for $(i=0 ; i<s->$ data.sg_src_num; ++i)

\{

dst $=(($ u $8 *)$ page_address $($ s->data.sg_dst [i].page $))+$ s->data.sg_dst [i].offset;

src $=((u 8 *)$ page_address $(s->$ data.sg_src[i].page $))+$ s->data.sg_src[i].offset;

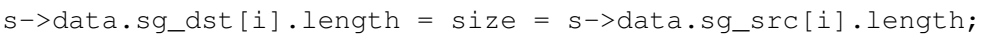

switch (s->ci.mode) \{

case ACRYPTO_MODE_ECB:

hwaes_ecb(s->data.priv, dst, src, iv, size, s->ci.operation); break;

\}

\}

return;

\}

static void

hwaes_data_ready (struct acrypto_device *dev)

\{

struct acrypto_session $\star s$;

while ( $(s=$ acrypto_session_dequeue (dev) ) != NULL $)\{$

set_bit(SESSION_DIRECT, \&S->Ci.flags);

process_session(s);

acrypto_complete_session(s);

\}

\}

static int

_init hwaes_init (void)

\{

int $\mathrm{rc}$;

inicializa_coproc();

hwaes_device.cap_number = hwaes_cap_number;

$r c=$ acrypto_device_add (\&hwaes_device);

return rc;

\}

static void

_exit hwaes_fini(void)

\{

acrypto_device_remove(\&hwaes_device) ; 
module_init(hwaes_init);

module_exit(hwaes_fini);

MODULE_DESCRIPTION("Nios2 AES Cryptographic Coprocessor");

MODULE_LICENSE ("GPL"); 
Para a realização deste trabalho foi utilizado um PC com o sistema operacional Linux, distribuição Fedora Core 5, com Kernel versão 2.6.17.4, compilador gcc versão 3.2 e ipsec-tools 0.6.6. Para o sitema embarcado foi utilizado o $\mu$ Clinux com kernel versão 2.6.17, busybox para os utilitários gerais, ipsec-tools versão 0.6 .6 e as ferramentas necessárias para se fazer cross compiling.

Neste apêndice serão listadas as configurações necessárias para se estabelecer a VPN. Primeiramente deve-se habilitar o IPSec no Kernel do $\mu$ Clinux (no caso do sistema embarcado) e no do Linux do PC bem como as configurações de criptografia necessárias.

No sistema embarcado, deve-se configurar o Kernel e compilá-lo de maneira diferente de um Linux comum. Será listado abaixo os procedimentos para se compilar do Kernel do $\mu$ Clinux. Na primeira etapa é necessário instalar o compilador cruzado e a $\mu$ Clibc. Após isso deve-se executar o comando:

make vendor_hwselect SYSPTF «arquivo PTF»

$\mathrm{O}$ arquivo PTF é gerado pelo SOPC Builder e contém todas as definições de endereços de memória, interrupções, endereços de E/S, etc. Quando o comando acima é executado, a seguinte tela é apresentada ao usuário para se escolher as opções desejadas.

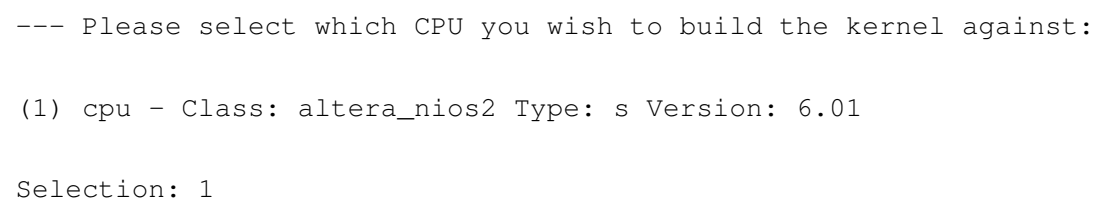


--- Please select a device to upload the kernel to:

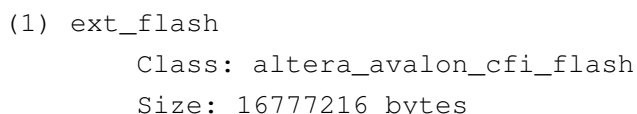

Selection: 1

--- Please select a device to execute kernel from:

(1) onchip_ram_64_kbytes

Class: altera_avalon_onchip_memory2

Size: 65536 bytes

(2) ext_ram

Class: altera_nios_dev_kit_stratix_edition_sram2

Size: 1048576 bytes

(3) sdram

Class: altera_avalon_new_sdram_controller

Size: 16777216 bytes

Selection: 3

--- Summary using

PTF: /home/marcelo/hardware/coproc/std_2s60.ptf

$\mathrm{CPU}$ : $\mathrm{cpu}$

Device to upload to: ext_flash

Program memory to execute from: sdram

--- Settings written to /home/marcelo/uclinux-dist/linux-2.6.x/arch/nios2nommu/hardware.mk

No caso do sistema SOPC implementado, poderia-se escolher executar o Kernel em três diferentes dispositivos de memória. A SDRAM foi escolhida por ter maior capacidade de armazenamento. Quando o Kernel for compilado, o arquivo nios2_system.h será gerado com todas as informações de endereçamento de memória e E/S do sistema construído.

O próximo passo é gerar o sistema de arquivos. Isso é realizado através do comando:

make romfs

Este comando cria toda a estrutura de diretórios de um sistema Linux padrão. Realizado esses passos iniciais agora se pode configurar efetivamente o Kernel através do conhecido comando:

make menuconfig

Para se habilitar o suporte a IPSec devem ser escolhidas as seguintes opções:

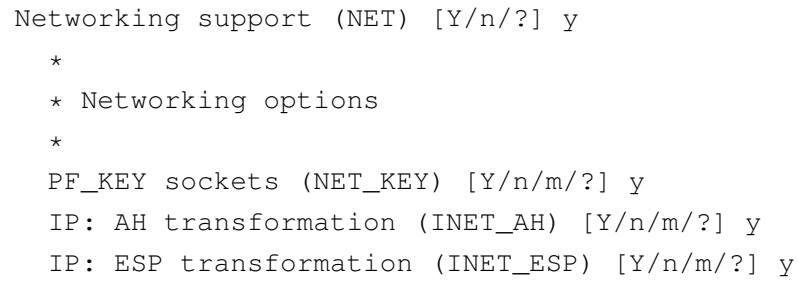




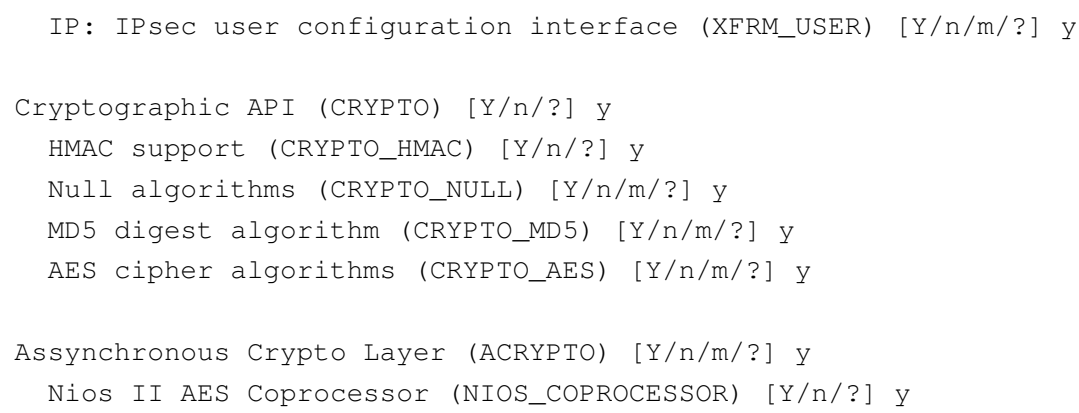

No caso do PC, não existe as opções Assynchronous Crypto Layer e Nios II AES Coprocessor, como já era de se esperar. A parte restante deve ser configurado da mesma maneira. Após habilitar a IPSec no Kernel, o mesmo deve ser devidamente (re)compilado. No caso do sistema embarcado, isso é realizado por meio dos comandos: make seguido do comando make linux image. O segundo comando faz com que o núcleo do sistema operacional e o sistema de arquivos sejam compilados e anexados em uma única imagem inicializável (trata-se do conceito de initramfs).

Após se ter a imagem gerada, deve-se descarregá-la na placa. O programa responsável por essa tarefa é o nios2-download, como pode ser visto na figura B.1.

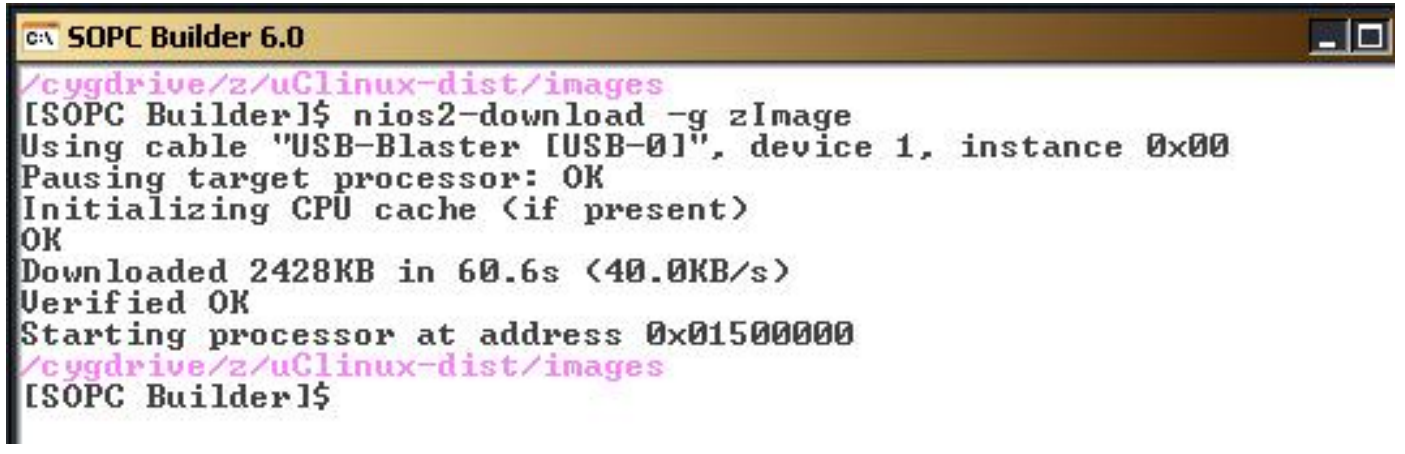

Figura B.1: Descarregando a imagem do Kernel na placa

Com a imagem descarregada basta, finalmente, iniciar o sistema através do comando nios2terminal.

Para se estabelecer uma VPN devem ser feitas as configurações pertinentes ao tipo de sistema que se deseja implementar. Para começar será descrito como se estabelecer uma VPN em modo transporte manualmente.

Deve ser criado um arquivo, normalmente chamado de setkey.conf, com as configurações das chaves para autenticação, usado pelo protocolo AH, as chaves para o processamento dos dados, usado pelo protocolo ESP, e configurar os IPs que realizarão a comunicação segura. Segue abaixo $\mathrm{o}$ arquivo do sistema embarcado.

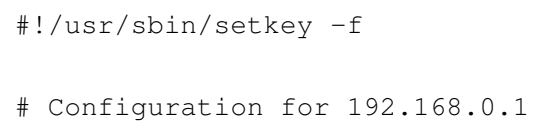




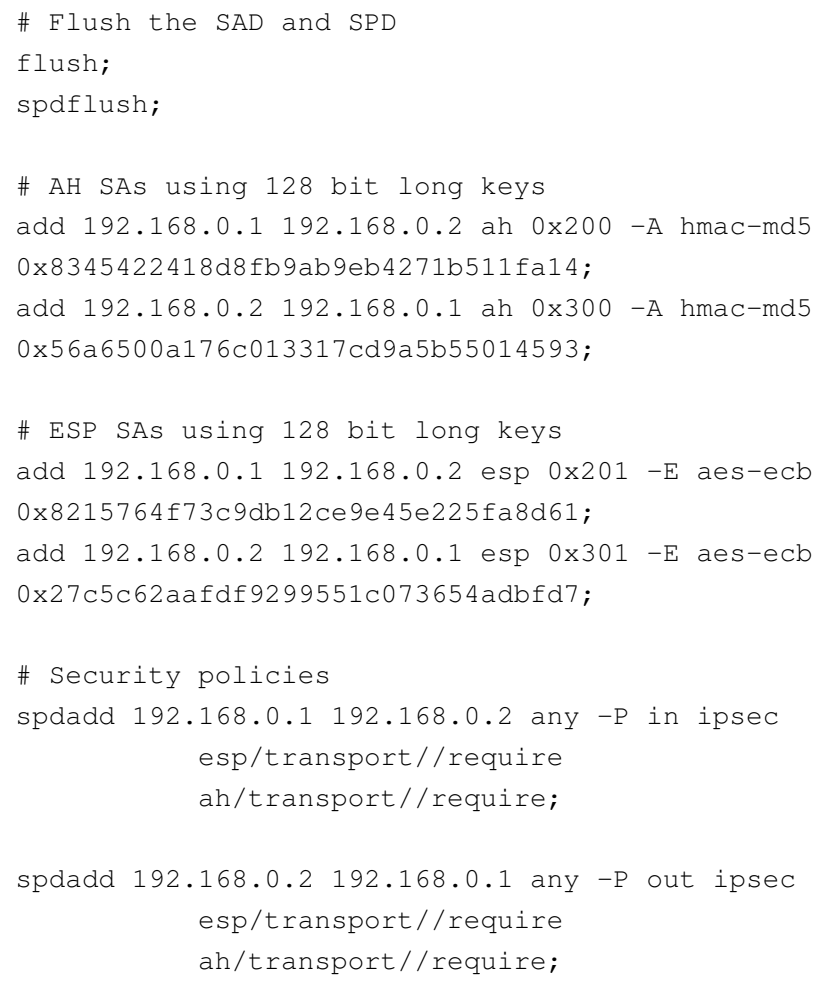

Um detalhe interessante a observar: o algoritmo de criptografia utilizado é o aes-ecb. De fato, o framework de criptografia assíncrona utiliza as variáveis exportadas da crypto api.

A configuração do PC é praticamente idência, sendo necessária a modificação de uma regra no arquivo de configuração: deve-se trocar o in por out e vice-versa. Como pode ser visto no arquivo de configuração abaixo:

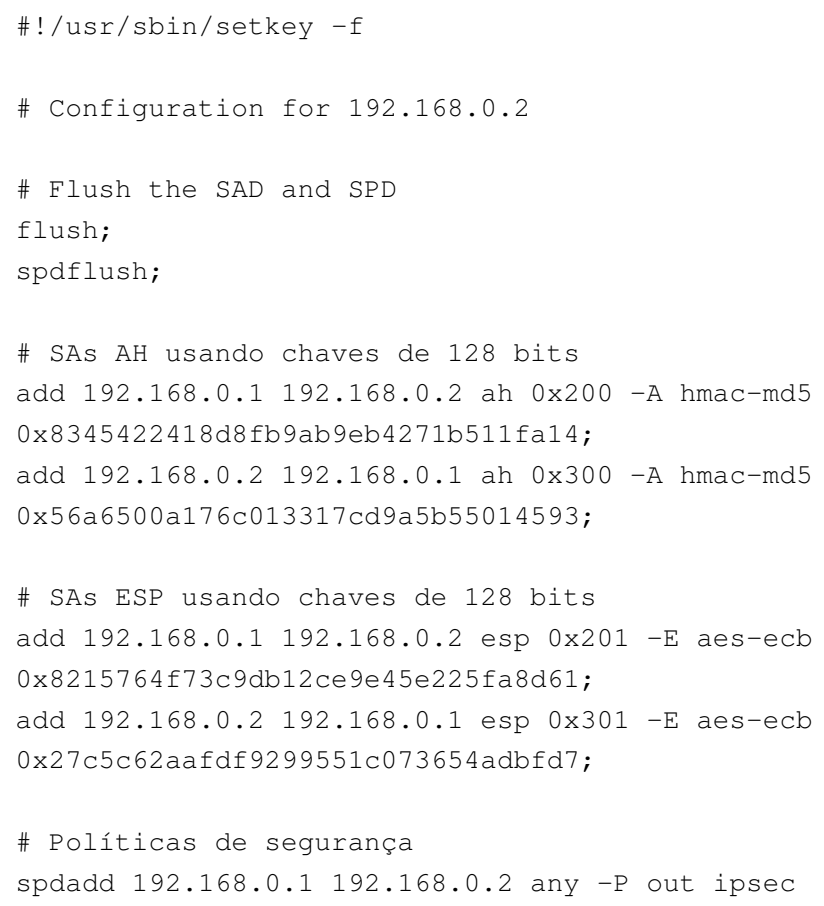




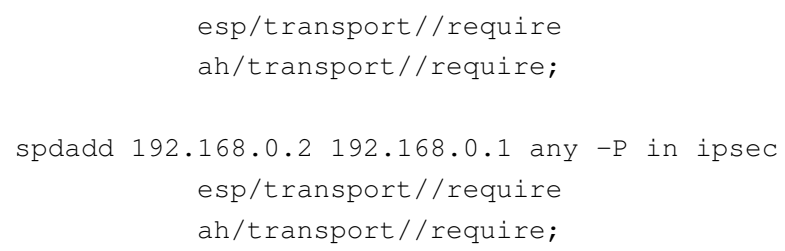

Agora basta se executar o comando setkey -f /etc/setkey.conf em ambas as partes da comunicação e a VPN estará configurada. Qualquer conexão pela rede estará devidamente criptografada.

A seguir, será descrito como se criar uma VPN em modo túnel. Para a configuração do modo túnel devemos fazer algumas modificações no setkey.conf.

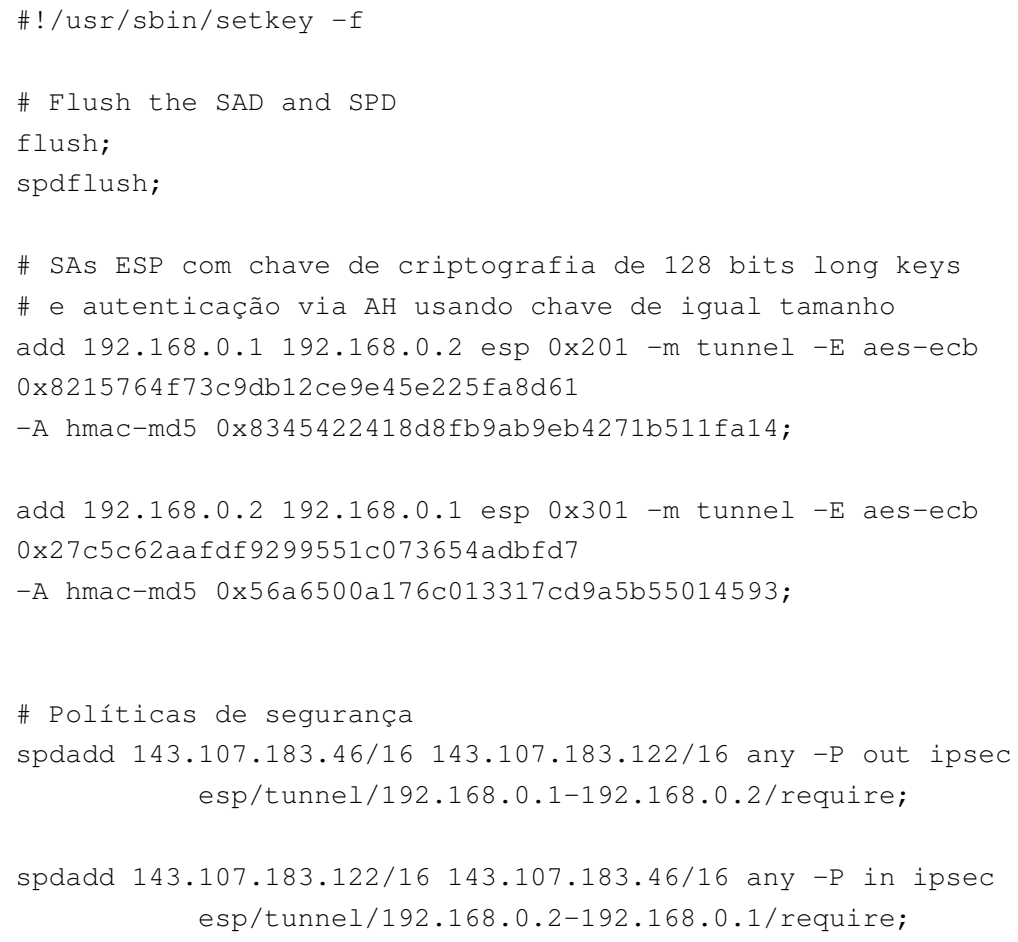

Novamente, o comando a se executar é o setkey -f/etc/setkey.conf em ambos os gateways de segurança.

O modo transporte é o modo padrão para o programa setkey. Portanto quando se deseja utilizar a VPN em modo túnel é necessário adicionar a regra - $m$ tunnel para se estabelecer a VPN. Deve ser também configurado os IPs da rede interna que realizarão a comunicação segura e os gateways de segurança que realizarão efetivamente a vpn.

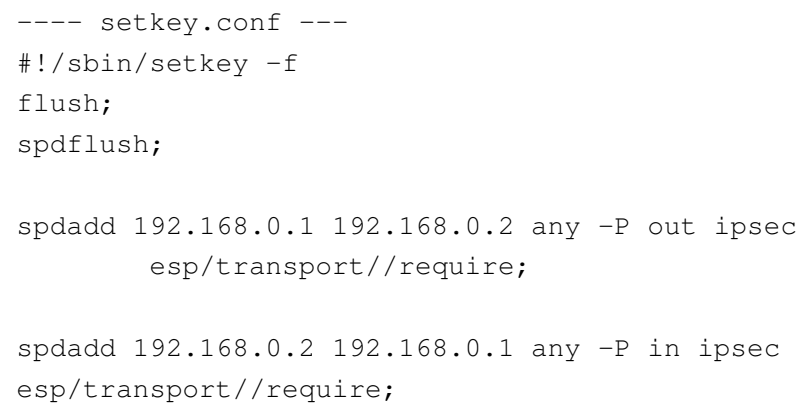




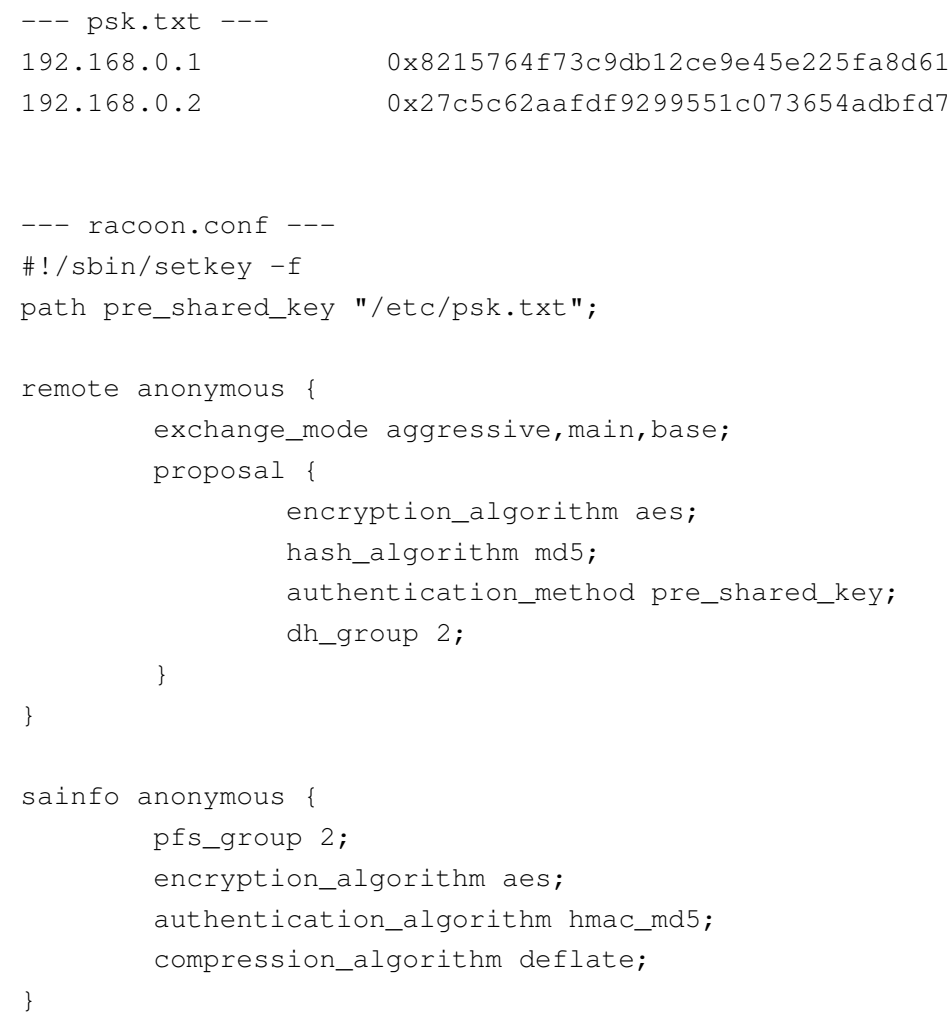

Um detalhe a ressaltar: como não há MMU no sistema de hardware embarcado, o software racoon, não pode ser executado como daemon, necessitando ser executado com a opção $-F$ de Foreground. Para finalizar, basta executar os comandos para se estabelecer a VPN no sistema embarcado:

setkey -f/etc/setkey.conf

e

racoon $-F-f / e t c / s e t k e y . c o n f$ 


\section{Referências Bibliográficas}

ALTERA Site: http://www.altera.com, acessado em: Fevereiro, 2005, 2005.

ALTERA, C. Stratix. Site: http://www.altera.com/products/devices/stratix/stx-index.jsp, página com informações sobre o dispositivo Stratix da Altera. Acessado em: Fevereiro, 2005, 2002.

ALTERA, C. Analyzing designs with the quartus ii rtl viewer \& technology map viewer. version 2.0. pág. 1. Site: http://www.altera.com/literature/hb/qts/qts_qii51013.pdf, Altera, Corp., San Jose, EUA, acessado em: Fevereiro, 2005, 2004a.

ALTERA, C. Analyzing designs with the quartus ii rtl viewer \& technology map viewer. version 2.0. pág. 2. Site: http://www.altera.com/literature/hb/qts/qts_qii51013.pdf, Altera, Corp., San Jose, EUA, acessado em: Fevereiro, 2005, 2004b.

ALTERA, C. Quartus ii development software. Site: http://www.altera.com/literature/litqts.jsp, página contendo breve sumário do que é e como funciona o LogicLock e com link para literatura relacionada. Acessado em: Fevereiro, 2005, 2004c.

ANDERSEN, E. uclibc. Site: http://uclibc.org/, a C library for developing embedded Linux systems. Acessado em: Fevereiro, 2007, 2002.

ANDERSEN, E. Buildroot. Site: http://buildroot.uclibc.org/, set of Makefiles and Patches for cross-compiling. Acessado em: Fevereiro, 2007, 2005.

ARM, C. Amba specification rev. 2.0. Site: www.arm.com, Arm, Corp., página contendo informações sobre o abarramento AMBA. Acessado em: Março, 2005, 1999.

BECKET, J. As you like it: New technology lets non-techies customize computers. www.hpl.hp.com/news/shackleford.html, acessado em: Novembro, 2004, 2000.

BIRKNER, J. From simple pals to high-speed, high-density leading edge fpgas, their technologies and applications. http://klabs.org/richcontent/MAPLDCon98/Papers/b0_birkner.ppt, acessado em: Fevereiro, 2005, 2000. 
BROWN, S. Field-programmable gate arrays. EUA: Kluwer Academic Publishers, 1992.

BROWN, S.; ROSE, J. Architecture of fpgas and cplds: A tutoria, ieee design and test of computers. 1997.

BROWN, S.; VRANESIC, Z. Fundamentals of digital logic with vhdl design., v. 1.ed. EUA: McGraw Hill, 2000.

BTF, I. . V. Boyd technology inc. Site: http://www.boyd.com/1364_btf/index.shtml, acessado em: Janeiro, 2005, 2004.

CHAN, P. K.; MOURAD, S. Digital design using field-programmable gate arrays, v. 1.ed. New Jersey: Prentice Hall Inc., 1994.

CHIN, L. K. Rede privada virtual. http://www.rnp.br/newsgen/9811/vpn.html, acessado em: Novembro, 2004, 1998.

COMPTON, K. Programming architectures for run-time reconfigurable systems. Dissertação de Mestrado, Northwestern University, 1999.

COMPTON, K.; HAUCK, S. Configurable computing: A survey of systems and software. Relatório Técnico, 1999.

COMPTON, K.; HAUCK, S. An introduction to reconfigurable computing. IEEE Computer, 2000.

CSRC Csrc - cryptographic toolkit. Site: http://csrc.nist.gov/CryptoToolkit/aes/, histórico do desenvolvimento do algoritmo AES. Acessado em: Fevereiro, 2007, 2000.

DEHON, A. Reconfigurable architectures for general-purpose computing. Tese de Doutoramento, MIT, 1996.

DEHON, A. The density advantage of configurable computing. IEEE Computer Magazine, 2000.

DEHON, A.; WAWRZYNEK, J. The case for reconfigurable processors. http://www.cs.berkeley.edu/amd/CS294S97/papers/case_for_rp.ps, 1997.

DONACHY, P. Design and implementation of a high level image processing machine using reconfigurable hardware. Tese de Doutoramento, The Queen's University of Belfast, 1996.

DUARTE, N. M. Coprocessador criptográfico padrÃo advanced encryption standard (aes) baseado em lógica programÁvel. Dissertação de Mestrado, Escola Politécnica da Universidade de São Paulo, 2004. 
ETHEREAL A gui network analyzer tool. Site: http://www.ethereal.com, acessado em: Fevereiro, 2007, 1998.

FLEX Fast lex analyzer. Site: http://flex.sourceforge.net/, acessado em: Fevereiro, 2007, 1997.

GILMORE, J. Free vpn solution for the linux plataform. Site: http://www.freeswan.org, acessado em: Fevereiro, 2007, 1996.

GLESNER, M. Programmable logic devices. alemanha: Darmstadt university of technology. Site: http://www.microelectronic.etechnik.tudarmstadt.de/lectures/winter/vlsi/vorlesung_pdf/PLD.pdf, acessado em: Fevereiro, 2005, 2004.

GMBH, S. Pretty good privacy. Site: http://www.securstar.com, página principal da empresa que desenvolve o software DriveCrypto. Acessado em: Fevereiro, 2007, 2007.

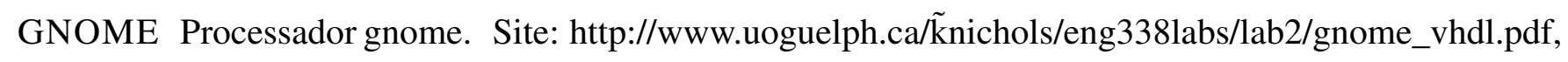
página contendo o código do processador Gnome em VHDL e explicações sobre a implementação. Acessado em: Fevereiro, 2005, 2002.

GNU The gnu compiler collection. Site: http://gcc.gnu.org/, acessado em: Fevereiro, 2007, 1987.

GPL Gnu general public license. Site: http://www.gnu.org/licenses/gpl.html, acessado em: Fevereiro, 2007, 1991.

HAMACHER, C.; VRANESK, Z.; ZAKY, S. Computer organization. Crawfordsville, IN: Mc Graw Hill, 2002.

HARKINS, D.; CARREL, D. The internet key exchange (ike). Site: http://tools.ietf.org/html/rfc2409, acessado em: Fevereiro, 2007, 1998.

HAUCK, S. The future of reconfigurable systems. In: 5th Canadian Conference on Field Programmable Devices, 1998.

HOLLABAUGH, C. Embedded linux: Hardware, software, and interfacing. Boston, MA: Addison Wesley, 2002.

HOSNER, C. Openvpn and the ssl vpn revolution. Site: http://www.sans.org/reading_room/whitepapers/vpns/1459.php, acessado em: Fevereiro, 2007, 2004.

IEEE Standard vhdl language reference manual. 1998.

IETF The internet engineering task force. Site: www.ietf.org, acessado em: janeiro, 2005, 2002. 
KAMATH, U.; KAUDIN, R. System-on-chip designs - strategy for success. Site: http://www.wipro.com/pdf_files/wipro_system_on_chip.pdf, Wipro Technologies, EUA, acessado em: Fevereiro, 2005, 2004.

KAME A port of kame's ipsec utilities to the linux-2.6. Site: http://ipsec-tools.sourceforge.net/, acessado em: Fevereiro, 2007, 2002.

KENT, S.; ATKINSON, R. Ip encapsulating security payload (esp). Site: http://tools.ietf.org/html/rfc2406, acessado em: Fevereiro, 2007, 1998.

LEON Leon research projects. Site: http://www.gaisler.com/products/leon2/leon_research.html, Leon Research, França, página com dados e referências ao projeto do processador RISC LEON. Acessado em: Janeiro, 2005, 2004.

LOGICLOCK Logiclock block based design. Site: http://www.altera.com/products/software/products/quartus2/design/qtslogiclock. htm, Altera, Corp., San Jose, EUA, página contendo breve sumário do que é e como funciona o LogicLock e com link para literatura relacionada. Acessado em: Fevereiro, 2005, 2004.

MAUGHAN, D.; SCHERTLER, M.; SCHNEIDER, M.; TURNER, J. Internet security association and key management protocol (isakmp). Site: http://tools.ietf.org/html/rfc2408, acessado em: Fevereiro, 2007, 1998.

MAZOR, S.; LANGSTRAAT, P. A guide to vhdl, v. 2.ed. Kluwer Academic Publishers, 1993.

MCCULLOUGH, D. Ocf-linux. Site: http://ocf-linux.sourceforge.net/, a port of the OpenBSD/FreeBSD Cryptographic Framework. Acessado em: Fevereiro, 2007, 2002.

MICROBLAZE Microblaze. Site: http://www.xilinx.com/ipcenter/processor_c entral/microblaze/architecture.htm, Xilinx, Inc., EUA, página com recursos e documentação do processador MicroBlaze. Acessado em: Novembro, 2004, 2004.

MICROTRONIX Sistema operacional uclinux. Site: http://www.uclinux.org, acessado em: Janeiro, 2005, 2000.

MICROTRONIX Microtronix nios ii linux distribution: Reference guide. Site: http://www.niosforum.com/downloads/v1_1/ref.pdf, acessado em: Janeiro, 2005, 2004.

NEKOOGAR, F. From asic to socs - a practical approach, v. 1. ed. EUA: Prentice Hall PTR, 2003.

NEXSYS Informações sobre o processo de produção de dispositivos em 90nm. Site: http://www.tsmc.com/english/technology/t0113.htm, acessado em: Fevereiro, 2005, 2000. 
NIOS Nios embedded processor system development. Site:

http://www.altera.com/products/ip/processors/nios/nio-index.html, Altera Corp., página com dados sobre o sistema de desenvolvimento do processador RISC NIOS. Acessado em: Dezembro, 2004, 2004.

NIOSII Processador nios ii. Site: http://www.altera.com/literature/lit-nio2.jsp, acessado em: Março, 2005, 2004.

NIST Federal information processing standard (fips) for the advanced encryption standard, fips197. Site: http://csrc.nist.gov/publications/fips/fips 197/fips-197.pdf, announcing the Advanced Encryption Standard (AES). Acessado em: Fevereiro, 2007, 2000.

NIST Recommendation for block cipher modes of operation. Site: http://csrc.nist.gov/publications/nistpubs/800-38a/sp800-38a.pdf, página contendo uma publicação especial do NIST sobre os modos de operação de criptografia, 2001. Acessado em Janeiro, 2006, 2001.

NLANR/DAST Iperf. Site: http://dast.nlanr.net/Projects/Iperf/, the TCP/UDP Bandwidth Measurement Tool. Acessado em: Fevereiro, 2007, 2003.

OPENCORES Site: www.opencores.org, página com diversas implementações e documentações sobre dispositivos de hardware. Acessado em: Março, 2005, 2004.

OPENRISC An overview. Site: http://www.opencores.com/projects.cgi/web/or1 k/overview, OpenCores, EUA, página principal do projeto do processador OpenRisc. Acessado em: Novembro, 2004, 2004.

OPENSSL Implementação open source da ssl, tls e bibliotecas de criptografia. Site: http://www.openssl.org/, acessado em: Fevereiro, 2007, 2000.

OPENSWAN A fork of frees/wan implementation. Site: http://www.openswan.org, acessado em: Fevereiro, 2007, 2003.

OPENVPN A full-featured ssl vpn solution. Site: http://openvpn.net, acessado em: Fevereiro, 2007, 2002.

PERKOWSKI, M. Lecture on programmable devices and vhdl. portland: Portland state university. Site: http://www.ee.pdx.edu/m̃perkows/CLASS_VHDL_99/tran888/lecture002-diagramsvhdl-intro.pdf, acessado em: Fevereiro, 2005, 2004.

PERRY, D. L. Vhdl. McGrawHill, 1991.

PERRY, D. L. Vhdl international edition, v. 3.ed. McGraw-Hill, 1999. 
PGP Pretty good privacy. Site: http://www.pgp.com/, página principal da empresa. Acessado em: Fevereiro, 2007, 2007.

PICOBLAZE Picoblaze. Relatório Técnico, Xilinx, Inc., EUA, página com recursos e documentação do processador PicoBlaze. http://www.xilinx.com/products/design_resources/proc_central/grouping/picobl aze.htm. Acessado em: Novembro, 2004, 2004.

PIPER, D. The internet ip security domain of interpretation for isakmp. Site: http://tools.ietf.org/html/rfc2407, acessado em: Fevereiro, 2007, 1998.

POLYAKOV, E. Asynchronous crypto layer for linux kernel 2.6. Site: http://tservice.net.ru/s̃ombre/old/?section=projects\&item=acrypto, acessado em: Fevereiro, 2007, 2005.

REDHAT Sistema operacional ecos. Site: http://sources.redhat.com/ecos/, acessado em: Fevereiro, 2005, 2003.

RINGSTROM, T. An ipsec tunnel implementation for linux 2.4. Site: http://ringstrom.mine.nu/ipsec_tunnel/, acessado em: Fevereiro, 2007, 2002.

ROSE, J.; GAMAL A.E.; VICENTELLI, A. S. Architecture of field programmable gate arrays. In: 5th Canadian Conference on Field Programmable Devices, 1993.

SIGNALTAPII Signaltap ii embeeded logical analizer. Site: http://www.altera.com/products/software/products/quartus2/verification/signalt ap2/sigindex.html, Altera, Corp., San Jose, EUA, página contendo breve sumário do que é e como funciona o LogicLock e com link para literatura relacionada. Acessado em: Fevereiro, 2005, 2004.

SILICORE, C. Wishbone system-on-chip interconnect architecture for portable ip cores. Site: http://www.opencores.org/projects.cgi/web/wishbone/wishbone, Silicore, Corp., página com especificações técnicas do barramento Wishbone. Acessado em: Março, 2005, 2001.

SPIEGEL, J. V. D. Hdl-abel primer. Relatório Técnico, University of Pensilvania, EUA, site: http://www.seas.upenn.edu/ese/rca/software/abel/abel.primer.html. Acessado em: Fevereiro, $2005,1999$.

STEFFEN, A. A fork of frees/wan implementation. Site: http://www.openswan.org, acessado em: Fevereiro, 2007, 2003.

STEVEN Altera hardware description language. Site: http://www.ife.ee.ethz.ch/z̃inniker/digiprakt/download/Altera_Tutorial_PLD_an d_MAXplus2.pdf, acessado em: Fevereiro, 2005, 2004. 
SYSTEMC Systemc. Site: http://www.systemc.org, EUA, página principal da linguagem de descrição de hardware SystemC. Acessado em: Fevereiro, 2005, 2004.

TCPDUMP A network analyzer tool. Site: http://www.tcpdump.org/, acessado em: Fevereiro, $2007,1997$.

VEMURI, R. R.; HARR, R. E. Configurable computing: Technology and applications. IEEE Computer Magazine, 2000.

VHDL Vhdl-200x the future of vhdl. Site: http://www.eda.org/vhdl-200x/, informações sobre a linguagem de descrição de hardware VHDL. Acessado em: Dezembro, 2004, 2003.

VILLASENOR, J.; MANGIONE-SMITH, W. Configurable computing. Scientific American, 1997.

VLASENKO, D. Busybox. Site: http://www.busybox.net/about.html, a C library for developing embedded Linux systems. Acessado em: Fevereiro, 2007, 2000.

VPNC Virtual private network consortium. Site: http://www.vpnc.org, acessado em: Fevereiro, 2005, 2002.

XILINX Design tools center. Página com informações e manuais sobre a ferramenta de desenvolvimento da Xilinx. http://www.xilinx.com/products/design_resources/design_tool/index.htm. Acessado em: Janeiro, 2005, 2004.

YONAN, J. The user-space vpn and openvpn. Site: http://openvpn.net/papers/BLUG-talk/, acessado em: Fevereiro, 2007, 2003. 